\title{
Modeling and Analysis of Distribution System with Demand Response and Electric Vehicles in Personal and Public Transportation
}

Venkata Satish Kasani

West Virginia University

Follow this and additional works at: https://researchrepository.wvu.edu/etd

\section{Recommended Citation}

Kasani, Venkata Satish, "Modeling and Analysis of Distribution System with Demand Response and Electric Vehicles in Personal and Public Transportation" (2014). Graduate Theses, Dissertations, and Problem Reports. 370.

https://researchrepository.wvu.edu/etd/370

This Thesis is protected by copyright and/or related rights. It has been brought to you by the The Research Repository @ WVU with permission from the rights-holder(s). You are free to use this Thesis in any way that is permitted by the copyright and related rights legislation that applies to your use. For other uses you must obtain permission from the rights-holder(s) directly, unless additional rights are indicated by a Creative Commons license in the record and/ or on the work itself. This Thesis has been accepted for inclusion in WVU Graduate Theses, Dissertations, and Problem Reports collection by an authorized administrator of The Research Repository @ WVU. For more information, please contact researchrepository@mail.wvu.edu. 


\title{
Modeling and Analysis of Distribution System with Demand Response and Electric Vehicles in Personal and Public Transportation
}

\author{
By \\ Venkata Satish Kasani \\ Thesis submitted to the \\ Benjamin M. Statler College of Engineering and Mineral Resources \\ at West Virginia University \\ in partial fulfillment of the requirements for the degree of \\ Master of Science \\ in \\ Electrical Engineering \\ Dr. Sarika Khushalani Solanki, Ph.D., Chair \\ Dr. Jignesh Solanki, Ph.D. \\ Prof. Muhammed A. Choudhry, Ph.D. \\ Lane Department of Computer Science and Electrical Engineering \\ Morgantown, West Virginia \\ 2014
}

Keywords: Plug-in Hybrid Electric Vehicles (PHEVs), Personal Rapid Transit (PRT), Battery Electric Vehicles (BEVs), OpenDSS, Demand Response, Three

Phase Unbalanced Distribution power flow.

Copyright 2014 Venkata Satish Kasani 


\section{ABSTRACT \\ Modeling and Analysis of Distribution System with Demand Response and Electric \\ Vehicles in Personal and Public Transportation}

Venkata Satish Kasani

Master of Science in Electrical Engineering

West Virginia University

Advisor: Dr. Sarika Khushalani Solanki, Ph.D.

The government policies and cost benefits led to the surge in penetration of Plug-in Hybrid Electric Vehicles (PHEVs) and Battery Electric Vehicles (BEVs) into both public and private sectors, challenging the electric grid's potential to maintain its stability and efficiently serve the purpose. The penetration of PHEVs brings technological advancements and environmental benefits to the traditional transportation and electrical power systems. Designing of appropriate charging methods to satisfy PHEV owners helps to improve system performance and avoid transmission and distribution system expansion.

The primary objective of this thesis is to model a coordinated charging algorithm to charge maximum number of PHEVs with the existing infrastructure at a Charging Station (CS) located in residential locality. The stochastic driving patterns of PHEVs are studied and different charging strategies are developed. The Optimized charging scheme is obtained for American Electric Power utility distribution feeder modeled in OpenDSS. Further, PHEV customers are modeled into price responsive consumers capable of participating in Demand Response programs to economically charge their vehicles and render support to the stabilization of power system. Consumer behavior modeling has been done by developing extensive demand-price elasticity matrices (PEMs) which are utilized to calculate the level of demand response.

This thesis also proposes a concept of converting the existing Personal Rapid Transit (PRT) system from guideway power rail propelling vehicles to Battery Electric Vehicles (BEVs) by developing a novel routing algorithm based on the data provided by West Virginia University's Department of Transportation and Parking. This turns into a feasibility analysis of implementing new EV technologies in electrification of public transportation. The routing algorithm involves Mixed Integer Linear Programming (MILP) Optimization resulting in hourly schedule of all the vehicles satisfying the passenger demand. The effect of charging load of BEVs on the electrical distribution system is analyzed by performing a time series simulation on AEP distribution feeder.

Additionally, the impact of PHEV charging on power market prices i.e. Locational Marginal Prices (LMP) in a distribution microgid scenario is presented. Locational marginal pricing is a market based wholesale pricing approach adopted by six out of ten national electricity markets. The uncoordinated charging of EVs results in unplanned peak demand causing system changes and fluctuation of LMP. The stabilizing effect of coordinated charging scheme is demonstrated on IEEE 13 Node test system. 


\section{ACKNOWLEDGEMENTS}

I would like to express my sincere gratitude to my advisor, Dr. Sarika Khushalani Solanki, for her invaluable guidance, support, and encouragement. I thank Dr. Sarika for believing in me that I can accomplish this goal with hard work and sincere effort. I thank her for providing me that confidence which lead to completion of this research work. Next, I would like to thank my second committee member Dr. Jignesh Solanki. It was from him that I learned the difference between mere hard work and hard work with focus and dedication. Both Dr. Sarika Khushalani Solanki and Dr. Jignesh Solanki have been with me, guiding me throughout my two years of research. I would also like to thank my other committee member Dr. Muhammed A. Choudhry, whose feedback and reviews helped me improve the quality of this thesis.

I gratefully acknowledge the financial support provided through Graduate Teaching Assistantship by Freshman Engineering Department, West Virginia University. Special thanks to Dr. Robin Hensel and Michelle Poland for their constant support.

I would like to thank my parents for their moral support throughout my graduate studies. Their love and affection have helped me overcome the toughest of challenges during these two hard years. Lastly, but in no sense the least, I am thankful to all my friends who made my stay at the West Virginia University a memorable and valuable experience. 


\section{Contents}

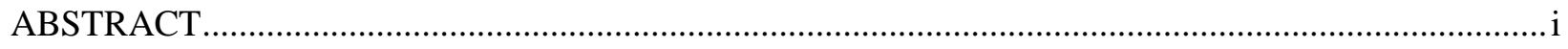

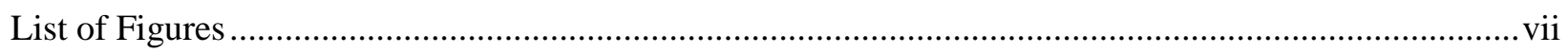

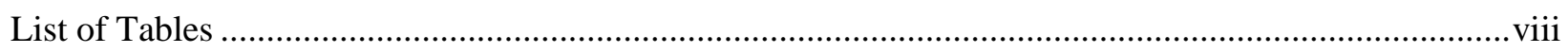

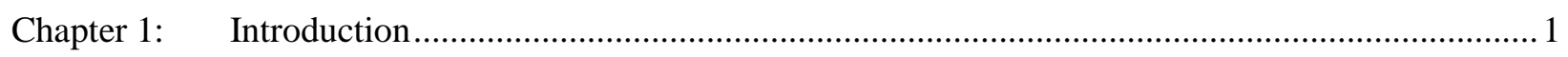

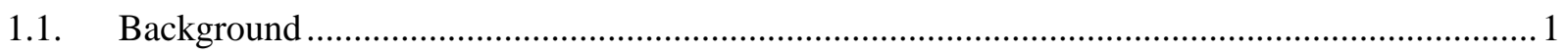

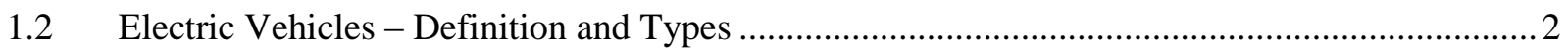

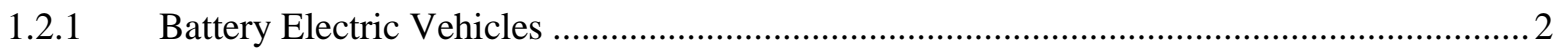

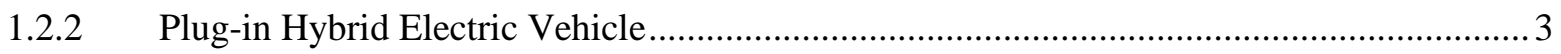

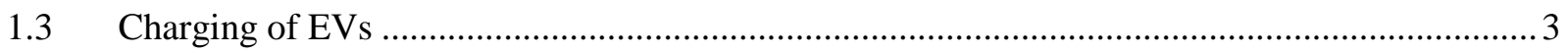

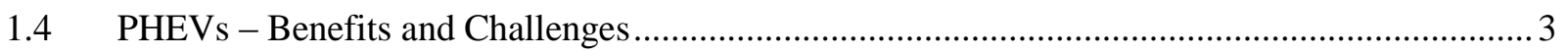

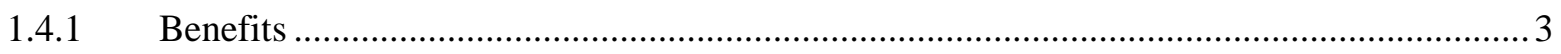

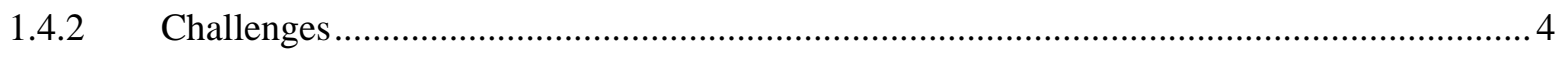

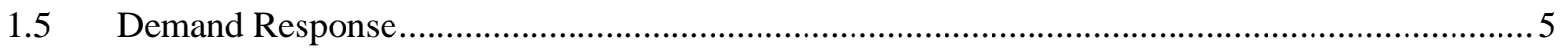

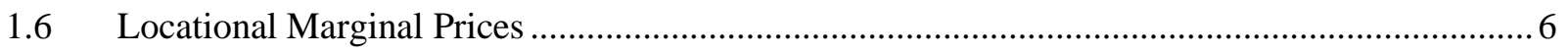

1.7 Electrification of Public Transportation...........................................................................

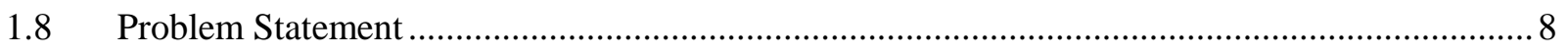

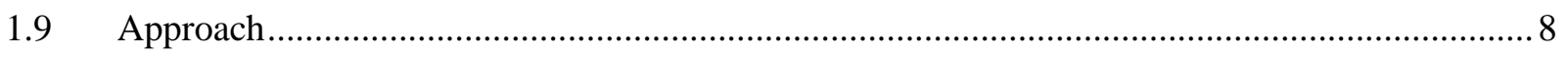

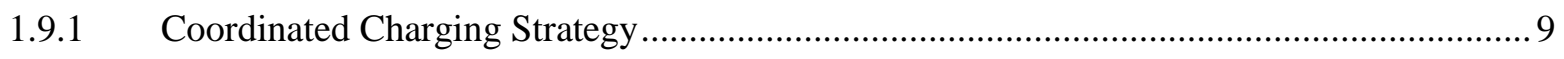

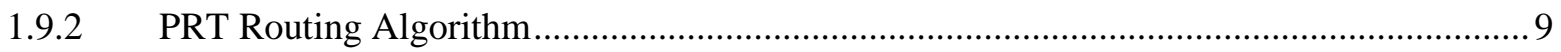

1.9.3 PHEV Charging Effects on Market Prices .................................................................. 10

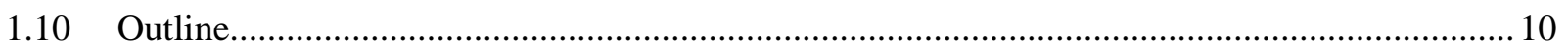

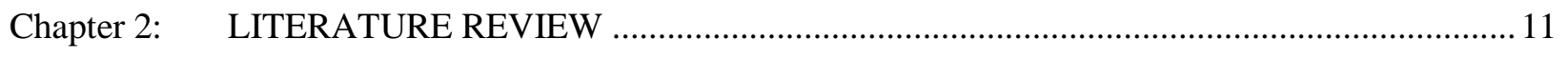

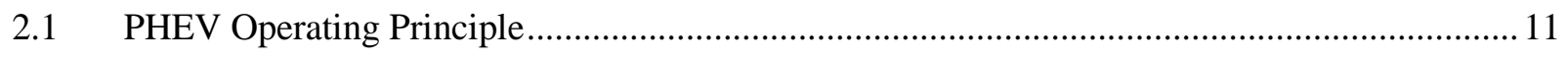

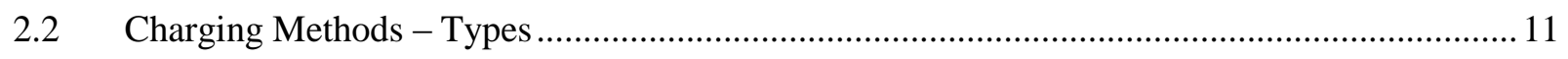

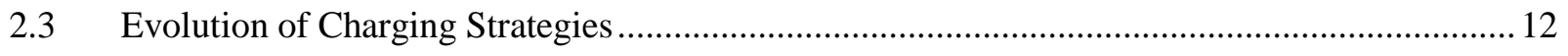

2.4 Practical Demonstration of PHEV Charging Stations ......................................................... 13 
2.4.1 San Diego's Fashion Valley Mall Charging Station, CA............................................. 13

2.4.2 Trans-Canada Highway Charging Station, Canada ....................................................... 13

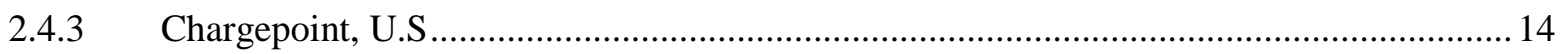

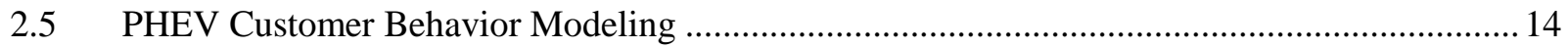

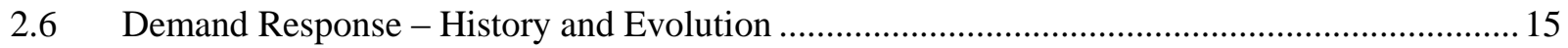

2.7 Demand Response and Consumer Behavior Modeling …............................................... 15

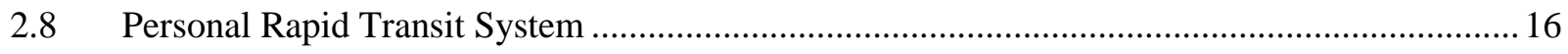

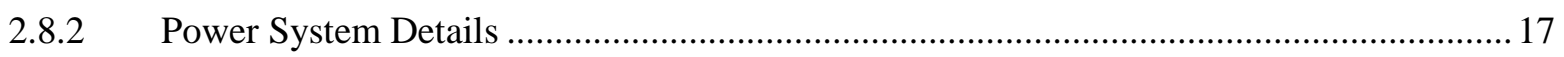

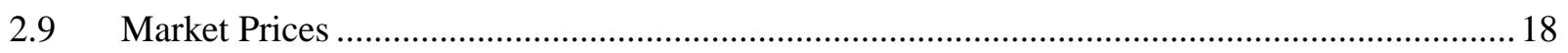

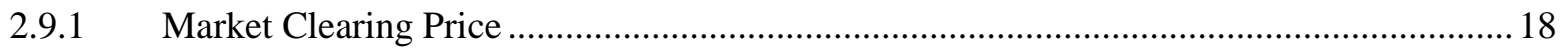

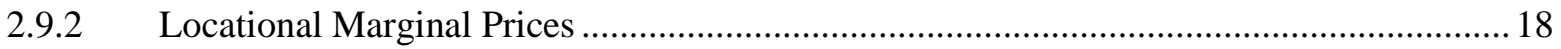

Chapter 3: $\quad$ MATHEMATICAL MODEL AND FORMULATION ….............................................. 19

3.1 Vehicular Behavior: Extraction of Probability Distribution Functions .................................... 19

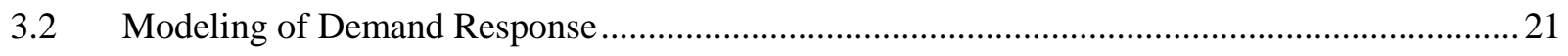

3.2.1 Price Elasticity Matrix - Fundamentals ............................................................... 21

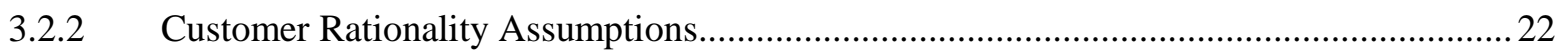

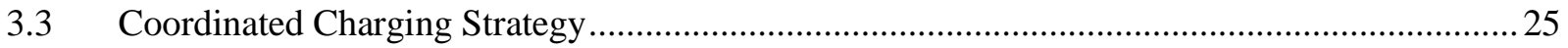

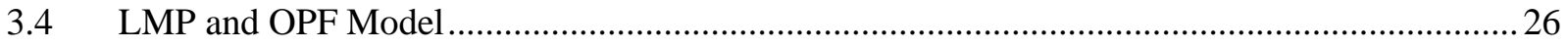

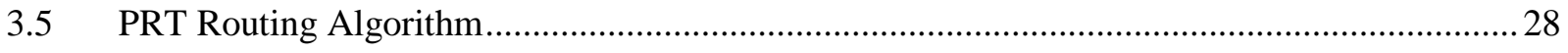

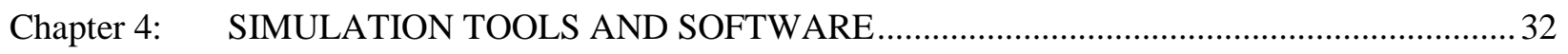

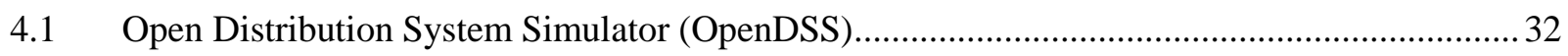

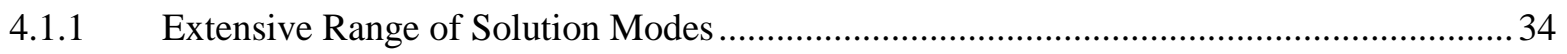

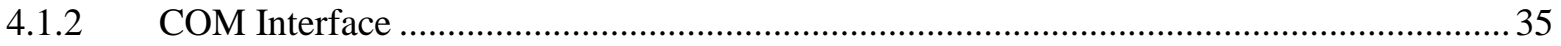

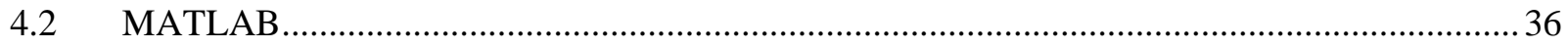

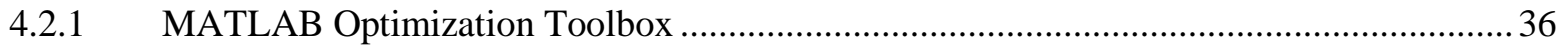

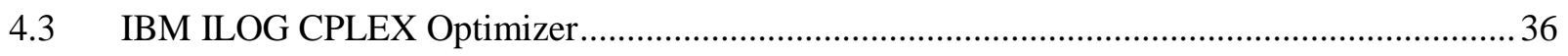

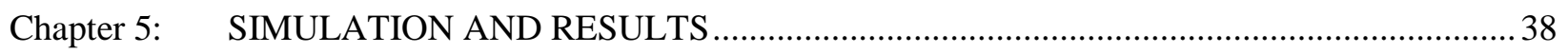




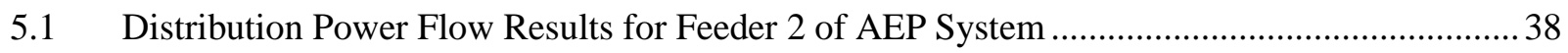

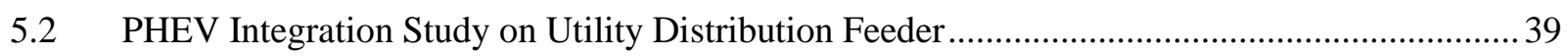

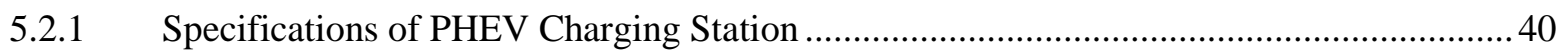

5.2.2 Uncoordinated Charging and Monte Carlo Simulation................................................... 40

5.2.3 Coordinated Charging of PHEV s............................................................................ 42

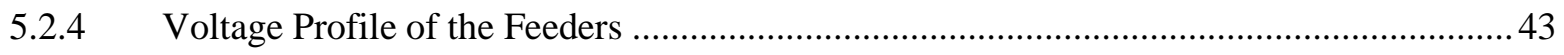

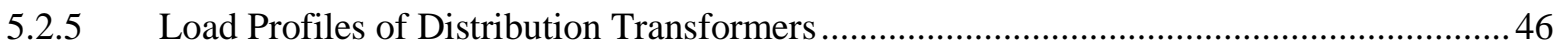

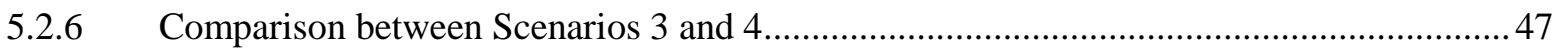

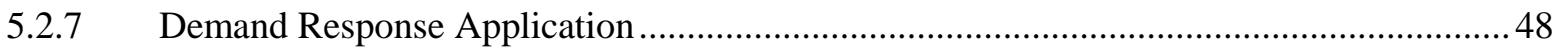

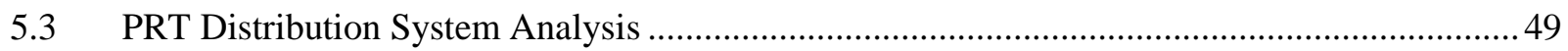

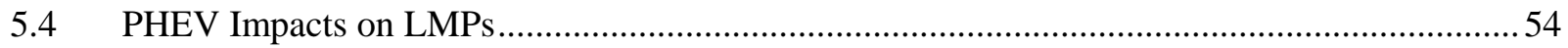

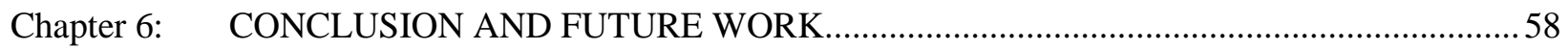

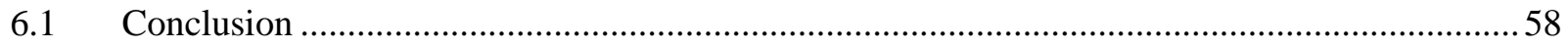

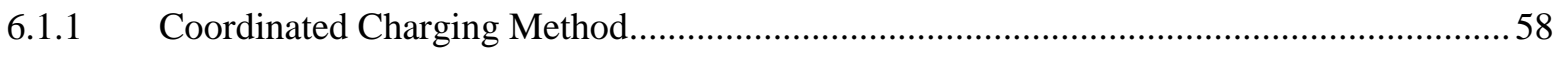

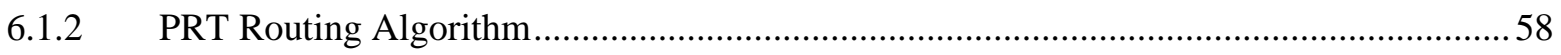

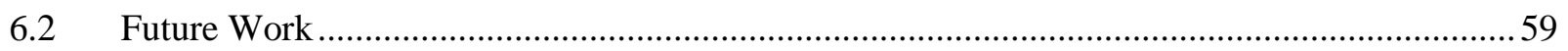

References 


\section{List of Figures}

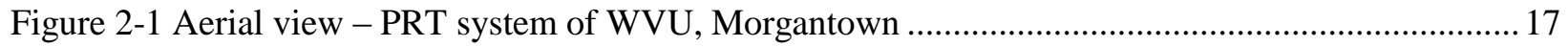

Figure 3-1 PDFs of (a) Distance Travelled and (b) Home Arrival Time .................................................2 20

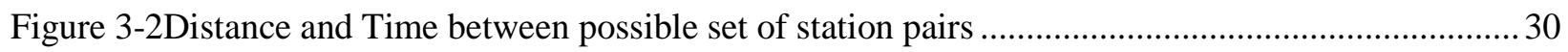

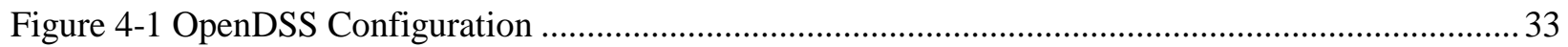

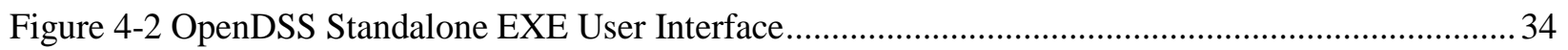

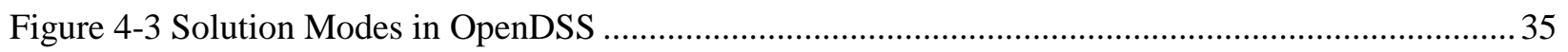

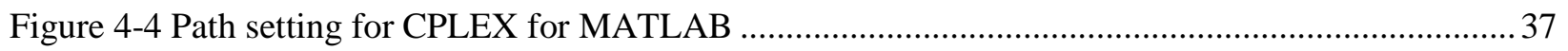

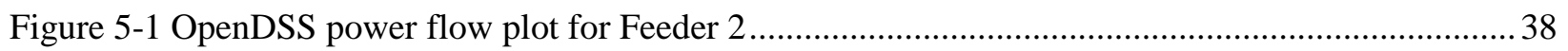

Figure 5-2 AEP Feeder model with PHEV Charging Stations and meter locations ................................... 40

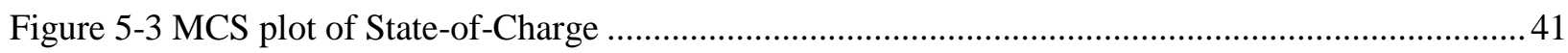

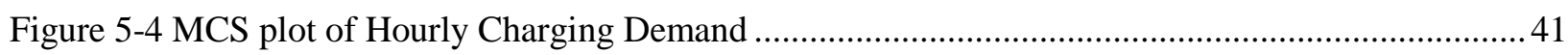

Figure 5-5 Voltage profile for 24-hours of Feeder 2 ........................................................................ 43

Figure 5-6 Transformer loading for different charging methods ...........................................................4 43

Figure 5-7 Feeder 2 Voltage Profile - Base Case................................................................................. 44

Figure 5-8 Feeder 2 Voltage Profile - Uncoordinated Charging........................................................... 45

Figure 5-9 Feeder 2 Voltage Profile - Coordinated Charging............................................................. 45

Figure 5-10 Distribution Transformer Loading Patterns ....................................................................... 46

Figure 5-11 Time taken by random vehicles to reach 70\% SOC ........................................................ 47

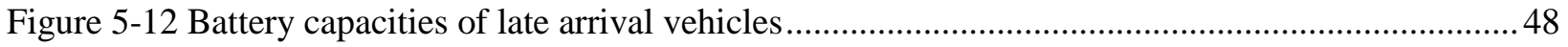

Figure 5-13 Transformer loading for different charging methods - with Demand Response....................49

Figure 5-14 Hourly passenger demand at all 5 stations .......................................................................50

Figure 5-15 Number of vehicles at each station pair ..................................................................... 50

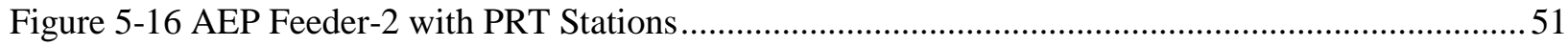

Figure 5-17 Total number of BEVs in Service and Charging modes …...............................................52

Figure 5-18 Base load and charging load of AEP distribution feeder ..................................................52

Figure 5-19 Voltage profile for 24-hours at all metered locations..........................................................53

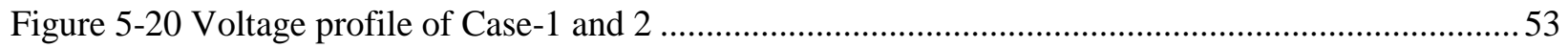

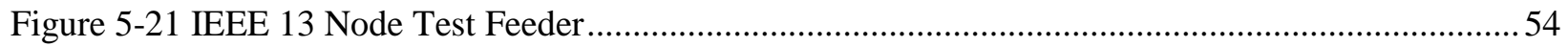

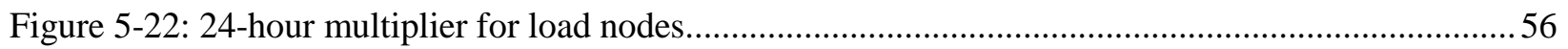

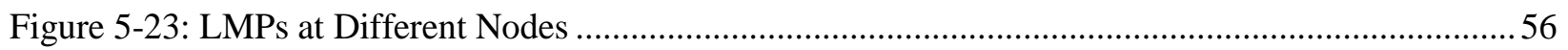

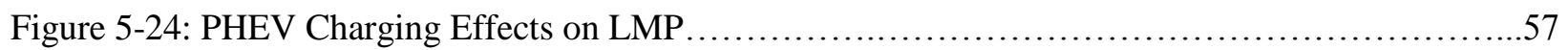




\section{List of Tables}

Table 3-1. Hourly Day Ahead RTP with Self Elasticity Coefficients …................................................23

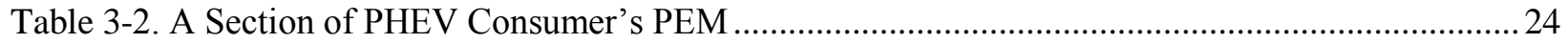

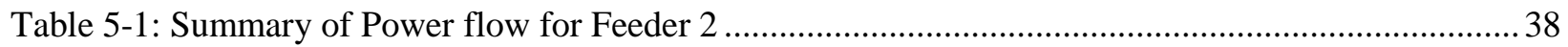

Table 5-2. PHEV Penetration and Loading in the Test Feeder.............................................................. 42

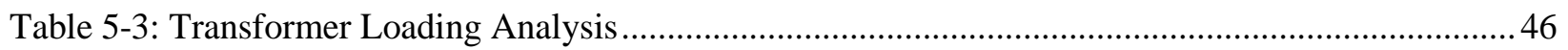

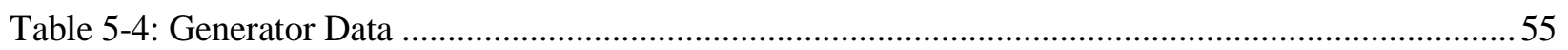

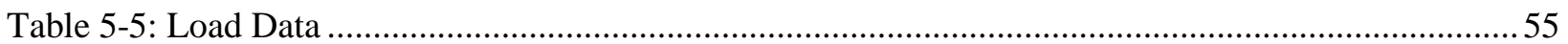




\section{Chapter 1: Introduction}

\subsection{Background}

The electric power system is one of the highly invested industries undergoing constant technology renovations in all the three fields - generation, transmission and distribution; emerging into more complex grid to efficiently serve its purpose. The resultant of these innovations leads to SCADA Management, Smart Grid, Distribution Operations and Automation in Electric industry. Energy deregulation has drastically changed the industry backdrop over the last decade generating new business models and turning others upside down.

The SCADA and EMS is the brain and central nervous system of utility operations which enables the success of current initiatives including Smart Grid deployment and Distributed Generation. Smart Grid is a podium for converting electric utility business models from customer enablement and improved operations to new ways to accomplish supply and demand. Some of the features of today's Smart Grids as described in [1] are as follows -

1. Distribution Automation (DA): System monitoring and automation, integrated Volt-VAR control, communication infrastructure and operating efficiency are common distribution utility goals that present challenges due to the nature of distribution systems.

2. Automated Metering Infrastructure (AMI): AMI is the foundation technology of Smart Grid used by the utilities for enabling monitoring of feeders and transformers, outage management, fault detection, distributed generation and EV integration.

3. Geographic Information Systems (GIS): Improving operating efficiency, system reliability and safety to manage system assets and electrical network connectivity is the main goal of GIS. The smart grid features of DA, AMI depend on the accurate asset records and locational data managed in GIS

4. Demand Management System (DMS): Managing demand has become more and more important for power delivery utilities. Increased penetration of non-dispatchable renewables and unpredicted loads such as EVs have increased intermittencies associated with development of new generation resources, making demand response a critical component of smart grid implementation. 


\subsection{Electric Vehicles - Definition and Types}

Though the political motive of reducing dependency on foreign oil initiated the revolution of Plug-in Hybrid Electric Vehicles (PHEVs) and Battery Electric Vehicles (BEVs), the characteristics like low greenhouse gas emissions and related economies are the driving factors behind their popularity. The Federal government has designed policies aiming at 1 million PHEVs on road by 2015 [2] by providing incentives and tax exemptions. A significant contribution to pollutants due to Internal Combustion Engine (ICE) vehicles led to electrification of public transportation by introduction of BEVs and power train vehicles. Stabilizing the power system encompassing PHEVs and BEVs is a challenging issue in the near future as charging the vehicles imparts an additional electrical load on the system. Satisfying the PHEV owners with flexible charging schedules and maximizing social benefit by maintaining the system within network limits is the point of interest. Much emphasis is laid on facilitating the increasing load due to EV charging by maximum utilization of existing infrastructure with zero or little new reinforcement to the grid. The near term forecast of penetration of EVs into market is discussed in [3].

Electric vehicles or EVs can be classified into a broad category that comprises any vehicle with a battery that can be charged by plugging into an electric wall outlet. The first electric vehicle is dated back to initial decades of 1900 , but due to the availability of cheaper fossil fuels - diesel and petrol, the EVs are dominated by Internal Combustion Engine (ICE) vehicles. Once again in the year 1966, the U.S introduced a legislation recommending EVs as a means of reducing air pollution. With this initiative, the market share of EVs plunged to new peaks every year starting from early $21^{\text {st }}$ century [4].

\subsubsection{Battery Electric Vehicles}

Battery Electric Vehicles (BEVs) are EVs that operate solely on the battery power without any ICE cycles. A typical BEV consists of a battery and an electric drivetrain and has zero direct emissions. The introduction of new battery technology, particularly the advancement of Lithium-Ion batteries, has greatly affected the sales of BEVs in today's automotive marketplace. In today's automobile market Nissan Leaf, Mitsubishi iMiEV, Ford Focus, Tesla Roadster and Chevy Spark fall into the category of BEVs. BEVs consist of fewer moving parts than an ICE vehicle and the conversion of electricity to mechanical work by an electric motor is far superior. Therefore the total vehicle efficiency is nearly three times higher than an ICE vehicle [5]. Different types of batteries available or under development for EV technology are - Lead/acid, Nickel Metal Hydride, Lithium-Ion (Tesla Roadster, Mitsubishi iMiEV), Metal Air and Sodium Nickel Chloride or Zebra battery (Think City EV). The battery capacity dictates the mileage of the vehicle and the charging technology plays a major role in penetration of BEVs into light-duty vehicle market. 


\subsubsection{Plug-in Hybrid Electric Vehicle}

Plug-in hybrid Electric Vehicles (PHEVs) are EVs with both conventional internal combustion engine (ICE) and rechargeable battery that is able to function on both the combustion and battery exclusively. Few PHEVs available in market are - Toyota Prius, Chevy Volt, BMW i8, Ford Escape. The battery technology is similar to that of BEVs but with smaller capacities. These vehicles are designated as PHEV $x$, where $x$ denotes the number of miles covered by the vehicle in all electric mode before turning into charge sustaining mode. For example, a PHEV40 is capable of commuting 40 miles before it requires connecting to electric grid for recharging its battery. It is predicted that PHEVs will constitute 1 to $5 \%$ of auto sales by 2020 depending on government regulation decisions and global energy prices. This prediction requires a sale of approximately 200,000 to 1 million EVs which also represent a portion of Obama's administration goal of placing 1 million PHEVs on road by 2015[6].

\subsection{Charging of EVs}

Since EVs use battery power for commuting, the capacity of the battery called State-of-Charge (SOC) depletes by distance travelled which demands timely recharge of battery for the following trips. This is the point of interest that connects the transportation sector with electric power systems. Charging of EVs comes as an additional load on the grid, demanding increase in the generation capacity. The charging - discharging cycle has significant effect on the life of battery that still remains a challenge for EV manufacturers limiting the owner's freedom in multiple charging of vehicle battery [7]. Various facilities are available for charging of EVs such as connecting to wall outlet at home, community charging stations at public places, battery swapping stations and quick charging stations.

\subsection{PHEVs - Benefits and Challenges}

\subsubsection{Benefits}

PHEVs offer multiple benefits in certain aspects with intelligent planning and advanced technologies.

1. System benefits: Gasoline or diesel is less efficient fuel than electricity, so an extensive use of PHEVs can result in overall Greenhouse Gas reductions.

2. Consumer benefits: Purchase of PHEVs provides tax incentives as well as reduction in spending on gasoline. PHEVs also equip customers with the ability to sell the energy back to the grid another financial incentive to embrace this technology. 
3. Electric Utility benefits: PHEV customers incline to charge their vehicles at night-during a utility's low demand period - when electricity is cheaper, and when most utilities have idle capacity. The additional demand by PHEVs will support fill in the off-peak valleys in the load curve, evading some expensive cycling activity of generation services.

4. Mobile Storage: PHEVs with V2G facilities represent dispersed, mobile energy storage that is supported by the vehicle owner. The use of PHEVs as mobile storage devices has the potential to significantly change a utility's load shape. Integrating storage with grid will decrease generation costs as well as capacity. PHEV battery storage could also improve system performance by negating expensive peak demand periods with available storage, thereby reducing the high cost less efficient peak generation in the short-run, and increase base-load capacity in the long run.

5. Integration of Intermittent Renewables with PHEVs: The intermittent nature of renewables can be efficiently tapped into charging of PHEVs and the storage capabilities of PHEVs could help balance the normal fluctuations of demand and intermittent renewable supply.

6. Ancillary Services: V2G helps to provide stability and emergency services for the utility grid. Most importantly, the quick response time of the battery makes $V 2 \mathrm{G}$ technology providing the instantaneous balancing of supply to load (frequency regulation) and for assuring that sufficient generation resources are available in the event of a power station or transmission outage (spinning reserves).

\subsubsection{Challenges}

Integration of PHEVs into the US electric grid has gradually started moving from pilot projects into actual deployment. However, there are still certain barriers/challenges to PHEVs deployment [8].

1. Cost and complexity of two powertrains: Since PHEVs are capable of running both on battery power and ICE, they must be equipped with machinery related to both technologies. Two powertrains will increase weight of the vehicle which has impact on mileage.

2. Drivers adapting to dual-fueling scenarios: PHEV drivers need to keep track of fuel consumptions in both modes and must be mindful about switching between modes based on the terrain travelling.

3. Component availability: As PHEVs use entirely new technology apart from conventional ICE, components such as batteries, powertrains and power electronics are crucial for maintenance of 
vehicle. PHEV industry is still novice and availability of such components in the market is a challenge for owners.

4. Higher initial capital costs: People are willing to buy PHEVs only with the support of government incentives due to higher initial costs and not all states provide tax incentives to PHEV owners.

5. Cost of batteries and potential battery replacements: Since the charging - discharging cycle has significant effect on loss of life of battery, their replacements are mandatory after certain time and corresponding costs are higher.

6. Need for public recharging infrastructure: Vehicles home parking time is less during the day compared to parking at work or public place, so government needs to provide with public charging stations to push the penetration of PHEVs into public.

\subsection{Demand Response}

Federal Energy Regulatory Commission (FERC) defines demand response as: changes in electric usage by end-use customers from their normal consumption patterns in response to changes in the price of electricity over time, or to incentive payments designed to induce lower electricity use at times of high wholesale market prices or when system reliability is jeopardized. In simpler terms Demand Response means demand responding to generation. DR helps in achieving the market balance between generation and load. DR programs are classified into two basic types: Incentive Based Programs (IBP) and Time Based Programs (TBP) [9].

Incentive Based Programs are based on the incentives paid by the electric utility to the customers during times of peak electricity prices in order to encourage customers to reduce their usage. Different IBP are discussed below -

1. Direct Load Control (DLC): These refer to programs in which a utility or system operator remotely shuts down or cycles a customer's electrical equipment on short notice to address system or local reliability contingencies in exchange for an incentive payment or bill credit.

2. Interruptible/curtailable service (I/C): Customers on interruptible/curtailable service receive a rate discount or bill credit in exchange for agreeing to reduce load during system contingencies. If customers do not curtail, they can be penalized.

3. Emergency Demand response Programs (EDRP): EDRP provides an incentive payment to customers for reducing their loads during reliability-triggered events, but curtailment is voluntary. 
4. Capacity Market Program (CMP): In capacity-market programs, customers commit to providing pre-specified load reductions when system contingencies arise, and are subject to penalties if they do not curtail when directed.

5. Demand Bidding/Buy Back: These programs encourage large customers to offer to provide load reductions at a price at which they are willing to be curtailed, or to identify how much load they would be willing to curtail at posted prices. These demand-bidding programs provide a means to elicit price responsiveness when prices begin to increase.

6. Ancillary service Markets $(A / S)$ : Ancillary services programs allow customers to bid load curtailments in Independent System Operator (ISO) markets as operating reserves. In order to participate in ancillary-service markets, customers must be able to adjust load quickly when a reliability event occurs.

Time Based Programs rely on customer's choice to decrease or change their consumption in response to changes of electricity's price during a 24 hour period. Different TBP programs available in the market are

1. Real Time Pricing (RTP) Program: In this program, the day is usually divided into a number of time slots, for example 24 one hour slots and each slot has a different price for electricity that reflects the real market clearing price.

2. Time-of-Use (TOU) Program: Time of Use (TOU) pricing is more or less similar to real time pricing, but with a fewer number of time slots to reduce the complexity involved with real time pricing. In most TOU schemes, the day is divided into two pricing periods namely peak hours and off peak hours. Some utilities use three different pricing periods with a flat period included between the peak and the off peak periods. Peak periods will have higher tariff compared to off peak periods where the prices are comparatively lower.

3. Critical Peak Pricing (CPP) Program: This program has fixed rate tariff for most part of the day and high rate for consumption of electricity during a few pre-specified hours of the day.

\subsection{Locational Marginal Prices}

In United States, Locational marginal pricing (LMP) is a market based pricing method embraced by six (CAISO, MISO, ISO-NE, NYISO, PJM and ERCOT) out of ten Independent System Operators/Transmission System Operators (ISO/TSO). The locational marginal prices (LMP) constitute the basis of the new generation of electric market design. FERC has proposed LMP as a way to achieve 
short- and long-term efficiency in electric power wholesale market [10]. It is a method of calculating the market price for energy and transmission at all the nodes on the power grid at which the energy transactions are held. The wholesale electricity prices in LMP-based markets are defined as the incremental cost of re-dispatching the system to serve one more MW of demand at a given location subjected to generation and transmission constraints. From this definition, the subsequent LMPs are location specific stochastic methods. LMPs fluctuate intensely over time since electricity travels at light speed and cannot be economically stored which has to be generated instantaneously as it is being consumed. As demand of electricity swings over time, different generators with varying costs will have to be operated at different capacities, causing LMPs to fluctuate accordingly.

\subsection{Electrification of Public Transportation}

Electricity is considered as a substituent fuel for road transport due to numerous benefits such as reduction in air pollution, greenhouse gas emissions and noise pollution. The transfer from conventional ICE based transportation to more electric or full electric mobility has been given utmost priority in both developed and developing nations - the US, Japan, China, Korea and EU. Vehicles such as bikes, scooters, passenger cars, delivery vans and vehicles for public transport which use battery power to commute are generally referred to as electrification of transportation sector. This electrification associates the link between the energy and vehicular sectors and a novel field of services with respect to the management of Electric Mobility. For the first time ever since, it gets together utilities and power grid operators with the manufacturers and users of the automobile.

Many public transportation models were developed using electricity as fuel - Airport Terminal Connectors, Bus Rapid Transit, Metro Rail System, Group Rapid Transit, Automated People Movers and Personal Rapid Transit and Light Rail Transit. All these technologies draw electric power from the guideways to power the traction system. Examples of such systems are - the MetroTransit serving the Minneapolis/St. Paul area, PHX SkyTrain of Phoenix Sky Harbor International Airport, SkyTrain (Advanced Rapid Metro) of City of Vancouver, San Francisco Municipal Railway fleet, Massachusetts Bay Transportation Authority.

Apart from above models, breakthroughs in motor drive system technology as well as the extensive application of power electronics lead to introduction of Battery Electric Vehicles (BEVs) called Electric Buses into public transportation. These vehicles solely run on power supplied by high capacity batteries rather than the online power from guideways. Many demonstration and pilot projects have come into full-fledged implantation. Foothill Transit providing service to suburb areas of Los Angeles and the Santa Barbara MTD are few to name which are using 26-feet long regular size battery buses. These 
projects are well equipped with fast charging stations capable of charging the entire battery in 10mins of layover time [11].

\subsection{Problem Statement}

The primary objective of this thesis is to model a coordinated charging algorithm to charge maximum number of PHEVs with the existing infrastructure at a Charging Station (CS) located in residential locality. Different charging strategies are developed and response of power system to the charging strategies is obtained by modeling American Electric Power utility distribution feeder in OpenDSS. Further, PHEV customers are modeled into price responsive consumers capable of participating in Demand Response programs to economically charge their vehicles and render support to the stabilization of power system. Consumer behavior modeling has been done by developing extensive demand-price elasticity matrices (PEMs) which are utilized to calculate the level of demand response.

This thesis also proposes a concept of converting the existing Personal Rapid Transit (PRT) system from guideway power rail propelling vehicles to Battery driven vehicles by developing a novel routing algorithm. The routing algorithm involves Mixed Integer Linear Programming (MILP) optimization resulting in hourly schedule of all the vehicles satisfying the passenger demand. The effect of charging load of BEVs on the electrical distribution system is analyzed by performing a time series simulation on AEP distribution feeder.

The impact of PHEV charging on power market prices is also analyzed in a microgid scenario. The uncoordinated charging of EVs results in unplanned peak demand causing system changes and fluctuation of Locational Marginal Prices (LMP).

A few assumptions made in this thesis work are listed below,

- Smart meters are assumed to be deployed at the charging station premises to provide day ahead real time pricing signal.

- $\quad$ Elasticity coefficients (introduced later in chapter 3) used to model DR have been either inferred from available data or extrapolated from previous works.

\subsection{Approach}

The sections to follow will model PHEV owner behavior and consumer demand response and design a coordinated charging strategy. The key aspects of this research are highlighted in subsections below. 


\subsubsection{Coordinated Charging Strategy}

Uncontrolled charging of PHEVs imposes unwanted stress on the power system leading to deterioration of component life such as distribution transformers, line conductors and protection circuits. This drawback can be overcome by designing coordinated charging strategies to aid the power system as well as satisfying the PHEV owner's needs.

- Probabilistic Driving patterns of the vehicles - Time-of-Arrival, distance travelled and State-ofCharge (SOC) patterns are generated from historical data.

- Monte-Carlo Simulation is run to compute the arrival SOC of PHEVs and the hourly load imposed by these PHEVs to study the effect of uncoordinated charging on distribution system.

- A coordinated charging strategy for a Charging Station (CS) in the direction of maximizing the number of PHEVs charged by formulating a Mixed Integer Linear Programming (MILP) Optimization in MATLAB.

- Analysis of coordinated charging on utility distribution system is done using OpenDSS.

- $\quad$ PHEV customers are modeled as price responsive consumers capable of participating in demand response programs by developing extensive demand-Price Elasticity Matrices (PEMs) which are utilized to calculate the level of demand response.

\subsubsection{PRT Routing Algorithm}

An optimized routing scheme is developed and can be used as a scheduled mode of operation to dispatch the vehicles based on the historical passenger demand data. This algorithm also helps in tracking the vehicular travel, charging and ideal times for the purpose of analysis which is taken care by the control center in real time.

- Data for passengers demand, BEV battery capacity, available vehicles, commuting distance and time between pair of stations, occupancy ratio is obtained from West Virginia University Department of Transportation (WVU DOT).

- $\quad$ The PRT stations are interfaced with AEP distribution feeder.

- A routing algorithm is formulated in MATLAB to find optimal number of BEVs required to satisfy the student demand on a normal university working day. 
- $\quad$ Response of distribution system to hourly charging demand of BEVs from optimized routing algorithm is analyzed using OpenDSS.

\subsubsection{PHEV Charging Effects on Market Prices}

The charging of PHEVs comes as an additional load to the grid demanding an increase in the generation capacity which leads to change in the price of energy. The effects of uncoordinated and coordinated charging techniques on market prices of a microgrid with renewable sources such as PV and wind is studied as follows -

- Monte-Carlo Simulation is run to compute the arrival SOC of PHEVs and the hourly load imposed by these PHEVs on the system.

- $\quad$ A lossless DCOPF on IEEE 13 Node test system is formulated in MATLAB.

- Also Power Transfer Distribution factors (PTDFs) are computed to impose as constraints in DCOPF.

- The effect of previously formulated coordinated charging strategy on LMPs is analyzed.

\subsection{Outline}

The outline of the remaining chapters is given in this section.

Chapter 2 is a comprehensive literature review on PHEVs, history and evolution of PHEVs, charging technology and charging stations. Various charging methods with different objectives and industry experiences with PHEVs are discussed. A literature review on demand response, PRT system and LMP markets is also included.

Chapter 3 is about mathematical formulation of vehicular behavior, coordinated charging strategies and for obtaining the demand response model. The PRT routing optimization problem is formulated and DCOPF model to calculate LMP is also developed.

Chapter 4 gives a detailed description of the software packages used in this research. The advantages offered by the software to the relevant applications are also discussed.

Chapter 5 presents the test systems, simulations for analyzing charging methods of PHEVs and effects of converting PRT vehicles to BEVs on distribution system are analyzed with results.

Finally, chapter 6 lists conclusion of this study and provides scope for future work. 


\section{Chapter 2: $\quad$ LITERATURE REVIEW}

This chapter reviews the literature for PHEV charging methods and influence on market prices.

\subsection{PHEV Operating Principle}

The size and configuration of PHEVs is still an evolving factor depending on the technology growth with regard to battery and powertrain. The present automobile market has a range of models with different drivetrain strategies and electric ranges. PHEVs are designed to operate in two modes - initially in battery run mode and then switch to a charge-sustaining mode i.e. conventional ICE mode which may not restrict other operation strategies. PHEVs can be also operated in combined mode, where the ICE periodically helps the electric motor in delivering the tractive energy (happens in a parallel PHEV with a relatively weak electric traction motor). Therefore, the operation of PHEVs can be categorized into the charge-depleting (CD) mode and the charge-sustaining (CS) mode [12]. In CD mode, the vehicle runs on the battery power slowly deteriorating its capacity, with either a part of or the whole tractive energy being supplied from the battery. The total distance ' $x$ ' that a PHEV can commute in CD mode with its batteries fully charged is defined as its "charge-depleting range" (CDR) and the PHEVs are designated as PHEVx in the market. After the battery energy reaches a specified threshold limit given by the manufacturer for the longevity of the battery life, the PHEV operates on CS mode, where it is then operated similar to a conventional ICE vehicle, with all necessary energy supplied by the fuel. Several of the previous studies treat CD operation the same as all-electric operation. Notable PHEV makers included the battery technology which can aid the power system in V2G mode during times of peak loads by connecting to the grid.

\subsection{Charging Methods - Types}

The PHEVs interaction with the electric grid is essential to study their significant impacts caused by the additional charging load. The possibility of energy flow to the grid through V2G technology may happen in the future, but the initial interface will most likely be one-way i.e. from the grid to vehicle. The Electric Power Research Institute (EPRI) has come up with three different charging levels. The basic models of PHEVs initially were charged with Level 1 charging which has the standard household rating of $120 \mathrm{~V}$ AC $15 \mathrm{~A}$ outlet that is available in many attached garages [13]. The batteries are charged at a rate of $1.44 \mathrm{~kW}$. 
The technology advancements led to the design of an improved charging level with ratings 240VAC 40A that can be made available at home garage with little infrastructure. This is defined as Level 2 charging and is measured as the ideal way to charge PHEVs in terms of recharging time. Level 2 charging is often limited to $15 \mathrm{~A}$ and the batteries are charged at a rate of $3.3 \mathrm{~kW}$. Most of the public charging such as charging at shopping malls, community charging stations are equipped with level 2 charging for the convenience of employees which also aids with increase in penetration of PHEVs.

A typical PHEV with battery capacity of $10 \mathrm{kWh}$ is capable of driving twenty miles in charge depletion mode and then shift into ICE mode. The lowest threshold a 10kWh battery can reach is limited to $4 \mathrm{kWh}$ before charging due to the battery lifespan constraint and need 5.5 hours to charge at Level 1. This same vehicle would require only a single hour to charge $100 \%$ at Level 2 charging rates. The charging rates may undergo rapid change with the increase in penetration of PHEVs when the PHEV owners may look for sources which provide fast charging similar to gas refilling stations. These fast charging stations are facilitated with infrastructure that can recharge 50\% capacity in just 10 to 15 minutes through a 480VAC, three phase circuit and this is termed as Level 3 charging. An alternative to Level 3 charging stations are battery swapping stations. These stations maintain completely charged batteries which can be readily replaced with the empty ones when the PHEV arrives rather than staying ideal for the recharging purpose. These stations require less infrastructure than the fast charging station; but demands significant investment in batteries to provide service to the local population. Also, ownership of the batteries at end-of-life becomes a concern.

\subsection{Evolution of Charging Strategies}

Many previous works have focused on various aspects of PHEV penetration from different perspectives. Reference [14] provides literature on significant effects of PHEVs on the low voltage distribution grid and [15] discusses the negative effects on distribution transformers in particular. The importance of analyzing the vehicle behavior through probability distribution functions is discussed in [16] and the influence of stochastic nature on power demand is elaborated in [17]. Real-world driving cycles are developed in [18] using naturalistic driving data to estimate PHEV energy consumption. The above discussed methods involve in estimating the Time-of-Arrival and State-of-Charge of PHEVs, but do not provide charging algorithms using these parameters. Assessment of charging based on demographic data is introduced in [19] that shows a well-developed public charging infrastructure could reduce stress on the system. Different battery charging levels available in today's market and their charging durations are presented in [20]. Considerable work has been done towards minimizing the grid losses due to PHEV charging through efficient charging techniques [21] - [22]. These methods involve 
charging algorithms with different objective functions. Reference [23] develops a control charging strategy to minimize total generation cost and losses along with improving the voltage profile of the system. The impacts of PHEV charging on distribution system operating costs and methods to minimize them are analyzed in [24]. The application of renewables in PHEVs is discussed in [25] - [26], where the capability of PHEVs is used to support wind integration considering variations in wind generation and demand of PHEVs. In [27], the distributed generations are used to minimize the charging costs of PHEVs simultaneously reducing the losses of the system. References [28] - [29] discusses about smart charging mechanisms involving communication systems called Home Area Network (HAN), that provides interaction between utility or distribution feeder with the PHEVs about when to charge and when not to charge. In [30], a coordinated charging algorithm to maximize the SOCs of PHEVs in a charging station scenario is developed. This thesis utilizes the parameters - Time-of-Arrival, State-of-Charge and distance travelled and designs a coordinated charging strategy for a Charging Station (CS) in the direction of maximizing the number of charged vehicles in case of PHEVs.

\subsection{Practical Demonstration of PHEV Charging Stations}

Practical demonstrations of PHEV charging stations around the world provide us with a tremendous volume of information on its implementation, control strategies and energy management strategies. Some of the important charging station demonstrations are described in brief.

\subsubsection{San Diego's Fashion Valley Mall Charging Station, CA}

The first public EV charging station in the United States that supports all models of electric vehicles has opened in San Diego [31]. It can charge the batteries of cars that operate on any of the three existing connection systems. Located at the Fashion Valley Mall, the charging station features both SAE Combo and CHAdeMO direct current (DC) fast charge connectors. Both are direct-current quickcharging systems designed to charge an EV's battery to 80 percent in about 20 minutes. The charging station also offers traditional alternating current (AC) J1772 Level 2 electric vehicle charging to serve electric vehicles that do not have a fast charging option. Available 24/7, the combined charging station is placed near retail stores and restaurants to allow drivers the option to shop or eat while charging.

\subsubsection{Trans-Canada Highway Charging Station, Canada}

In 2012, a series of free public electric vehicle charging stations were installed along the main route of the Trans-Canada Highway by a private company, Sun Country Highway, permitting electric vehicle travel across the entire length [32]. As of 2012 this made it the longest electric vehicle ready highway in the world. The same company also partnered with Canadian rural hardware retailer Peavy 
Mart to add free public charging stations to its 29 stores across Western Canada and includes chargers located at Best Western hotels in Canada and the US on its online map of EV charging stations. As of 2013 the company's total network was over 700 chargers with plans to reach 1000 chargers by year end.

\subsubsection{Chargepoint, U.S}

Chargepoint has the largest and most open electric vehicle (EV) charging network in the world, with more than 15,000 places to charge, 1,900 customers and a 70\%+ share of all networked public charging stations, operating charging spots on four continents including North America, Europe, Asia and Australia [33]. Chargepoint installed CT2000 family of networked stations with visibility and access limited to employees using ChargePoint RFID cards and mobile app. ChargePoint offered six CT2021 dual-port Level $2 \mathrm{EV}$ charging stations, networked and managed through their cloud-based platform. ChargePoint's cloud-based software provides the ability to make the stations visible and accessible to all EV drivers.

\subsection{PHEV Customer Behavior Modeling}

The basic assumption considered in this study is that the driving pattern of PHEV owners will be alike to the behavior of drivers of conventional ICE vehicles. It is assumed that PHEVs will not change the daily travel needs and lifestyles of the owners in any significant style i.e. customers will have the same travel demands as earlier and will use their PHEVs to run every day needs. The limitation of this assumption is that PHEV owners may drive differently than the average driver. The underlying cause for this - a PHEV (being a different type of vehicle) impacting the travel patterns, or to specific attributes of PHEV owners, such as increased environmental awareness or income level [34]. This may happen initially, when PHEVs are a new technology into the market, this assumption could be valid. However, as the penetration of PHEVs increases, then the PHEV driver will "converge" to a normal ICE driver.

The 2009 National Household Travel Survey (NHTS) collected the key information required to model the behavior of vehicle owners. Data such as mode of transportation, trip origin and purpose, and trip distance on the travel behavior of a sample of U.S. households is collected and made avail for researchers. The database files can be found online [35]. Two important files - the DAYPUBLL and VEHPUBLL are used for analyzing the vehicle data. DAYPUBLL contains the information about travel day trip and the file VEHPUBLL contains data regarding vehicle. The survey consists of 150,147 U.S households and 294,408 Light-duty Vehicles (LDVs). It was noticed that the factors like household area urban or rural and also the day of the week - weekday or weekend greatly impact the vehicle travel patterns. The parking start/end times and location of parking e.g., home, work, shopping mall, etc. for 
every vehicle throughout the day is available in the vehicle database. This kind of information is required for the determination of the charging profile.

\subsection{Demand Response - History and Evolution}

The spot pricing was introduced for the first time in the late decades of 1900 and established as a new concept of electricity pricing which lead to the development of DR [36]. This paper discusses the effect of spot prices on line losses, quality of supply and reactive energy. Also, it takes into consideration of participants of spot pricing market such as generating firms and consumers in formulating for optimum spot pricing with social welfare objectives. Significant theories on vital principles on spot pricing of electricity and economic analysis of spot pricing is provided in [37]. The authors have given a theoretically strong base on creating utility - consumer interaction for the benefit of both parties and the electricity market. In [38], the authors have also provided a thorough evaluation on the hourly based variable costs of electric energy on the spot prices. This work also involves decomposing of the spot prices into six basic constituents such as fuel cost, generation cost, network maintenance cost, losses cost and quality of supply cost. Further with annual network data, spot prices for the entire year were determined.

\subsection{Demand Response and Consumer Behavior Modeling}

Consumer behavior modeling assuming spot pricing of electricity is the next step following the spot electricity prices. In [39], the importance of consumer behavioral models for developing analytical models for electric systems with dynamic real time pricing is detailed. The concepts of demand elasticity across time, consumer economic rationality were used to model the behavior of consumers which also depends on the price formation model at the supply side. Based on their rationality consumers were classified into 3 types - as long range, short range and real world consumers. But, constant values for self and cross elasticities were supposed in this work leading to discrepancies in the correctness of the developed price elasticity matrices. In [40], the same authors analyzed the effect of large scale penetration of real time tariffs on the utility load curve which also includes the issues of ideal response of industrial consumers. Further in this work, the short term load and price forecast problem was discussed and how the spot pricing effects the forecast is studied as demand and price are interconnected and interdependent entities. In yet another work, these authors have used a real time optimal power flow algorithm that computes the real time price signals for the market using fixed demand curves [41]. These demand curves are then adjusted according to the demand price elasticity data of each consumer. The algorithm was applied to a test system with assumed values of price elasticities (again with the same limitation in PEM).

The customer type effects on the performance of the iterative OPF algorithm with day ahead and spot 
prices were analyzed. But, the existing nature of power systems and lesser flexibility among the end-users of that time limited the scope of spot pricing.

Application of Demand Response for coordinated charging of PHEVs in a microgrid is an area that is gaining a lot of research interest. Reference [42], gives a general idea on application of DR in charging of PHEVs. In [43], the Time-of-Use rate is provided to customers and impact of different DR strategies on load shapes is studied. This thesis uses PEM which is proven as an efficient tool for modeling consumer behavior for DR in our earlier work [44]. Also, this work builds a more comprehensive coordinated charging algorithm by modeling PHEV customers into different real world DR customers capable of affecting the load shapes.

\subsection{Personal Rapid Transit System}

The Morgantown Personal Rapid Transit system is a unique model of its kind which provides transit service between the campuses of West Virginia University (WVU). It is an Automated Guideway, easy-to-use transportation solution for WVU students, faculty, staff and general community. The system development and construction was funded by Urban Mass Transportation Administration to demonstrate the technological, operational and economic feasibility of a fully automatic urban transportation system. The system consists of fleet of electrically powered, computer monitored, passenger carrying vehicles. The PRT first began the passenger service in the year 1975 and since 60 million people have used the service and travelled 22 million miles. Approximately 15,000 people ride the PRT during the school year every day [45].

The different campuses connected by the PRT are - Walnut Street Downtown; Beechurst Avenue for the Downtown campus; Engineering Sciences; the Evansdale Residential Complex (or Towers); and Health Sciences which are indicated by circles in Figure 2.1. The longest ride is 3.1 miles and 11.5 minutes between the Walnut and Health Sciences stations. The case study of Chicago Transit Authority (CTA) is considered to check the economic feasibility of converting the fossil fueled bus transit into PHEVs in [46]. An effective solution for reducing environmental pollution using dual battery powered PHEVs is proposed in [47].

\subsubsection{Operating Principle}

The transit system is operated in two modes - scheduled and demand mode. The former mode is operated during the periods when passenger demand is highly predictable; and the later at times of less and unpredictable demand. Vehicles are dispatched between origin - destination pairs on a preset schedule i.e. the vehicle doesn't stop or commute passengers belonging to intermediate stations when 
travelling to extreme stations. Passengers have the feasibility of selecting the destination on entering the origin gateway by swiping the student identity card or by inserting the exact fare amount. This facility marks the passenger demand communication with the control center that dispatches the vehicles.

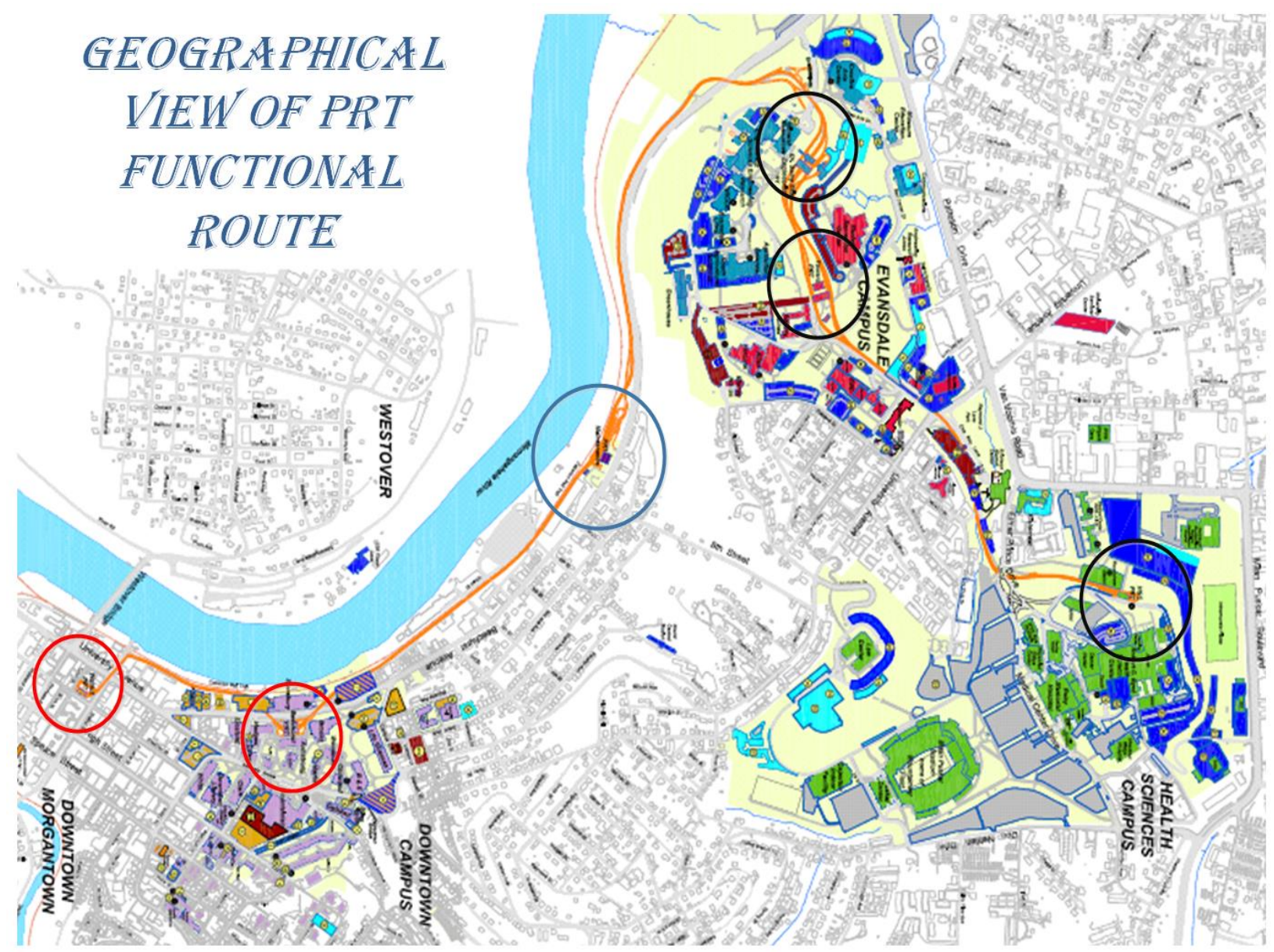

Figure 2-1 Aerial view - PRT system of WVU, Morgantown

\subsubsection{Power System Details}

The PRT system runs on $12.47 \mathrm{kV}$ medium voltage substation connected to propulsion substations which in turn supply $575 \mathrm{~V}$ AC, three phase delta power for distribution to the guideway power rails through five 1000kVA transformers. The switch gear is equipped with electrically operated circuit breakers which are controlled from the System Operator Control Console located in the Central Control Room. Power rails along the guideway distribute the 3-phase, 575V AC power to the vehicles picked up by a passive run-on run-off power collector mounted on the vehicle front wheel spindle which rides on the power rail as the vehicle travels along the guideway [48]. 


\subsection{Market Prices}

The restructuring of electric power industry led to the significance of electricity price and it has become the attention of all activities in the power market. The supply and demand of the commodity determines its price in the market. In the case of electricity market, other factors such as transmission congestion and losses also play a critical role in determining electricity prices; market rules also have impacts under certain circumstances.

\subsubsection{Market Clearing Price}

Generally, a congestion less transmission network is cleared on system wide and this is the most basic pricing concept in the electricity market called the market-clearing price (MCP). The MCP is determined by aggregating the generation bidding curves in increasing order to form a supply curve and the load bidding curves in decreasing order to form a demand curve, and to clear the market based on the aggregated supply curve and demand curve. The aggregation of curves is done by horizontally adding curves based on bidding prices: from low bidding price to high bidding price for generation bids, and from high bidding price to low bidding price for load bids.

\subsubsection{Locational Marginal Prices}

When there is no congestion in the system, LMP is the same as MCP. But, the electric power system is mostly unstable and vulnerable to congestion which forces the electricity market ineligible to be cleared on the system level. So, the market has to be cleared on the bus level and the clearing price at each bus is called locational marginal price (LMP). By definition, LMP is the cost of supplying the next MW of load at a specific location, after taking the generation marginal cost, cost of transmission congestion, and losses into consideration. In general, LMP could be different for different buses. When there is congestion, LMP will be determined based on the solution of an optimal power flow (OPF) that considers transmission line constraints. The marginal cost of each bus is the LMP. The calculation of LMP is more complicated than MCP since LMP considers transmission network while MCP overlooks the transmission effects. The additional coming from the PHEV charging demand has a significant effect on the LMP of the system which is detailed in the coming sections. 


\section{Chapter 3: $\quad$ MATHEMATICAL MODEL AND FORMULATION}

\subsection{Vehicular Behavior: Extraction of Probability Distribution Functions}

Analyzing the response of grid due to various system changes need accurate and detailed study of its electric behavior. Unlike many regular customer loads, PHEV loads are not deterministic. Investigating the impact of PHEVs on electric grid mandates information such as vehicle type, availability of vehicle to charge, present state of vehicle battery and charging infrastructure. Of these, the distance travelled, home and office arrival times and State of Charge (SOC) are stochastic in nature purely determined by driving patterns of individuals. Thus, in order to estimate the electric demand of PHEVs, it is essential to model the stochastic and probabilistic nature of driving behaviors. This modeling helps in designing optimal charging schedules providing valuable information for development of PHEVs and grid planning. This section deals with extraction of Probability Distribution Functions (PDFs) for Time of Arrival and distance travelled to derive the SOC of vehicles.

Reference [16], successfully formulated the PDFs for distance travelled and arrival time to calculate the load demand for a fleet of vehicle. In this paper, the PDFs are used to estimate the SOC of vehicles which are used in the following sections to study the effects of PHEVs on market prices and to design the proposed coordinated charging strategy. Type III Generalized Extreme Value (GEV) PDFs are used to model the behavior of required parameters. The daily distance traveled PDF is given as follows,

$$
g_{d t}=\frac{1}{\sigma_{d t}}\left(1+k_{d t} \frac{\left(d-\mu_{d t}\right)^{-\left(1+\frac{1}{k_{d t}}\right)}}{\sigma_{d t}} e^{-\left(1+k_{d t} \frac{\left(d-\mu_{d t}\right)}{\sigma_{d t}}\right)^{\frac{1}{k_{d}}}}\right.
$$

Where $\sigma \_\mathrm{dt}$ is standard deviation (7.1222), $\mu$ _dt is mean (17.6568) of the distribution and $\mathrm{k} \_\mathrm{dt}=$ 0.052368. Fig. 1(a) illustrates the distribution of miles travelled by a vehicle with the highest occurrences between 15 and 25 miles.

The home arrival PDF is given as follows,

$$
g_{a}=\frac{1}{\sigma_{a}}\left(1+k_{a} \frac{\left(t-\mu_{a}\right)^{-\left(1+\frac{1}{k_{a}}\right)}}{\sigma_{a}} e^{-\left(1+k_{a} \frac{\left(t-\mu_{a}\right)}{\sigma_{a}}\right)^{\frac{1}{k_{a}}}}\right.
$$


Where $\sigma \_\mathrm{a}$ is standard deviation (0.84832), $\mu \_\mathrm{a}$ is mean (17.2700) of the distribution and $\mathrm{k} \_\mathrm{a}=-0.060798$. Fig. 1(b) illustrates the distribution of PHEV home arrival times between 15:00 and 22:00 with the highest occurrences between 15 and 25 miles.

The present State of Charge depends on the distance travelled and capacity of the PHEV. Based on the developed PDFs, the SOC can be calculated as follows,

$$
S O C=100-\frac{d t}{\eta * C a p_{b a t}} * 100
$$

Where, dt is Distance Travelled, $\eta$ is efficiency coefficient $(2 \mathrm{mi} / \mathrm{KWh})$ and Cap ${ }_{\text {bat }}$ is capacity of the battery.

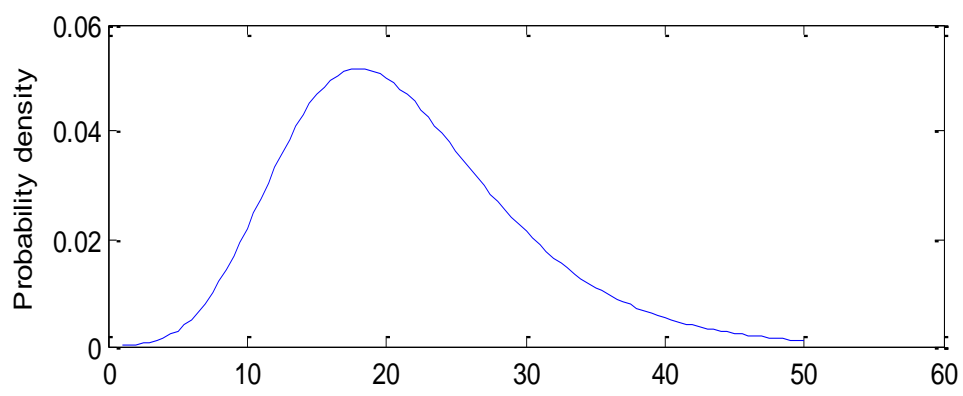

(a). Distance Travelled

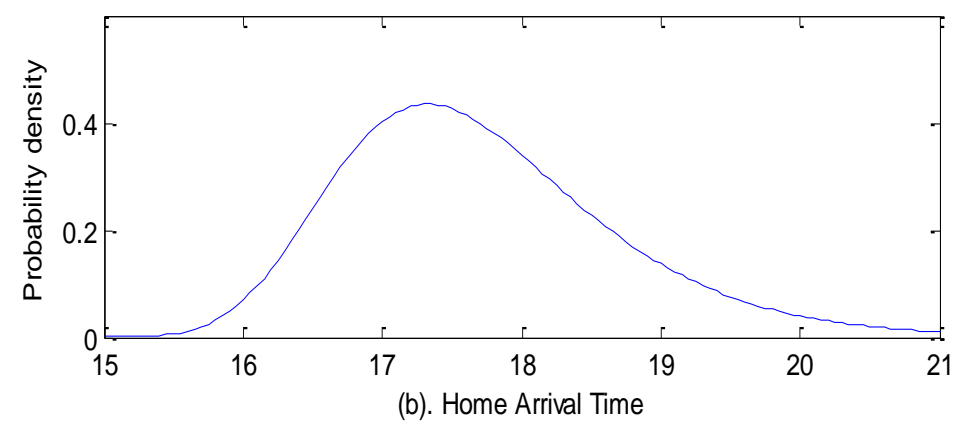

Figure 3-1 PDFs of (a) Distance Travelled and (b) Home Arrival Time 


\subsection{Modeling of Demand Response}

\subsubsection{Price Elasticity Matrix - Fundamentals}

This thesis uses PEM which is proven as an efficient tool for modeling consumer behavior for DR. Electricity can be considered as any other commodity where the demand decreases as the price increases and vice-versa. The price elasticity can be defined as,

$$
\rho=\frac{\Delta d / d_{0}}{\Delta p / p_{0}}
$$

Where $\Delta \mathrm{d}$ and $\Delta \mathrm{p}$ are the changes in demand and price respectively and $d_{0}$ and $p_{0}$ are the base demand and price respectively.

The correlation between price and price-responsive loads can be represented using the associated coefficients namely self-elasticity and cross-elasticity. The change in demand at a time instant ' $i$ ' due to change in price at the same time instant ' $i$ ' is defined as self-elasticity $\rho(i, i)$. Cross-elasticity $\rho(i, j)$ is defined as the change in demand at time instant ' $i$ ' due to change in price at some other time instant ' $j$ '. Generally, self-elasticity has a negative value because the change in price has an inverse effect on change in the demand and cross-elasticity contains a positive or zero value depending on whether the customer is willing to shift the load or not.

$$
\begin{array}{r}
\rho(i, i)=\frac{\Delta d\left(\mathrm{t}_{\mathrm{i}}\right) / d_{0}}{\Delta p\left(\mathrm{t}_{\mathrm{i}}\right) / p_{0}} \\
\rho(i, j)=\frac{\Delta d\left(\mathrm{t}_{\mathrm{i}}\right) / d_{0}}{\Delta p\left(\mathrm{t}_{\mathrm{j}}\right) / p_{0}}
\end{array}
$$

Load curtailment by the consumer can be measured through self-elasticity and load shifting can be measured by cross-elasticity. 
For a RTP scenario that has hourly varying rates, PEM will be of the order 24 X 24. Selfelasticity coefficients form the diagonal elements of the PEM and the off-diagonal elements correspond to the cross-elasticity coefficients. Each column of this matrix indicates how a price change during one single time period affects the demand during all other time periods. Consumers' reaction to high prices by moving ahead their loads are represented by nonzero elements above the diagonal. The nonzero elements below the diagonal represent the postponing of the demands. The change in the demand at time instant ' $i$ ' due to change in the price at all instants of the day is given by,

$$
\Delta d\left(t_{i}\right)=\sum_{j=1}^{24} E(i, j) *\left(\Delta p_{j} / p_{0}\right) * d_{0}
$$

Designing a perfect PEM is important to evaluate the effect of DR and load reduction or shifting that is possible per customer. In the following section, PHEVs are modeled as price responsive loads capable of modifying their charging needs and respective PEMs are calculated based on LMPs of the microgrid.

\subsubsection{Customer Rationality Assumptions}

The FERC defined the term Demand Response as change in electric usage by end use customers from their normal consumption pattern in response to change in the price of electricity over time or to incentive payments designed to induce lower electricity use at times of high wholesale market prices or when system reliability is jeopardized. This paper groups PHEV customers who can participate in demand response programs capable of influencing the electric usage during the times of high charging requests. Consider a utility real-time price curve over a period of PHEV available charging times at home i.e. from hour 16-07 the following morning as shown in table I. The RTP curves are season specific and the corresponding PEMs must be developed for different seasons using historical RTP data. The selfelasticity coefficients for low price hours are assumed as constant values and increases with increase in the prices beyond the limit of 3 cents per KWH. 
Table 3-1. Hourly Day Ahead RTP with Self Elasticity Coefficients

\begin{tabular}{|c|c|c|}
\hline $\begin{array}{c}\text { Hour of } \\
\text { Day }\end{array}$ & $\begin{array}{c}\text { Price (Cents per } \\
\mathrm{KWH})\end{array}$ & Self-Elasticity \\
\hline 16 & 14 & -.25 \\
\hline 17 & 15 & -.45 \\
\hline 18 & 12 & -.16 \\
\hline 19 & 12 & -.16 \\
\hline 20 & 10 & -.20 \\
\hline 21 & 13 & -.22 \\
\hline 22 & 12 & -.10 \\
\hline 23 & 10 & -.05 \\
\hline 24 & 5 & -.05 \\
\hline $1-6$ & 2 & -.01 \\
\hline
\end{tabular}

The PHEV customers are categorized as consumers whose insight depends on current and future prices only. A part of $24 \times 24$ matrix for these customers is shown in Table 3-2. Since, the perception is into future and due to procrastinating of load; the elements of the PEM above the diagonal are zeroes. The zeroes below the diagonal technically imply no shifting of loads to the future hours due to higher prices at those hours. The table displays only rows and columns from 18 to 04 since the interest is from hours 18:00 - 04:00 during which the vehicles are available for charging at home. Even the prices at far future are low, the consumers are inclined to shift the load to the low price hours at near future as the customers priority is to completely charge their vehicle batteries by the time they depart to offices. So, some weight in the value of cross elasticity is given for the shift within short range of time and the PHEV customers are tagged as Real World postponing customers with insight into near future unlike normal consumers participating in DR whose residential loads can be optimized throughout the day. 
Table 3-2. A Section of PHEV Consumer's PEM

\begin{tabular}{|c|c|c|c|c|c|c|c|c|c|c|c|}
\hline & 18 & 19 & 20 & 21 & 22 & 23 & 24 & 01 & 02 & 03 & 04 \\
\hline 18 & .20 & 0 & 0 & 0 & 0 & 0 & 0 & 0 & 0 & 0 & 0 \\
\hline 19 & 0 & .15 & 0 & 0 & 0 & 0 & 0 & 0 & 0 & 0 & 0 \\
\hline 20 & 0 & 0 & .26 & 0 & 0 & 0 & 0 & 0 & 0 & 0 & 0 \\
\hline 21 & 0 & 0 & 0 & .175 & 0 & 0 & 0 & 0 & 0 & 0 & 0 \\
\hline 22 & 0 & 0 & 0 & 0 & .42 & 0 & 0 & 0 & 0 & 0 & 0 \\
\hline 23 & 0 & 0 & 0 & 0 & 0 & .05 & 0 & 0 & 0 & 0 & 0 \\
\hline 24 & .11 & .07 & .018 & 0 & 0 & 0 & .05 & 0 & 0 & 0 & 0 \\
\hline 01 & .16 & .1 & 0 & .129 & .03 & 0 & 0 & .01 & 0 & 0 & 0 \\
\hline 02 & .15 & .07 & .01 & .258 & .02 & 0 & 0 & 0 & .01 & 0 & 0 \\
\hline 03 & .18 & .09 & .245 & .156 & .02 & 0 & 0 & 0 & 0 & .01 & 0 \\
\hline 04 & .16 & .13 & .266 & .057 & .3 & 0 & 0 & 0 & 0 & 0 & .01 \\
\hline
\end{tabular}




\subsection{Coordinated Charging Strategy}

Most of the researchers focused on centralized control of PHEV charging. The centralized techniques may fail with increase in the penetration of the PHEVs as controlling large number of vehicles cause computational burden on the control center. Also, communicating with large number of PHEVs in the real time pose a threat to the algorithm. Therefore, this paper proposes a localized coordinated charging technique that can efficiently deal with the problem of high penetration of PHEVs. In urban areas, since a significant percentage of population resides at residential apartments or colonies, most of the vehicles are parked at common parking lots instead of private garages. Thus, this charging strategy focuses on residential chagrining stations with limited PHEVs which are ideal for realization of localized coordinated charging.

Since the charging station is well located within the residential area, the distribution transformer (medium/low voltage) is the primary component that dictates the charging strategy based on power system operating conditions. The objective of this model is to maximize the number of vehicle getting charged for a given length of time satisfying the network and vehicle battery constraints.

$$
\max \sum_{k=1}^{K} \sum_{l=1}^{L} V_{l k} * D_{l k} * C_{\max } * \Delta h
$$

Subjected to:

$$
\begin{gathered}
\sum_{k=1}^{K} V_{l k} * D_{l k} * C_{\max } \leq \alpha_{k} S_{t} \Phi \\
\sum_{k=1}^{K} V_{l k} * D_{l k} * C_{\max } * \Delta h+S O C_{l}^{A} * B_{l} \leq B_{l} \\
\forall k \in\{1,2,3 \ldots, K\}, \forall l \in\{1,2,3 \ldots, L\} \\
0.6 b_{l k} \leq V_{l k} \leq b_{l k} \\
b_{l k} \in[0,1], \forall k \in\{1,2,3 \ldots, K\}, \forall l \in\{1,2,3 \ldots, L\}
\end{gathered}
$$

The capacity of the distribution transformer is $S_{t}$ with power factor $\Phi$. The charging station is equipped with $\mathrm{L}$ charging slots with maximum charging power of each slot being $C_{\max }$. The slot charging power is supplied as a continuous variable to the optimization which can be zero or a value between minimum 
threshold and maximum charging power $C_{\max }$. The algorithm changes the state of battery for every $\Delta \mathrm{h}$ interval of time which is 15 minutes. As the vehicle arrives and connects to the slot, the battery management system provides the charging station with vehicle battery capacity $B_{l}$ and the arrival state of charge $\operatorname{SOC}_{l}^{A}$. The PHEV owner has to register number of parking hours t to take part in the coordinated charging scheme which decides the value of $\mathrm{K}$ - number of time intervals for coordinated charging $(\mathrm{t} / \Delta \mathrm{h})$. $D^{L \times K}-$ Slot matrix of charging station, where $D_{l k}=1$ if slot is parked else 0 if available.

$V^{L x K_{-}}$- charging power decision matrix, where $V_{l k} * C_{\max }$ is the charging power of lth slot at kth time period.

$\alpha_{k}$ - available transformer capacity $\left(1-\frac{R_{l}}{S_{t}}\right)$ where $\mathrm{R} \_1$ is residential household load. $\alpha_{k}=1$, if the charging station is supplied by its own distribution transformer.

$b_{l k}-$ is the binary variable to control the charging power,

where $b_{l k}=0$ indicates off state of charging slot.

The objective function maximizes charging to maximum number of PHEVs available at that time interval. Equation (9) is the transformer capacity constraint which avoids the transformer from overheating i.e. overloading. At all the instants, the total of base load and charging load of PHEVs must stay within the tolerated limit of transformer capacity. Constraint (10) is the battery updating constraint after every charging period and limits the charging power in the next time step without exceeding the battery capacity. Different charging strategies are designed using the constraint (11) in the following sections. MATLAB is used for programming and a CPLEX solver is called to solve the Mixed Integer Linear Programming (MILP) problem efficiently.

\subsection{LMP and OPF Model}

Locational marginal pricing is a market based pricing approach adopted by todays' deregulated electricity industry. Electricity prices in these markets are determined by the incremental cost to supply the next MW of load at a specific location subjected to generation and transmission constraints. Mathematically, LMP at a bus is the dual variable of the load balance equality constraint of that bus in an Optimal Power Flow (OPF) solution. This paper develops a distribution microgrid model similar to transmission system adopting the concept of LMP. Analogous to the transmission LPMs, the distribution marginal prices also constitutes energy cost, loss cost and congestion cost and as the electricity demand varies over time, the system conditions changes causing the LMPs to fluctuate. This section considers a 
lossless DCOPF model for the calculation of Distribution LMPs which is a good approximation for AC load flow model.

A Microgrid is viewed as a cluster of Distributed Energy Resources (DER), storage devices, a number of end-users and an energy management system to optimize its performance. The generation and demand are proportioned to small scale compared to the main or macro-grid and any small change in the ratings of the network will have a considerable effect on the network stability. LMP is one such parameter which involves players from both demand and supply side and the study on impact of PHEVs on marginal prices is worth mentioning as the penetration of PHEVs into distribution system is treated as additional demand on the system which is expected to grow rapidly.

The traditional lossless DCOPF model of optimization for minimum total generation cost subjected to power system constraints is used to calculate the LMPs. For an $N$ bus test system connected with $L$ lines, consisting of $G_{n}$ generation units, the DCOPF objective function and constraints are defines as,

$$
\begin{array}{ll}
\min _{P, C, f} & \sum_{n \in S} \sum_{m \in G_{n}} C_{n, i, t} P_{n, i, t} \\
\text { s.t. } & \sum_{i \in G_{n}} P_{n, i, t}-f_{n, t}=d_{n, t}+D_{n, t}, \quad \forall n \in N \\
& \left|\sum_{n \in N} K_{l, n} f_{n, t}\right| \leq T_{l}, \quad \forall l \in L \\
& \sum_{n \in N} f_{n, t}=0 \\
& 0 \leq P_{n, i, t} \leq P_{\max _{n, i, t}}, \forall n \in N, i \in G_{n}
\end{array}
$$

Where, $S$ is set of supply nodes, $C_{n, i, t}$ is the bid price of generator $(n, i)$ in hour $t(\$ / \mathrm{MWh})$. The decision variables are $P_{n, i, t}$ - the generation dispatch of generator $(n, i)$ in hour $t ; f_{n, t}$ - net injection (generation less consumption) at node $n$. Base load at node $n$ in hour $t$ is given by $d_{n, t}, \forall \mathrm{n} \in \mathrm{D}$ (set of demand nodes) and the additional load due to PHEV charging is given by $D_{n, t} . K_{l, n^{-}}$is the Power Transfer Distribution Factor (PTDF) matrix and $T_{l}$ is the thermal limit of transmission line $l$. The dual variable of equality 
constraint (13) gives the LMP at all the n nodes of the system. The transmission capacity constraint is given by (14) subjecting the power flows in either directions to stay within the limit, equation (15) is the balancing constraint (total generation equals to total demand) and (16) is the generation capacity constraint for all the generators.

\subsection{PRT Routing Algorithm}

In order to test the feasibility of converting guideway power rail propelling vehicles to BEVs, a detailed evaluation of economical, environmental and technological benefits is indispensable. One aspect of feasibility study is response of power system (such as voltage and loss analysis) to the charging load of the BEVs. To assess the charging load, the energy consumption of BEVs needs to be computed based on commutation participation by individual vehicle which obliges demographic data using the transit service. Other parameters include physical data of the system such as number of stations, their location, commuting distance and time between pair of stations and occupancy rate of vehicle during different hours of operation for different station pairs. The passenger demand is obtained from the WVU DOT and the distance, time information is shown in Figure. 3.2. A generalized optimizing routing algorithm is developed and can be used as a scheduled mode of operation to dispatch the vehicles based on the historical passenger demand data. This algorithm also helps in tracking the vehicular travel, charging and ideal times for the purpose of analysis which is taken care by the control center in real time.

$$
\begin{aligned}
& \min \sum_{t=1}^{T} \sum_{\substack{a=1 \\
b>1 \\
b>a}}^{N} \sum_{a, b, t}^{N}\left(X_{a, b, t}\right) \\
& a, b \in[1,2, \ldots, N], t \in[1,2, \ldots, T]
\end{aligned}
$$

Subjected to:

$$
\begin{gathered}
\sum_{t=1}^{T} \sum_{\substack{a=1 \\
b>a}}^{N} \sum_{b=1}^{N}\left(X_{a, b, t}+Y_{a, b, t}\right)<\left(V_{a}-V_{c, t}\right) \\
\frac{X_{a, b, t} * 60 * \beta_{a, b, t}}{\tau_{a, b}}>2 * \min \left(D_{a}, D_{b}\right)
\end{gathered}
$$




$$
\begin{gathered}
\forall a, b \in[1,2, \ldots, N] \\
\frac{Y_{a, b, t} * 60 * \beta_{a, b, t}}{2 * \tau_{a, b}}>\max \left(D_{a}, D_{b}\right)-\min \left(D_{a}, D_{b}\right) \\
\forall a, b \in[1,2, \ldots, N]
\end{gathered}
$$

$N$ - Number of stations, $N_{C_{2}}-$ Number of station pairs

$T$ - Number of hours of operation

$X_{a, b, t}-$ Number of BEVs commuting passengers from station $\mathrm{a}$ to $\mathrm{b}$ and $\mathrm{b}$ to $\mathrm{a}$ as well

$Y_{a, b, t}-$ Number of BEVs commuting passengers in only one direction i.e. from station having higher demand to station having lower demand

$V_{a}-$ Total number of BEVs available

$V_{c, t}-$ Number of BEVs charging at time $t$

$\left(V_{a}-V_{c, t}\right)$-Number of BEVs available for transit at time $t$

$\beta_{a, b, t}$ - Occupancy rate of vehicle between stations $a$ and $b$ for time $t$ (passengers per vehicle)

$\tau_{a, b}$-Trip time from station $a$ to $b$

$D_{a}, D_{b}-$ Passenger demand at stations $a$ and $b$ respectively

This thesis considers a set of 5 stations as mentioned earlier resulting in passengers commuting between possible $5_{C_{2}}$ i.e. 10 station pairs. The PRT starts service at 06:30 in the morning till 22:15 at night and 80 fully charged BEVs are available for service at start of the day. The objective of the optimization is to minimize the number of service vehicles required to meet the passenger demand for a particular time period. This minimization helps the control center by reducing the vehicle traffic on the limited guideway, reduce the charging load on the grid as well as rendering support to the grid by the 


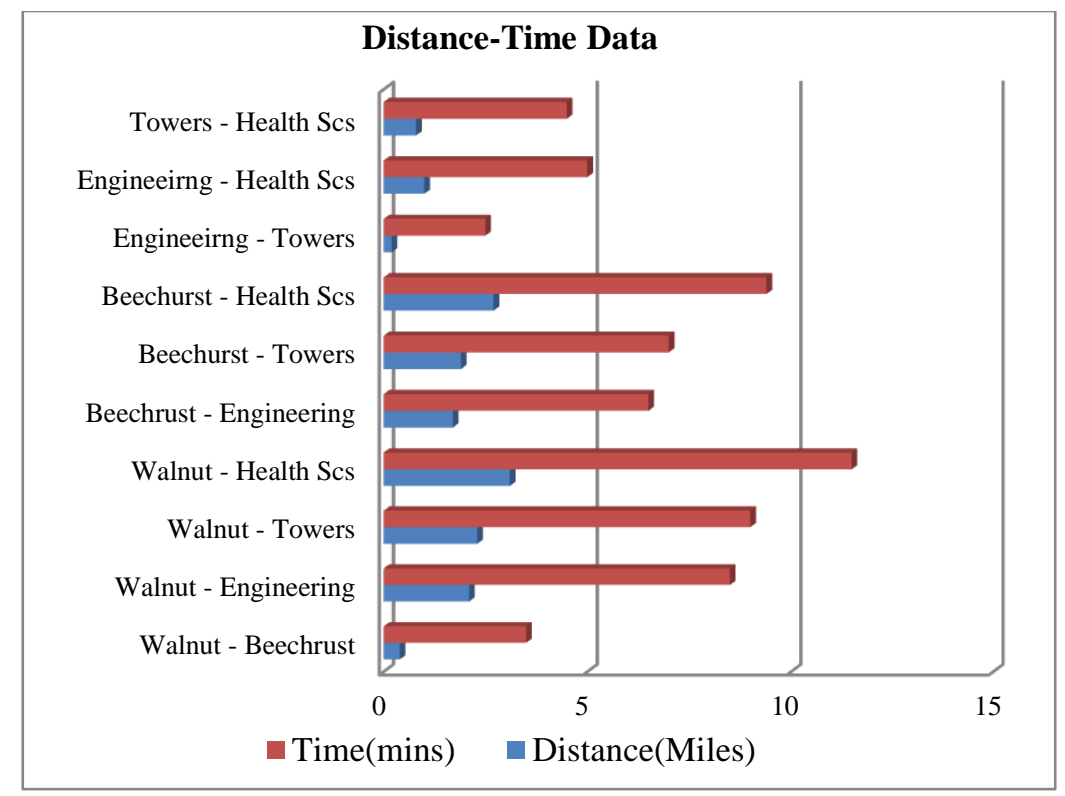

Figure 3-2Distance and Time between possible set of station pairs

BEVs in standby mode at the stations if planning for V2G technology. Constraint (18) imposes the limit on total number of BEVs available for service, deducting the charging vehicles. Number of charging vehicles depends on cumulative miles travelled by the BEVs in the previous time stamps and the present energy consumption for a vehicle operating between a station pair is calculated using the following formula -

$$
\begin{gathered}
E_{v}=\frac{P_{c}}{X_{a, b} \text { or } Y_{a, b} * \beta_{a, b}} * \mu_{a, b} * \varepsilon \\
\forall v \in[1,2, \ldots, 80]
\end{gathered}
$$

Where, $P_{c}$ - number of commuted passengers

$\mu_{a, b}-$ distance between stations in miles

$\varepsilon-$ energy consumption per mile $\mathrm{kWh} / \mathrm{mi}$

Constraints (19) and (20) limit the number of trips commuted per hour by a set of $X_{a, b}$ and $Y_{a, b}$ vehicles. On finding the number of vehicles in service using the optimization and present battery status of each vehicle using equation (21), the travel time, ideal time and charging time of each vehicle can be estimated. This formulation deals with passengers data accumulated for a single hour and does not give 
the minute wise schedule of the vehicles, hence the collision avoidance constraint due to limited guideways is not discussed. The optimization results and the effect of charging load of BEVs on electrical distribution system are discussed in detail in results section. 


\section{Chapter 4: SIMULATION TOOLS AND SOFTWARE}

This chapter briefly describes various software packages used in this thesis for modeling the electric distribution system, to study the effects of the PHEV charging models developed and formulating the DCOFP and PRT routing algorithm.

Numerous tools are available commercially as well as open source for modeling utility distribution systems. Few software tools that are proficient of solving 3-phase unbalanced distribution power flow are Cymdist, Milsoft Windmil and OpenDSS. Each of these tools has their own benefits and limits. After careful investigation and reasonable studies, OpenDSS was chosen for distribution power flow in this thesis. The mathematical models developed for coordinated charging have to be integrated with the distribution power flow in OpenDSS after programming in MATLAB.

The proposed PRT routing optimization has been formulated as a Mixed Integer Linear Programming (MILP) problem. Efficient MILP problem solving engines are available and few of them are IBM ILOG CPLEX Optimizer, General Algebraic Modeling System (GAMS), LINDO etc. Out of these available solvers, CPLEX was used to solve the proposed optimizations. The coordinated charging strategy logic and PRT scheduling algorithm are programmed in MATLAB while calling the CPLEX function to solve the MILP problem. Matlab is convenient to use for multi-time period optimization and can easily interface with other software tools. The tools used in this research work are described with their abilities and their detailed importance in the following sections.

\subsection{Open Distribution System Simulator (OpenDSS)}

OpenDSS (also called DSS) is a wide-ranging electrical power system tool for electric utility distribution systems developed by Electric Power Research Institute (EPRI) [49]. OpenDSS is an open source software for simulating electrical distribution systems and to perform various analyses namely power flow, harmonics and dynamics in frequency domain. OpenDSS facilitates a flexible research platform and scope for distribution planning and analysis, general multiphase AC circuit analysis, distributed generation interconnection analysis, annual load and generation profiles. Time series distribution analysis can be programmed in OpenDSS by which we can perform annual load simulations besides daily/yearly power flow solution modes. The DSS can also be interfaced and initiated from several other tools like Matlab through its command interface (COM interface). Also OpenDSS has developed test cases for all IEEE benchmark test feeders starting from IEEE 4 node to IEEE 8500 node test feeders. The harmonic flow solution is a fundamental feature of OpenDSS and it provides a good 
platform for analyzing Analysis of Unusual Transformer Configurations, Wind Plant Simulations, Neutral-to-earth Voltage Simulations. These know-hows of the tool have generated remarkable interest among utilities to perform various interconnection studies of their network in OpenDSS.

The configuration of OpenDSS is shown in figure 4-1 [50] shows a individual user interface. As seen from figure 4-1, the simulation engine can be initiated by three varied ways.

- $\quad$ OpenDSS scripts - The usual way to drive the simulation engine where the direct scripting codes are used to define the circuit and solve it.

- $\quad$ COM interface - OpenDSS can be driven externally from a MS Office tool through VBA, or from any other analysis programs that can handle COM.

- User Written DLL - Custom developed refined models can be merged in the simulation engine by writing suitable DLL and linking with the engine.

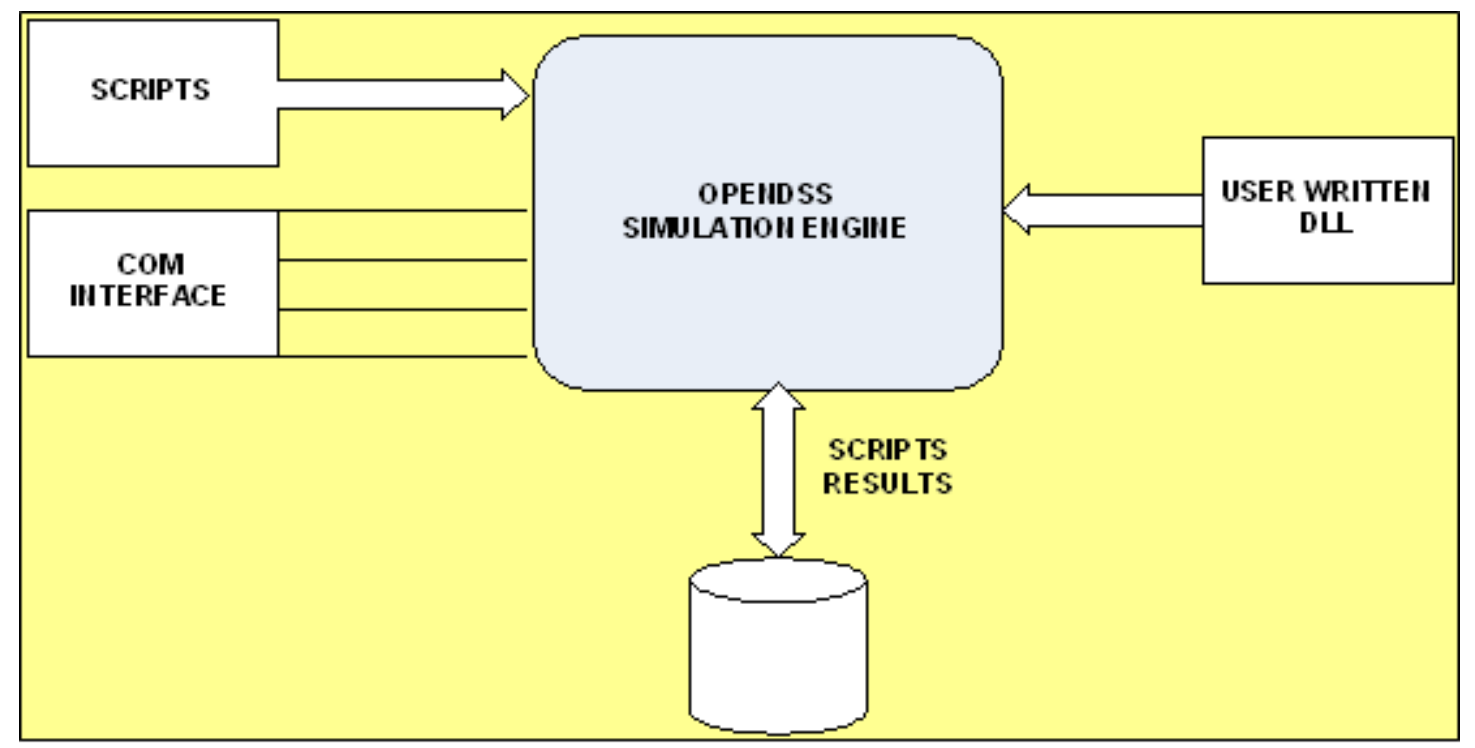

Figure 4-1 OpenDSS Configuration

Some of the special features of OpenDSS used in this work are listed below. 


\subsubsection{Extensive Range of Solution Modes}

A number of solution applications are available in OpenDSS. Some significant applications are shown in figure 4-2.

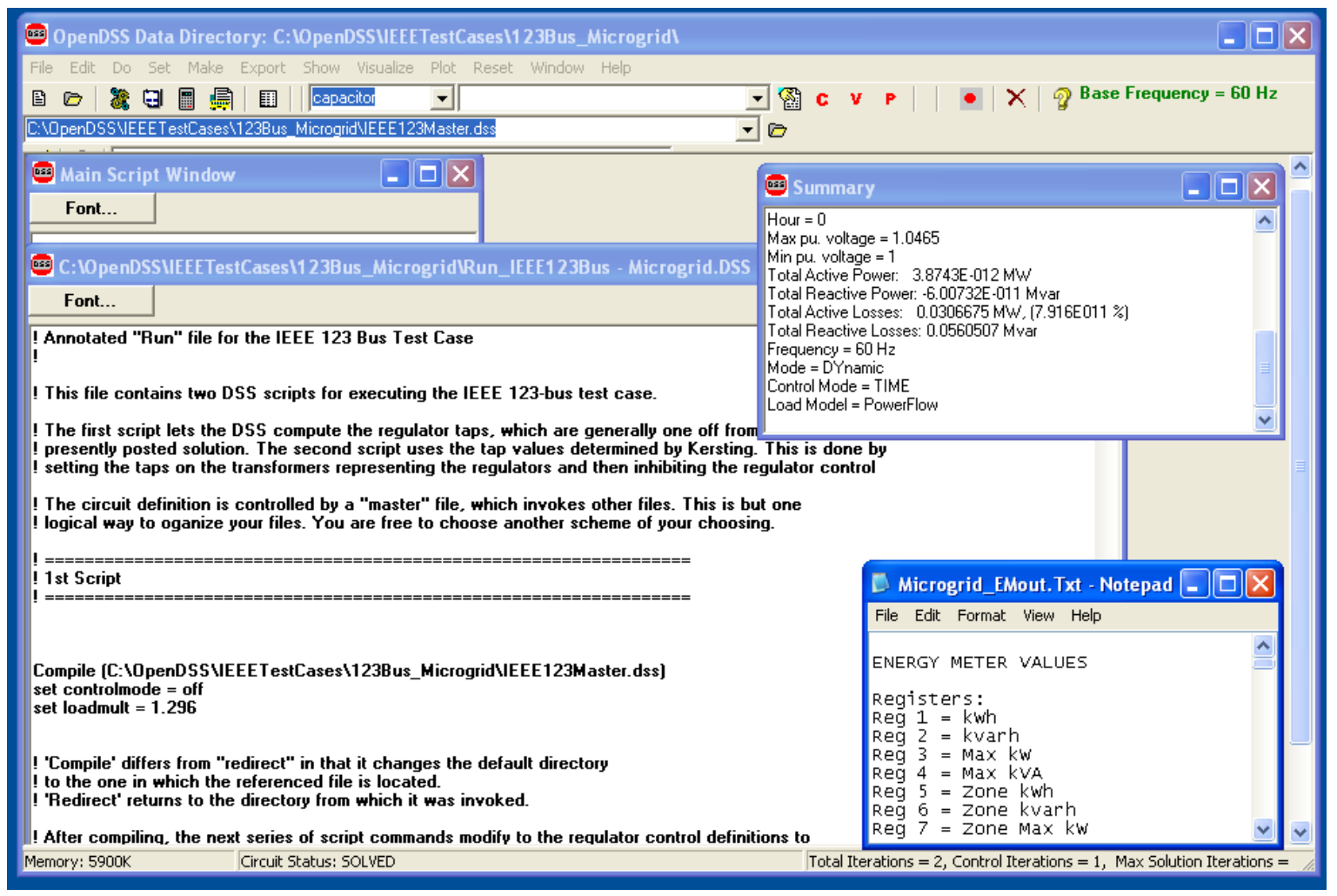

Figure 4-2 OpenDSS Standalone EXE User Interface

OpenDSS runs a basic power flow needed for a distribution system in which the substation is modeled as an infinite source of energy. It has the advantage of solving both the networked (meshed) systems and also radial systems. OpenDSS can employ either a multi-phase circuit model or a positive sequence depending on the user requirement. The snapshot power flow mode does a single power flow solution at the present load level and the daily power flow mode does 24 hour solution resulting load shape defined as "Daily". Similarly, a yearly power flow mode is also available for annual simulations. User specified load shape or a default load shape by the engine can be used for a daily power flow mode. Comma Separated Value (CSV) files can be used to supply multipliers for load shapes or can be directly scripted in the file in the form of load multipliers.

OpenDSS comprises one more solution mode called Dynamics which is capable for performing simple dynamics analysis for Distributed Generation (DG) interconnection. The "Dynamics" solution 
mode must be preceded by a successful power flow. The generators in the circuit are treated as voltage sources behind specified reactances when changed into dynamics mode.

The losses, voltages, currents and other data are available for the feeder system, each component or node and certain defined areas after the completion of the power flow. The energy meters provide the losses in terms of $\mathrm{kW}$ or kvar losses for each time instant for all the zones and loads, and this data can be used to integrate the power over a time interval. A three phase unbalanced distribution power flow for the AEP feeder is performed using OpenDSS in this thesis.

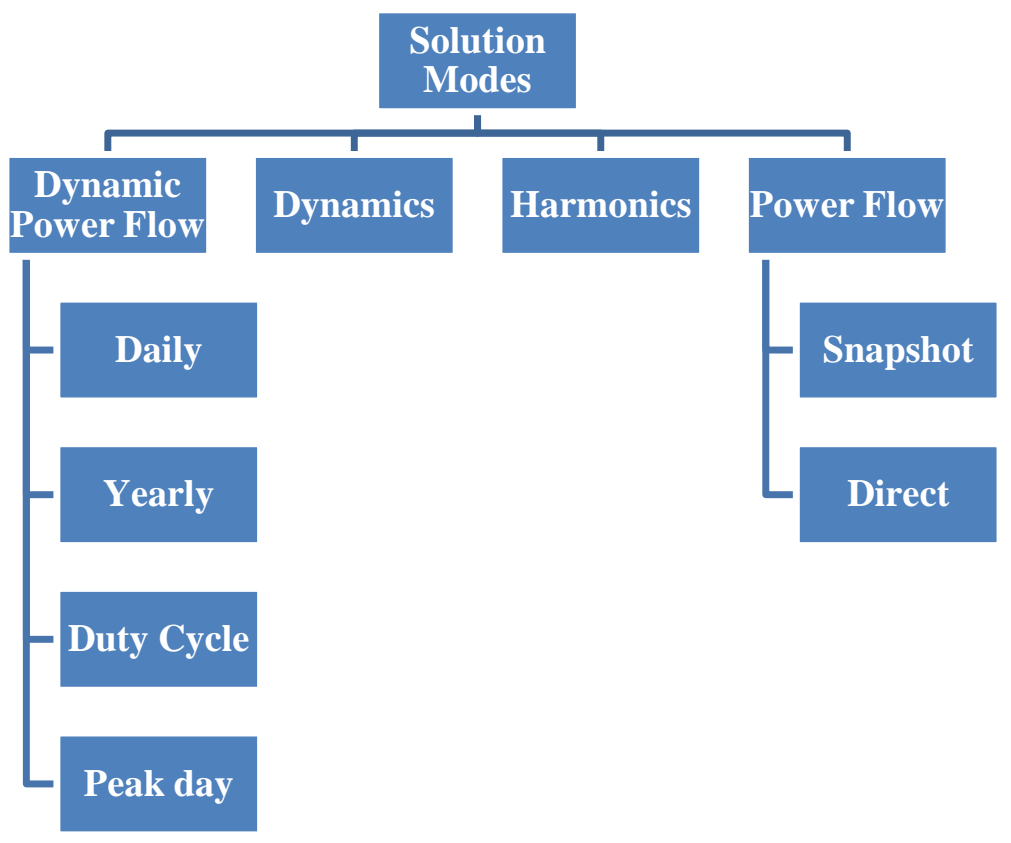

Figure 4-3 Solution Modes in OpenDSS

\subsubsection{COM Interface}

The COM interface of OpenDSS is a very useful feature to execute custom solution modes and features externally and perform the functions of the simulator, including definition of the model data. This feature allows DSS to be implemented entirely independently of any database or fixed text file circuit definition. For example, it can be driven entirely from a MS Office tool through VBA, or from any other 3rd party analysis program that can handle COM such as MATLAB, Python, C\# and other languages. The COM interface also provides direct access to the text-based command interface by which an access to all the models available in the simulator can be obtained. Through the command interface, user-written programs can generate scripts to do several desired functions in sequence. Most of the results of the simulation engine can also be accessed through the COM interface. 


\subsection{MATLAB}

MATLAB®, Matrix Laboratory, is a high-level language and numerical computing environment for logic development, data visualization and analysis, and numeric computation. Some of the important features of MATLAB are listed below [51].

- Communicating environment for iterative programming, design and problem solving

- $\quad$ High level language for technical computing

- Integrated graphics for imagining data and tools for making custom plots

- $\quad$ Can be integrated with external applications such as C, C++, FORTRAN, Java, and Microsoft Excel

- Tools for developing applications with custom graphical interfaces

In this thesis, numerous MATLAB functions were used to efficiently program the coordinated charging and PRT routing algorithms and to generate meaningful plots of voltage and loss analysis results of OpenDSS.

\subsubsection{MATLAB Optimization Toolbox}

The optimization toolbox of MATLAB consists of solvers for linear programming, mixed-integer linear programming, quadratic programming, nonlinear optimization, and nonlinear least squares. One can use these solvers to find optimal solutions to continuous and discrete problems and incorporate optimization methods into algorithms and applications. MATLAB also have additional features of Parallel Computing and Derivatives, Multi-objective Optimization

In this work, the linear programming application with simplex algorithm was used to solve the LP optimization problem that has been formulated for DCOPF to find the LMPs.

\subsection{IBM ILOG CPLEX Optimizer}

CPLEX optimizer is a high-performance mathematical programming solver for linear programming, mixed integer programming, and quadratic programming [52]. It solves linear and quadratic constrained optimization problems where the objective function can be expressed in a linear or a convex quadratic form. CPLEX Optimization Studio provides the fastest way to build efficient optimization models and state-of-the-art applications. A prominent feature of CPLEX is that it can be 
easily initiated from the command prompt. CPLEX models can be easily integrated into any application written in Java, .NET or C++.

CPLEX for MATLAB is an application of IBM ILOG CPLEX Optimizers which allows the user to define optimization problem in MATLAB and call the CPLEX function to solve the optimization. For instance, "cplexmilp" is the function called in MATLAB to solve Mixed Integer Linear Programming (MILP) problem in this thesis. It must be integrated into MATLAB environment to successfully avail its advantages. The setting up of path for integrating CPLEX with MATLAB is as shown in Figure. 4.4.

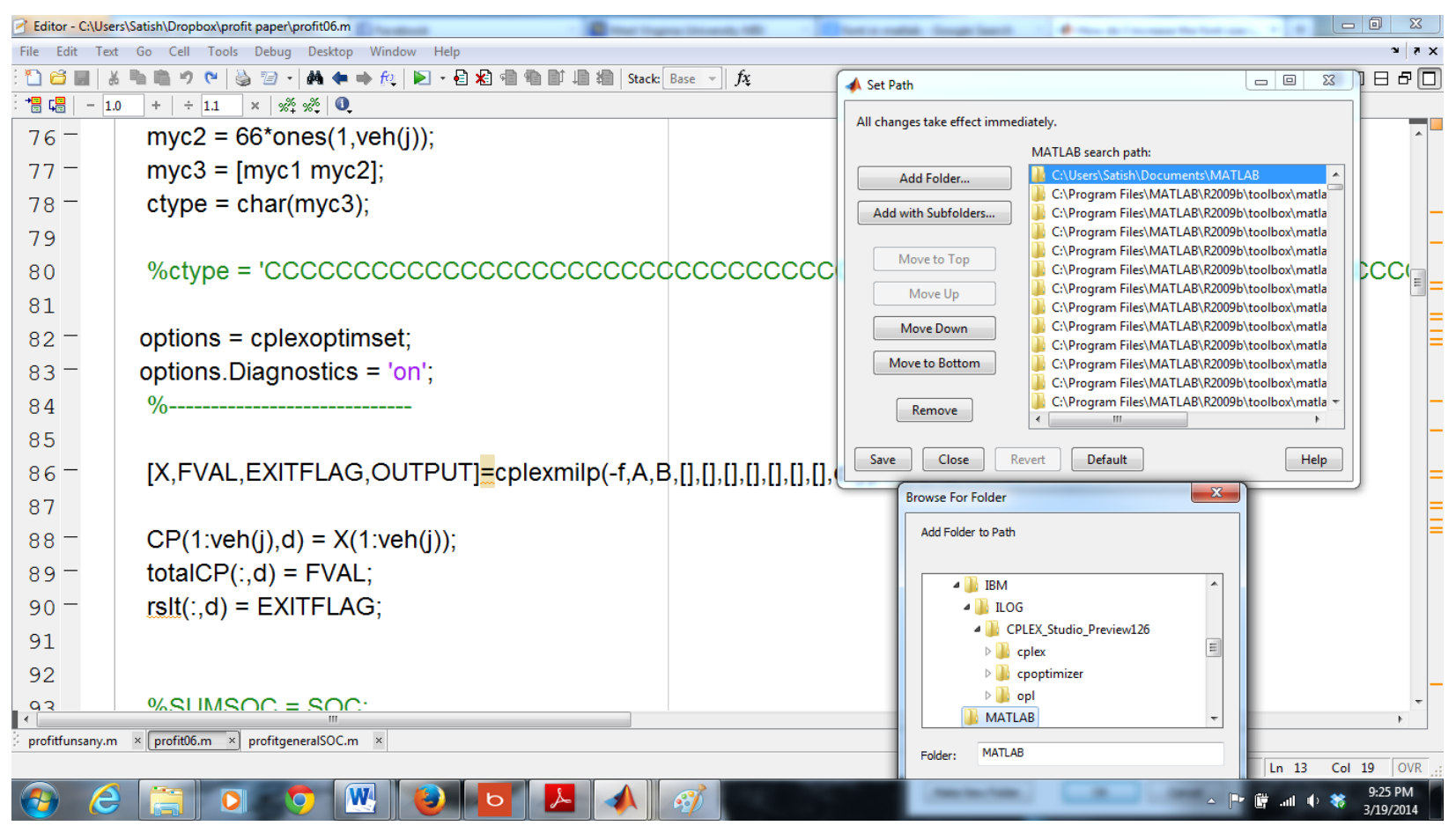

Figure 4-4 Path setting for CPLEX for MATLAB 


\section{Chapter 5: $\quad$ SIMULATION AND RESULTS}

This chapter discusses all the results of this research by introducing the test systems one by one used for the analysis and then the simulating the algorithms on these test systems. Also, the behaviors of the test system are studied through voltage and loss analysis results. Interpretations are drawn from these resultant plots to back the proposed ideas and goals of this thesis work.

\subsection{Distribution Power Flow Results for Feeder 2 of AEP System}

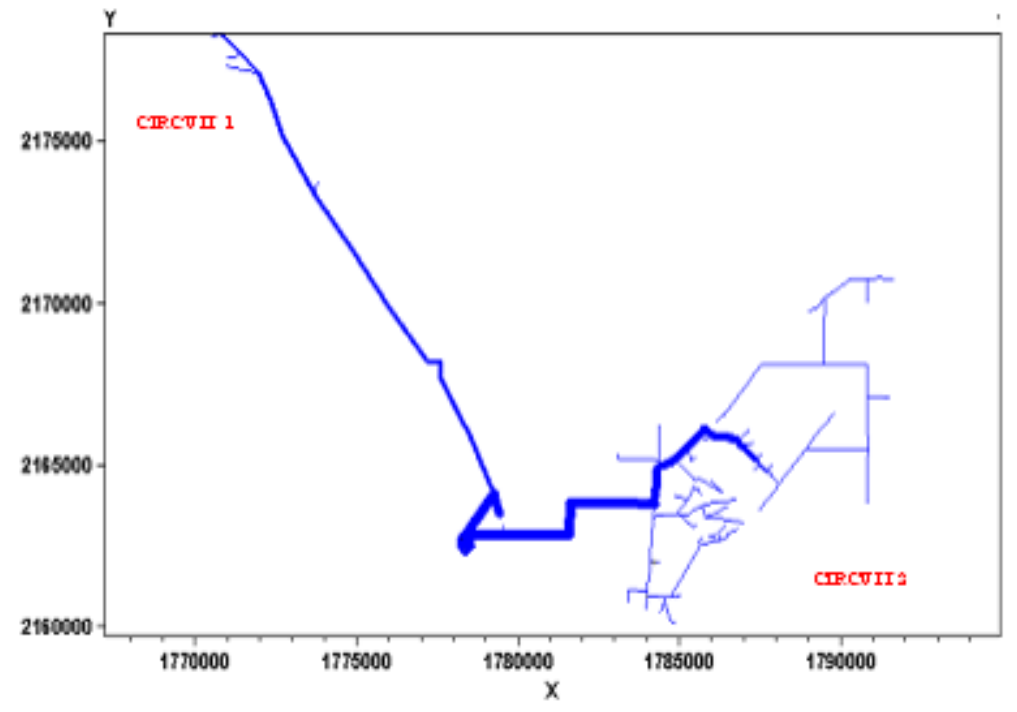

Figure 5-1 OpenDSS power flow plot for Feeder 2
Table 5-1: Summary of Power flow for Feeder 2

\begin{tabular}{|l|l|}
\hline Status & SOLVED \\
\hline Solution Mode & Direct \\
\hline Load multiplier & 1.00 \\
\hline Devices & 560 \\
\hline Buses & 266 \\
\hline Nodes & 566 \\
\hline Max p.u. voltage & 1.03 V p.u. \\
\hline Min p.u. voltage & 1.0033 V p.u. \\
\hline Total Active power & 12.994 MW \\
\hline Total reactive power & 2.07443 MVAR \\
\hline Total Active losses & 0.1249 MW (0.9618 \%) \\
\hline Total Reactive losses & 0.0323407 MVAR \\
\hline Frequency & $60 \mathrm{~Hz}$ \\
\hline
\end{tabular}


The Feeder 2 of AEP system is modeled in OpenDSS and a distribution power flow was run on it and Figure 5-1 shows a one line diagram of feeder 2 resulted from OpenDSS. The distribution power flow results for feeder 2 are listed in Table 5-1. Feeder 2 is a radial configuration and supplied by a $12.47 \mathrm{KV}$ medium voltage substation modeled as an infinite source. The distribution system comprises two main circuits with laterals and distributed loads. A single 3-phase voltage regulator is employed in this feeder at the substation. The system base is 100 MVA and $12.47 \mathrm{KV}$. PQ type loads are considered to model the loads buses of the system. Seven different locations are considered along the feeder to place the Switched capacitor banks. The loads of the system represent a mixture of residential and industrial loads and the total load on the system is 13.15 MVA (12.994 MW and 2.074 MVAR) and the active power losses represent $0.96 \%$ of the total system load. The node voltages of feeder 2 are in the range of 1.003 V. p.u. and 1.03 V.p.u.

\subsection{PHEV Integration Study on Utility Distribution Feeder}

The developed utility feeder 2 model is chosen for the PHEV integration study. Figure 5-2 shows the AEP feeder with the PHEV charging stations and meter locations. Based on the data (number of consumers and the distribution transformer ratings connected to these loads) provided by the utility, the locations for placing the PHEV loads are identified and can be seen as green triangles in the feeder diagram. The red dots in Figure 5-2 indicate the meters to analyze the system behavior (currents, voltages and losses) during implementation of different charging strategies. The radial test feeder is supplied by a $12.47 \mathrm{KV}$ medium voltage substation modeled as an infinite source. Time series distribution power flow is run for five different scenarios as follows.

- $\quad$ Scenario 1 - Without PHEVs: This is the base case distribution power flow with 24- hour load shape considered for loads given by the utility.

- $\quad$ Scenario 2 - Uncoordinated Charging of PHEVs: In this case, the vehicles do not follow any strategy to charge their batteries.

- $\quad$ Scenario 3 - Coordinated Charging of PHEVs with Maximum battery constraint: In this case, the vehicles enroll in a charging strategy where the constraint (16) settles to the maximum battery capacity.

- $\quad$ Scenario 4 - Coordinated Charging of PHEVs with Minimum battery constraint: In this case, the vehicles enroll in a charging strategy where the constraint (16) settles to the minimum battery capacity. 
- $\quad$ Scenario 5 - Coordinated Charging with Demand Response: In this case, the vehicles take part in a charging strategy involving DR programs. This strategy is discussed in detail in the following section.

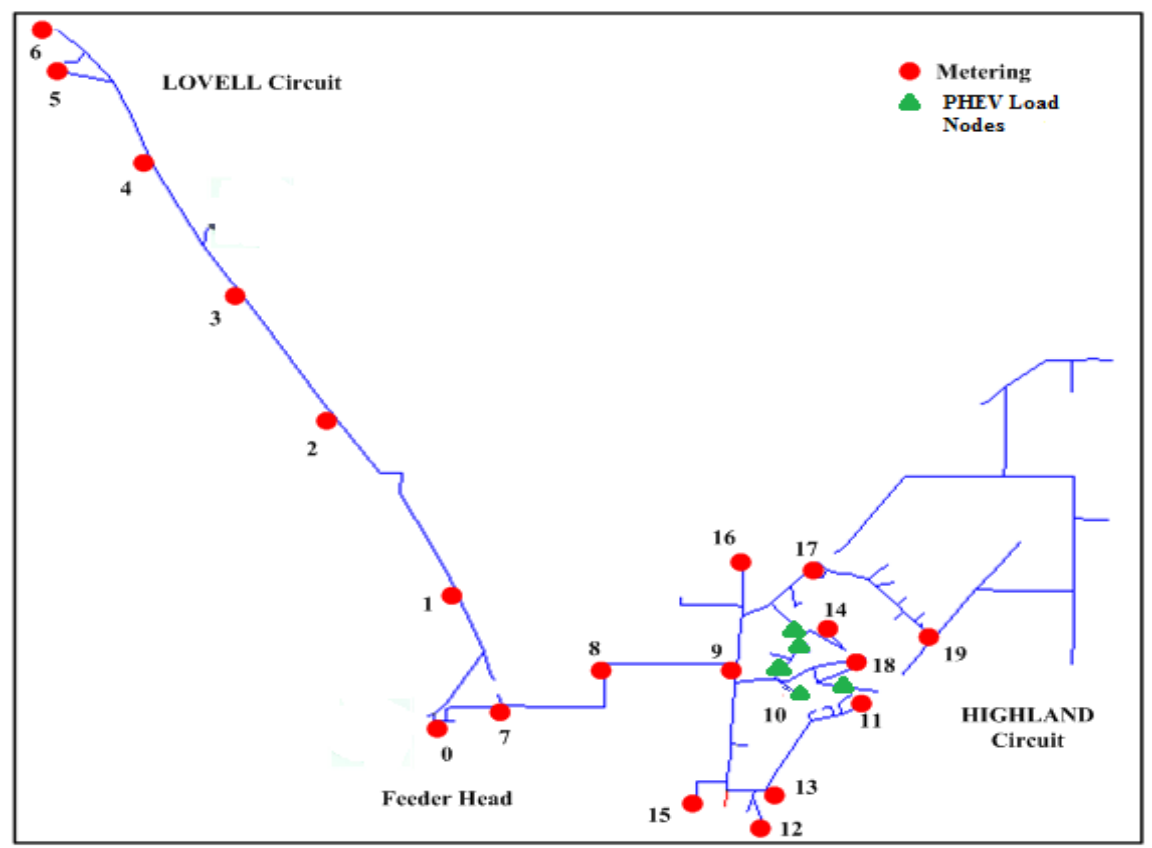

Figure 5-2 AEP Feeder model with PHEV Charging Stations and meter locations

\subsubsection{Specifications of PHEV Charging Station}

Each PHEV has a maximum storage capacity of $22 \mathrm{kWh}$ of which only $90 \%$ (i.e. $20 \mathrm{kWh}$ approx.) is allowed to deteriorate during charge depletion mode to maintain optimal battery life. The vehicle can travel a distance of 45 miles with this battery before entering the charge sustaining mode. The charging station is assumed to equip with 100 charging slots keeping in view the popularity of the PHEVs. Here even though 100 slots are available, the energizing of slots is a controlled action from the control center based on the coordinated charging algorithm implies not all the connected vehicles get charged but depends on the charging power decision matrix $V^{L x K}$. The slot has a maximum power output of $3 \mathrm{~kW}$ $(0.75 \mathrm{~kW}$ per 15 minutes interval) from a standard $230 \mathrm{~V}$ AC outlet which is considered as Level 2 charging.

\subsubsection{Uncoordinated Charging and Monte Carlo Simulation}

To highlight the significance of proposed coordinated charging techniques, the system performance is analyzed with uncoordinated charging at first. In uncoordinated charging scenario, the PHEVs are 
charged by connecting to the slots the very instant they arrive the CS and the slots were not controlled by the control center.

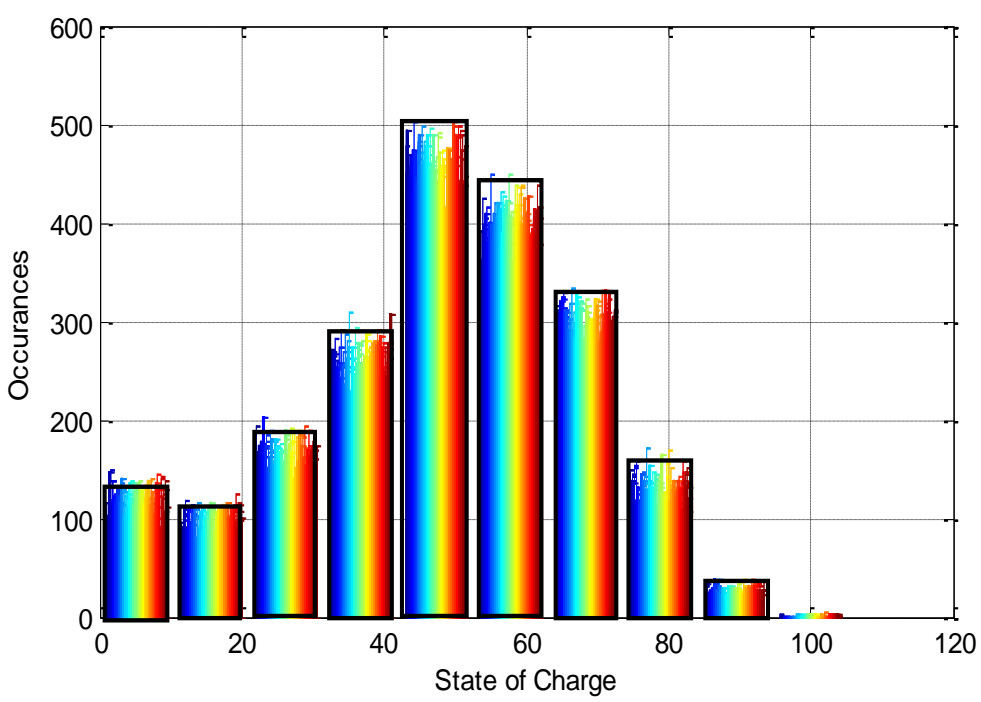

Figure 5-3 MCS plot of State-of-Charge

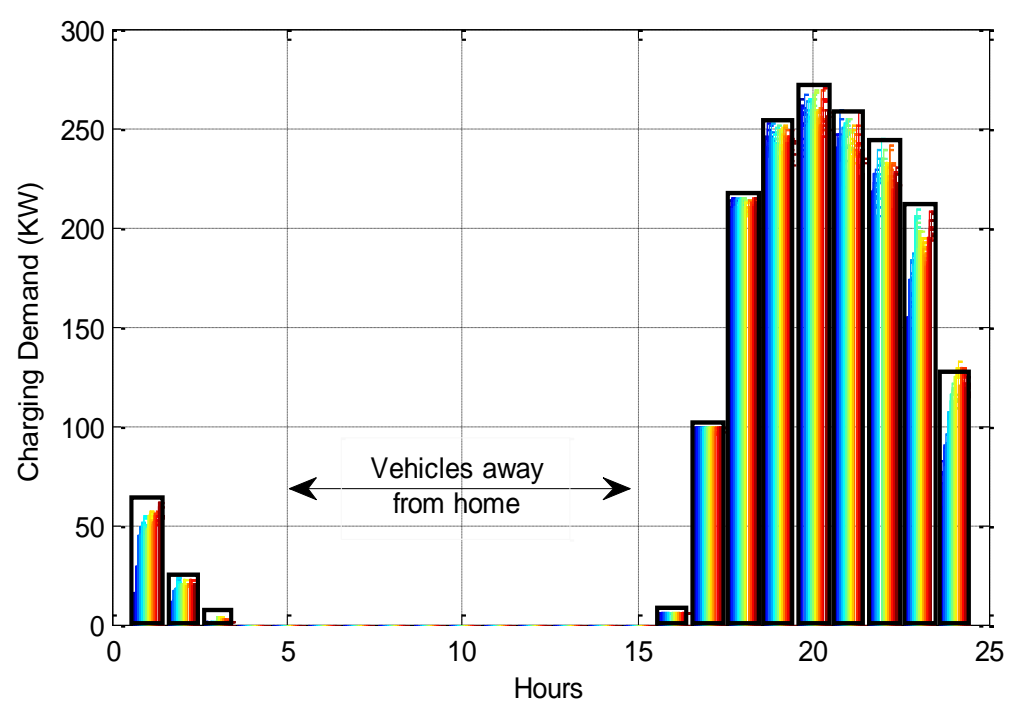

Figure 5-4 MCS plot of Hourly Charging Demand 


\begin{tabular}{|c|c|c|c|c|}
\hline & $\begin{array}{c}\text { Transformer } \\
\text { Rating (KVA) }\end{array}$ & Base Load (KVA) & $\begin{array}{c}30 \% \text { PHEVs } \\
\text { (Stochastic } \\
\text { Loading -kWh) }\end{array}$ & $\begin{array}{c}\text { 50\% PHEVs } \\
\text { (Stochastic } \\
\text { Loading -kWh) }\end{array}$ \\
\hline CS 1 & 150 & 81.469 & $31(328)$ & $52(575)$ \\
\hline CS 2 & 180 & 124.037 & $30(320)$ & $50(591)$ \\
\hline CS 3 & 140 & 66.124 & $12(110)$ & $20(226)$ \\
\hline CS 4 & 75 & 45.827 & $13(130)$ & $22(248)$ \\
\hline CS 5 & 200 & 61.102 & $56(570)$ & $94(1047)$ \\
\hline
\end{tabular}

Table 5-2. PHEV Penetration and Loading in the Test Feeder

\subsubsection{Coordinated Charging of PHEVs}

The coordinated charging is achieved by giving the Monte-Carlo simulation results as inputs to the optimization problem discussed. This setup is run in MATLAB for required number of time intervals (depending on individual vehicle departure times) and the average computational time is 20 seconds when run on a $2.2 \mathrm{GHz}$ Intel Core 2 Duo CPU with $4.00 \mathrm{~GB}$ of RAM computer. The uncoordinated and coordinated charging loads by the charging stations for 50\% PHEV penetration specified in Table 5-2 are evaluated using MATLAB and are given as hourly load multipliers for the OpenDSS and a 24-hour distribution power flow is run to analyze the voltage response of the feeder. It is noticed that uncoordinated charging causes the voltage at bus near to PHEV loads to reduce far below the lower limit of 0.95 per unit as shown in Figure 5.5. Optimizing the PHEV charging loads with transformer constraint, could potentially bring back the system voltage close to the limit. From hours 23:00 - 04:00 the voltage profile of uncoordinated charging is better compared to coordinated (but well within the limits) as the load curtailed during the peak hours is distributed to the later hours. Figure 5.6 gives the transformer loading profile for scenarios $1-4$ for CS 5. From equation (2), 90\% of the vehicles reach home by 19:00, and starts charging instantaneously causing a peak and overloading the transformer for next 3 to 4 hours. The optimization avoids the overloading of the transformer, charges maximum number of vehicles possible and maintains system stability. 


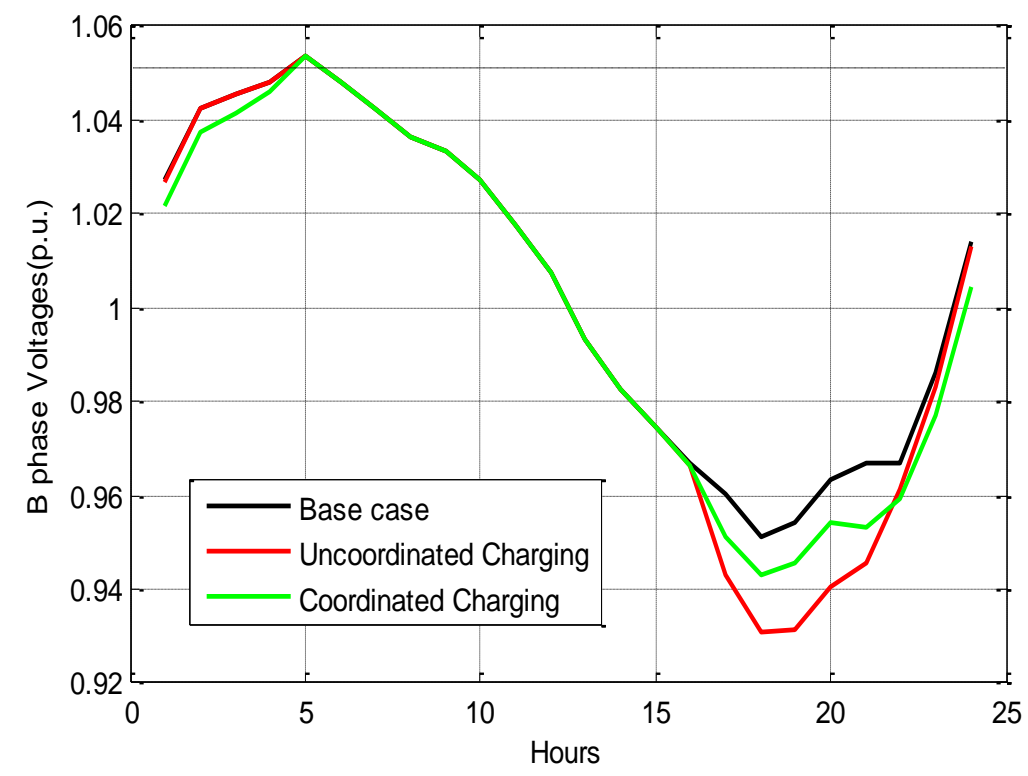

Figure 5-5 Voltage profile for 24-hours of Feeder 2

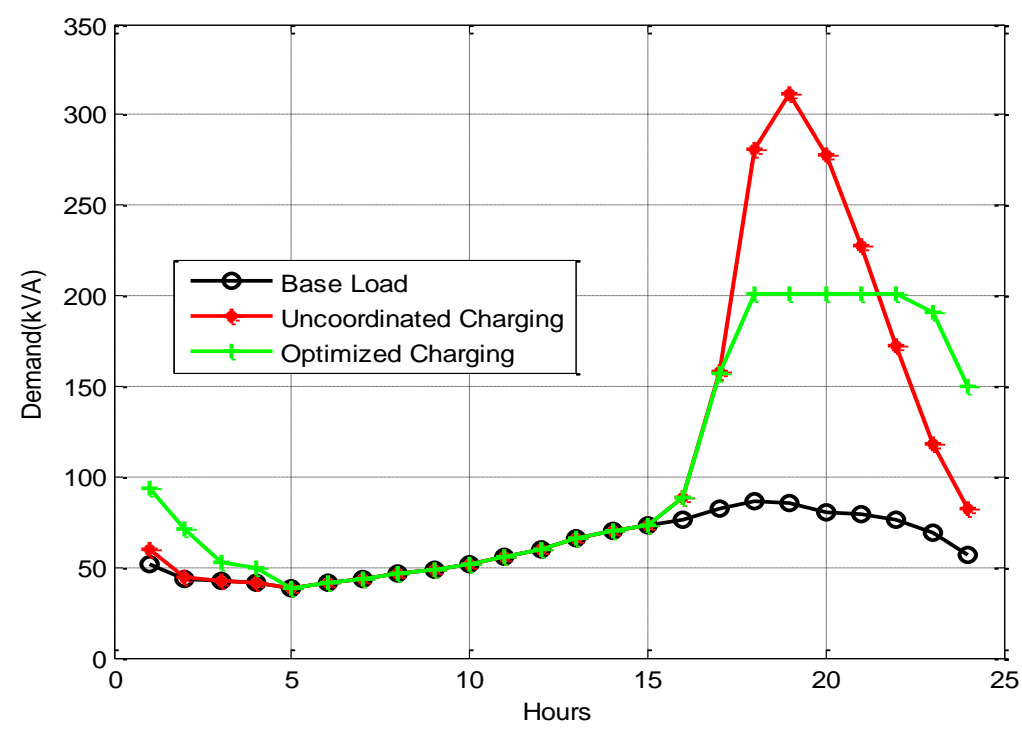

Figure 5-6 Transformer loading for different charging methods

\subsubsection{Voltage Profile of the Feeders}

A 24 hour time series power flow is executed in OpenDSS with varying PHEV charging methods. Figures 5-7 to 5-9 shows a comparison of the voltage profiles for different PHEV charging cases. The xaxis of Fig. 5-7 to 5-9 represents the nodes from source to end of Lovell and Highland circuits, the y-axis of Fig. 5-7 to 5-9 represent the hours of the day, and the z-axis of Fig. 5-7 to 5-9 represents the B-phase 
voltages in p.u. Figure 5-7 shows the base case solution with no PHEV load present on the system, indicating a wide range of voltages throughout the day owing to normal load variations. The surface plot of Figure 5-7 indicates that there is no lower voltage deviation from limits of 0.95 p.u for base case solution.

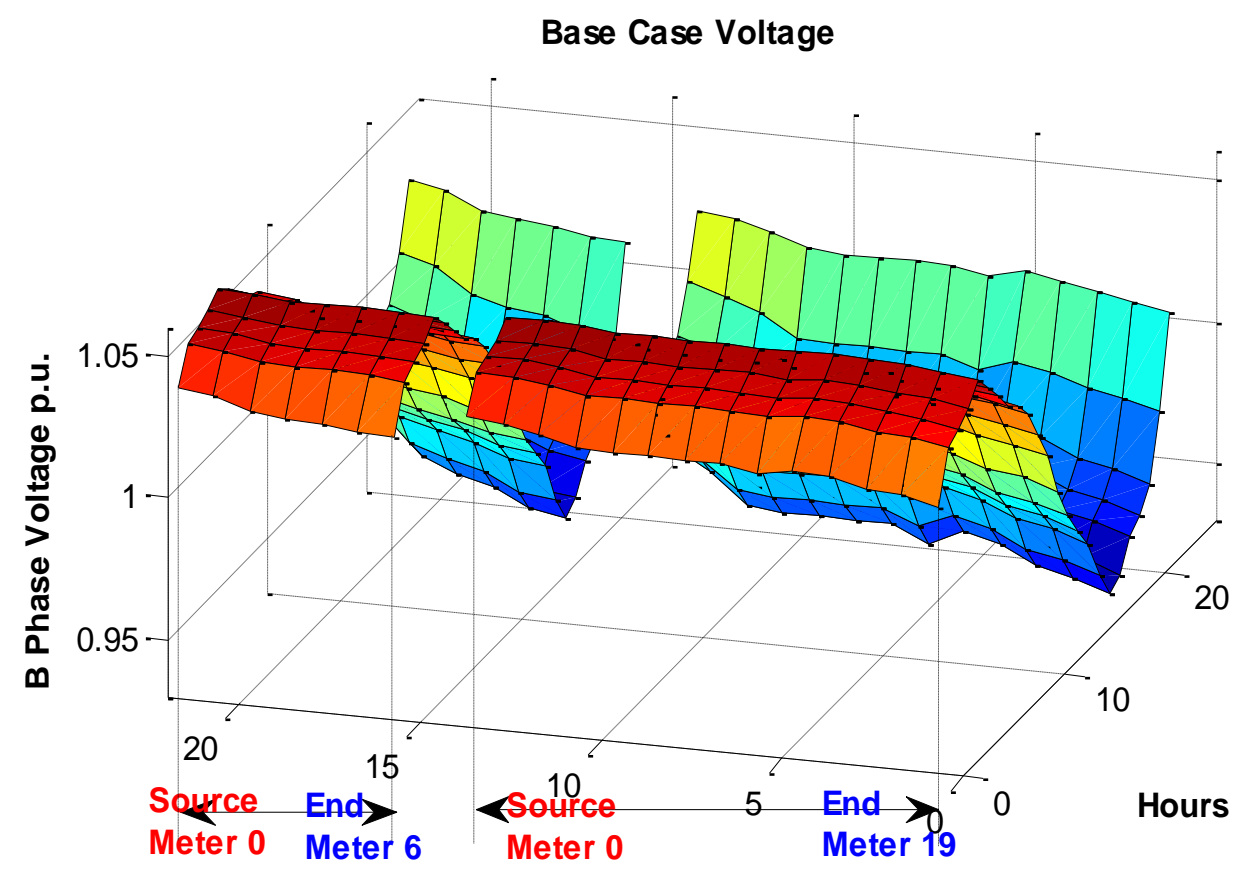

Figure 5-7 Feeder 2 Voltage Profile - Base Case

The voltage of the test feeder for uncoordinated charging is shown in Figure 5-8. Plot indicates a significant voltage drop in the Highland circuit (where the loads are purely residential) during the peak hours as the PHEV owners connect the vehicles as soon as they arrive home. This voltage instability motivates the distribution system operators to design efficient charging methods to satisfy the customers as well as maintain the voltage of the system well within limits. 


\section{Uncontrolled Charging Voltage Profile}

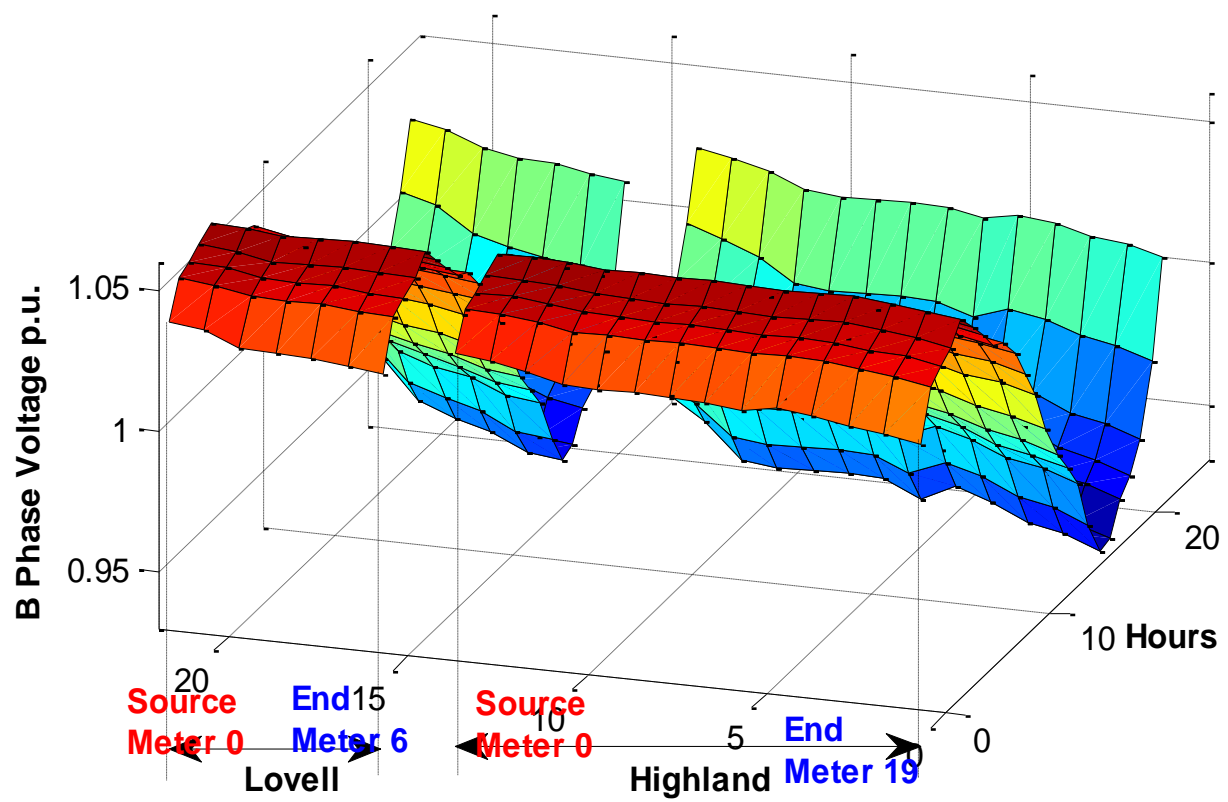

Figure 5-8 Feeder 2 Voltage Profile - Uncoordinated Charging

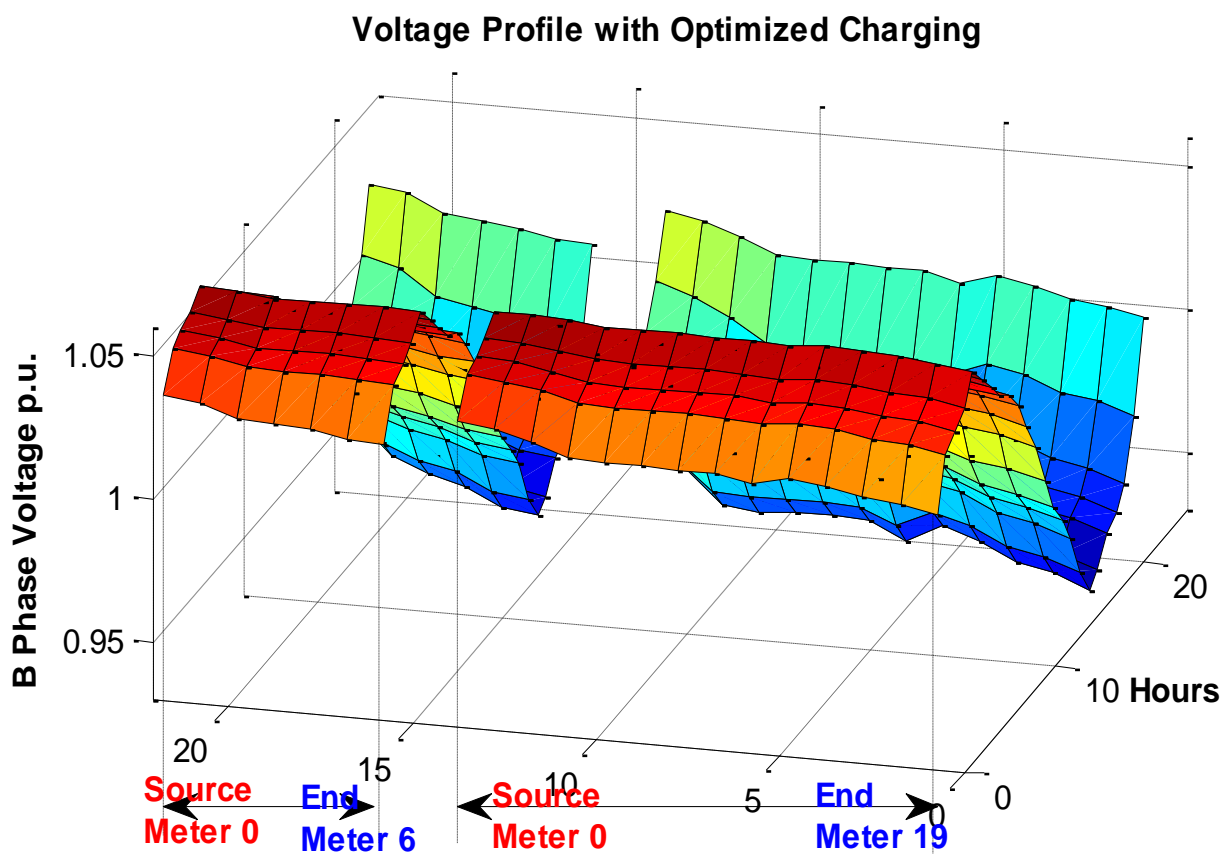

Figure 5-9 Feeder 2 Voltage Profile - Coordinated Charging

Figure 5-9 shows improvement in the voltage profile of the test feeder when a coordinated charging method is implemented on the PHEVs connected to the local utility. Smart charging methods not only help in energy management but also assist in maintaining system voltages well within limits. 


\subsubsection{Load Profiles of Distribution Transformers}

This section deals with study on extent of transformers capability to support the coordinated charging algorithm. Two transformers are considered with different capacities and number of customers supplied by the corresponding transformers. Table 5-3 gives the transformer information.

Table 5-3: Transformer Loading Analysis

\begin{tabular}{|c|c|c|c|c|}
\hline Load Name & Bus Name & $\begin{array}{c}\text { Transformer } \\
\text { Rating }\end{array}$ & $\begin{array}{c}\text { Load } \\
\text { Rating }\end{array}$ & $\begin{array}{c}\text { Number of } \\
\text { PHEVs }\end{array}$ \\
\hline 216_7231506-1 & fict26_HIGHLAND.3 & 200 & 61.102 & 94 \\
\hline 359_7231506-1 & fict20_HIGHLAND.3 & 140 & 66.194 & 20 \\
\hline
\end{tabular}

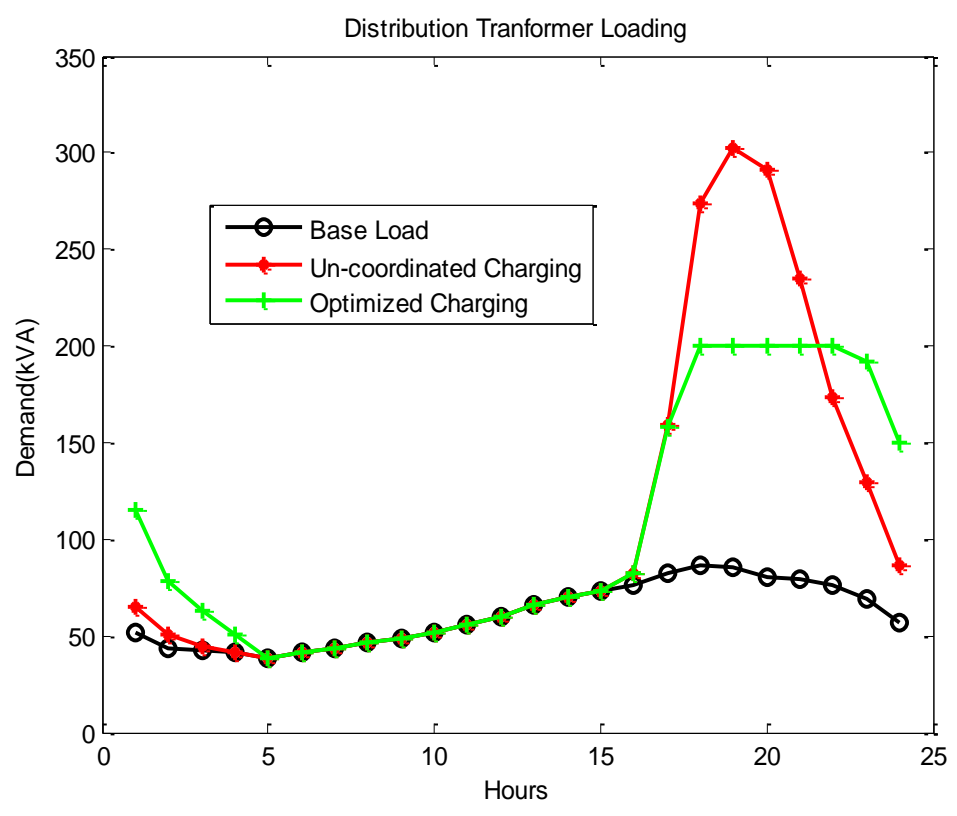

(a)

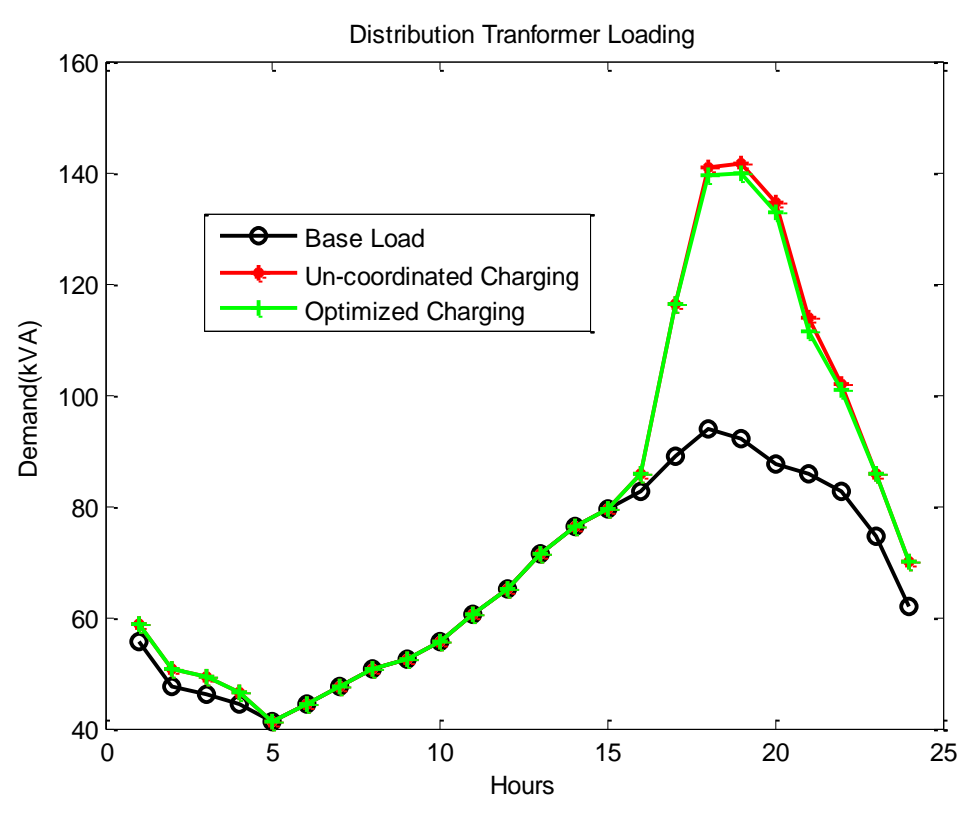

(b)

Figure 5-10 Distribution Transformer Loading Patterns

The loading patterns of considered transformers are shown in Figures 5-10 (a) and (b). Coordinated charging methods are implemented at charging stations (CS) supplied by the transformers with capacity less than required to support the PHEV customers connected to it. Figure 5-10 (a) clearly indicates this particular CS needs coordinated charging algorithm in order to protect the transformer from 
excess load due to PHEVs and thereby improving the life of transformer. The charging algorithm with a constraint on transformer capacity avoids peaks and extends the duration of PHEV charging to late hours of the night.

Transformers with sufficient capacity to support the customers charging needs need not participate in the charging algorithms. Figure 5-10 (b) shows the charging demand does not overload the transformer and the uncoordinated charging and coordinated charging curves coincide with each other. Such CS can also implement the coordinated charging methods by enforcing a less transformer capacity constraint which has the chance of delaying the charging needs of the customers.

\subsubsection{Comparison between Scenarios 3 and 4}

Scenario 4 (Coordinated Charging of PHEVs with Minimum battery constraint) is a strategy aimed at charging maximum number of PHEVs rather than charging limited number of PHEVs with maximum possible charging rate. The drawback of scenario 3 is that, the few vehicles arriving early to the CS or vehicles which are fed first to the optimization algorithm gets charged faster whereas the late arriving vehicles take much time to completely charge than average. This drawback can be overcome to some extent using scenario 4. The transformer load shape for these scenarios is expressed as a single coordinated charging curve because the energy consumption remains the same with the number of vehicles getting charged varies. It is also noticed that vehicles charging with scenario 4 are not left far behind in terms of SOC as shown in Figure 5-11. Three vehicles are chosen randomly and time taken to reach $70 \%$ SOC is computed which shows scenario 4 is also an ideal strategy to charge the PHEVs.

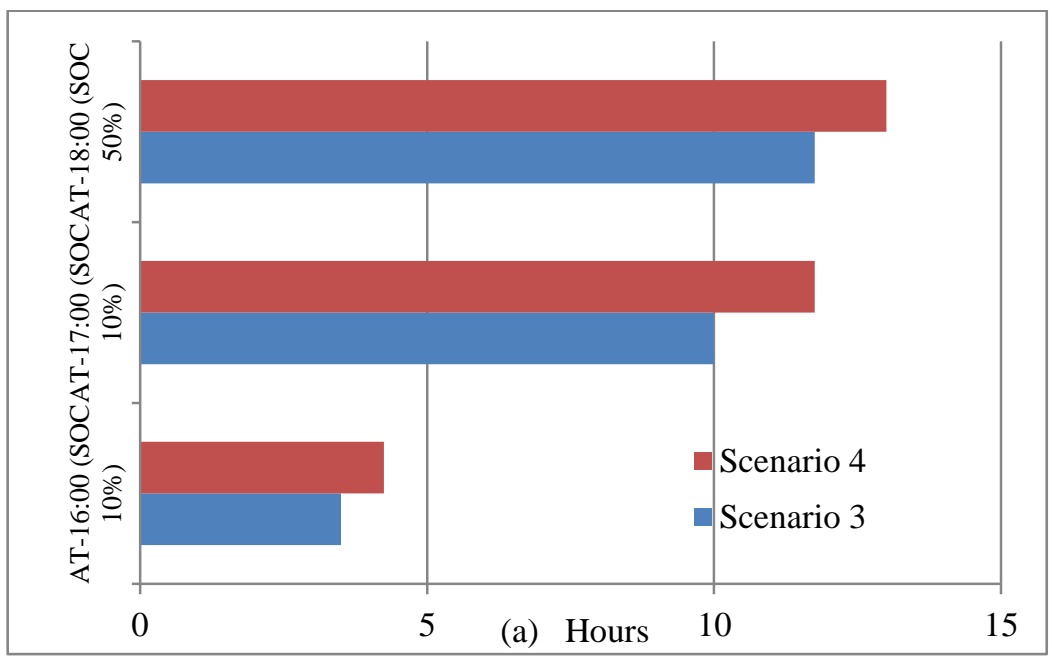

Figure 5-11 Time taken by random vehicles to reach $70 \%$ SOC 


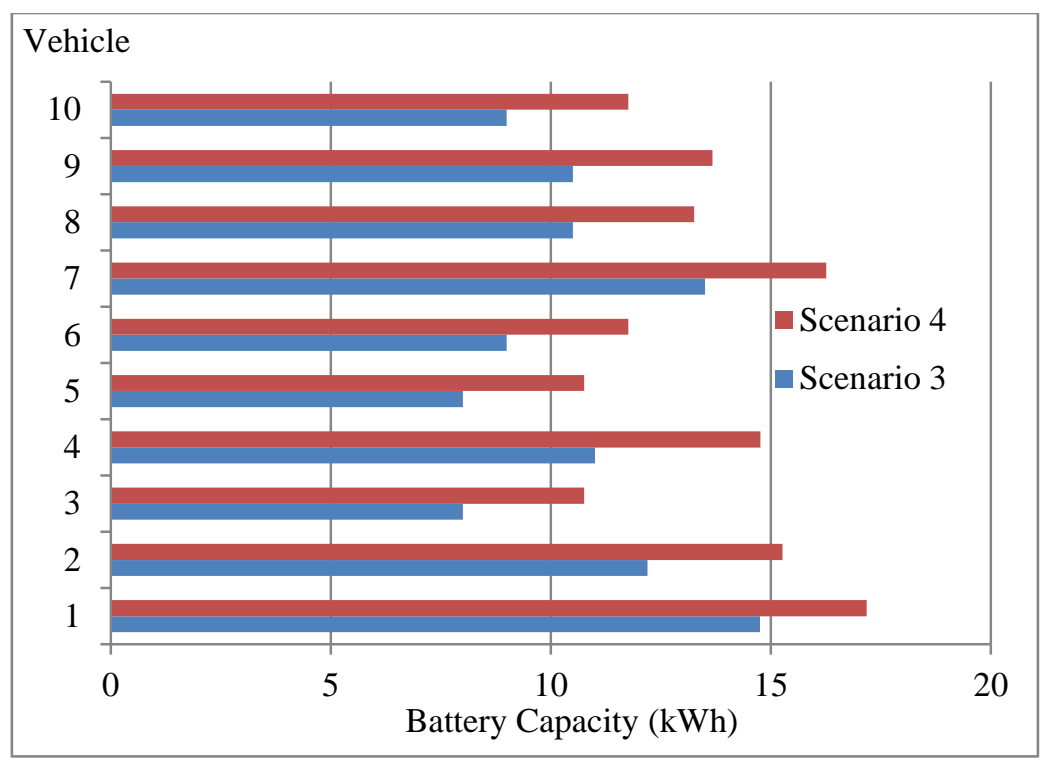

Figure 5-12 Battery capacities of late arrival vehicles

Scenario 4 is designed such that if the customer desires to leave early or has unplanned departure, this strategy has the advantage of improved state of charge from initial arrival SOC when compared to scenario 3. This is well explained in Figure 5-12 using a set of vehicles which arrived at CS after hour 19:00 with random initial SOCs. The battery states improved with scenario 4 due to early start of charging when compared with the unaltered states of scenario 3.

\subsubsection{Demand Response Application}

The coordinated charging algorithm satisfies the main objective of avoiding overloading of distribution transformer during times of heavy inrush of PHEVs. But, the transformer is loaded 100\% for more hours added to the peak hours as shown in Figure 5-6. As discussed in section III, DR helps at times of system emergencies by providing incentives to the consumers. The charging station reserves special slots for PHEV customers who are willing to take part in DR programs mostly encouraging the customers with lengthier parking times showing the hourly real time prices and cost benefits incurred due to late charging. The DR program is a self-prioritization algorithm in which the customers enroll themselves by placing the vehicles in the special slots which facilitates late charging thereby the remaining slots will be occupied with vehicles requiring early charging i.e. the slot matrix $D^{L x K}$ with priority vehicles is supplied to the coordinated charging algorithm. This strategy has the advantage of satisfying customers with early charging needs and also reduces the transformer loading by efficiently utilizing the extended low-price parking hours of vehicles as shown in Figure 5-13. 


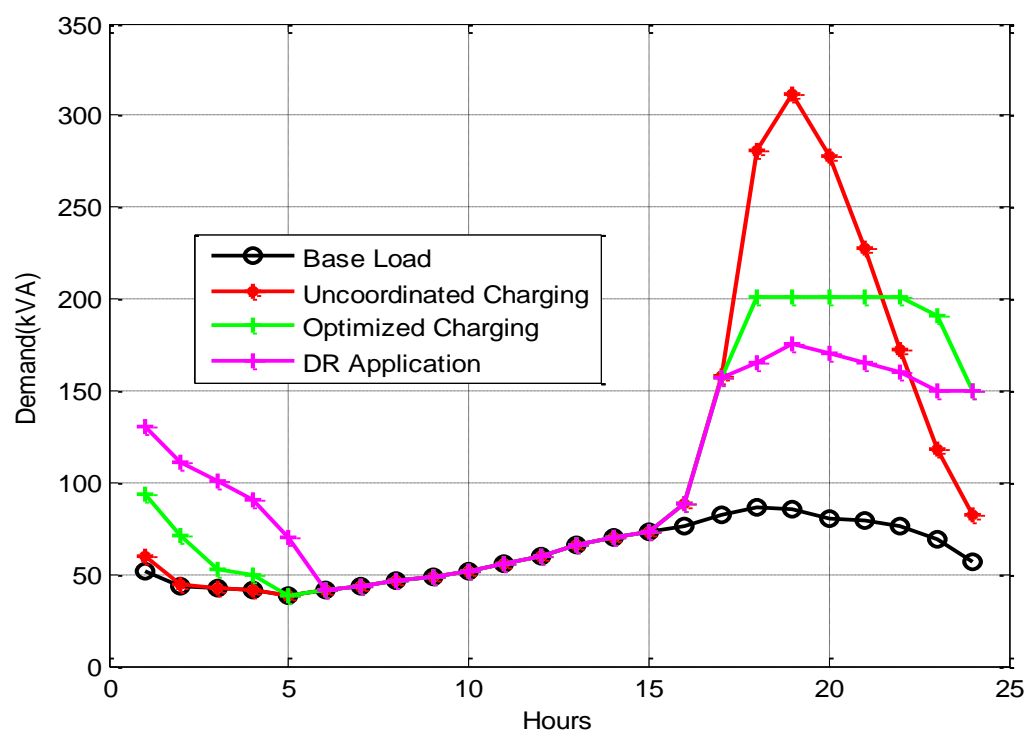

Figure 5-13 Transformer loading for different charging methods - with Demand Response

\subsection{PRT Distribution System Analysis}

The routing algorithm discussed in section VI is run as a MILP in MATLAB environment based on the passenger data provided by WVU DOT for a single day which is a normal university working day. The data consists of number of passengers travelling between all the possible station pairs, distance and time taken by a vehicle to commute between these stations. Figure 5-14 shows the hourly accumulated passenger demand at all the 5 stations starting from 07:00 till 22:15 (hours of operation of PRT). Each station has its own peak and off-peak demand hours depending on the locality, for instance, the Beechurst Avenue for the Downtown campus is the main campus and having more student traffic followed by Engineering Sciences station. Average energy consumption by a vehicle is $1 \mathrm{kWh} / \mathrm{mi}$ and $80 \mathrm{kWh}$ battery capacity is considered to be installed in the BEVs. The minimum number of BEVs required to transport the passengers at each station pair for each hour is obtained on running the routing algorithm and is shown in Figure 5-15. 


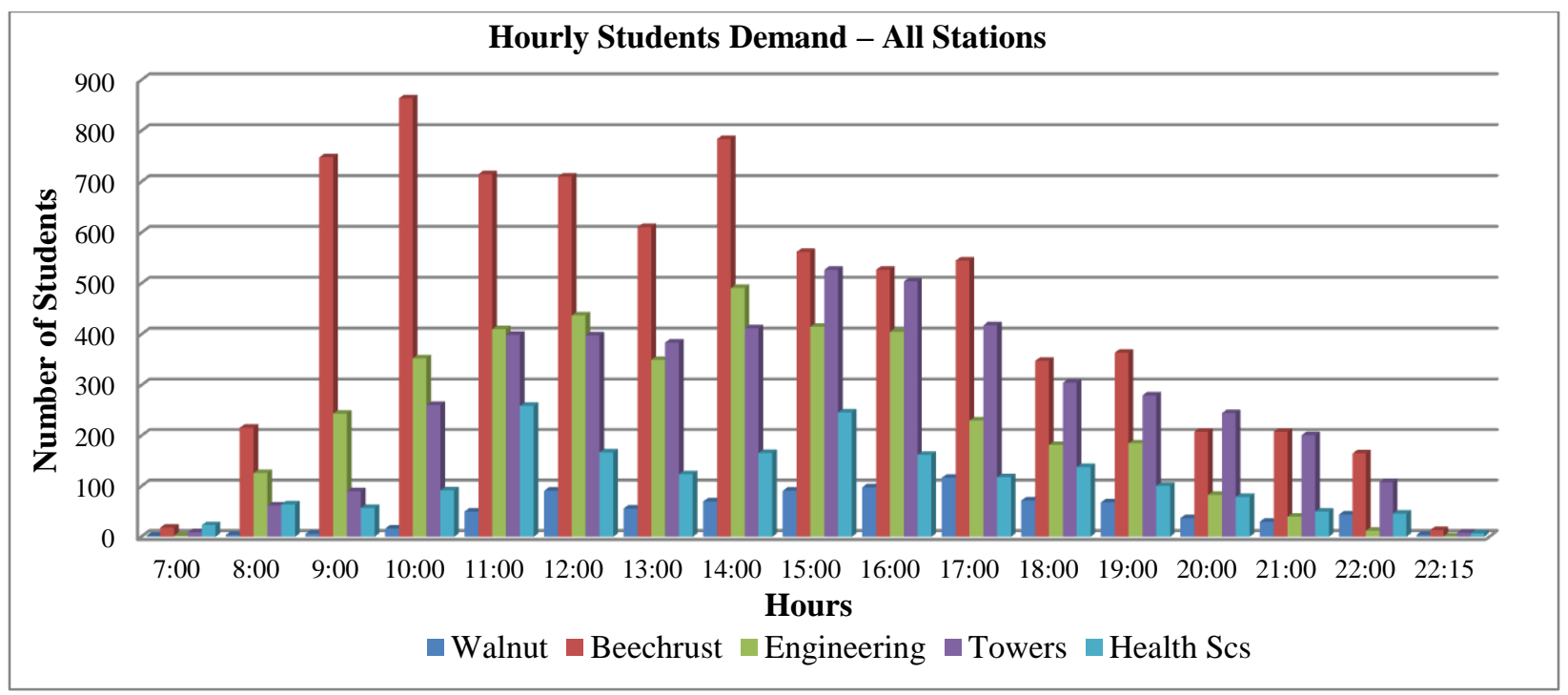

Figure 5-14 Hourly passenger demand at all 5 stations

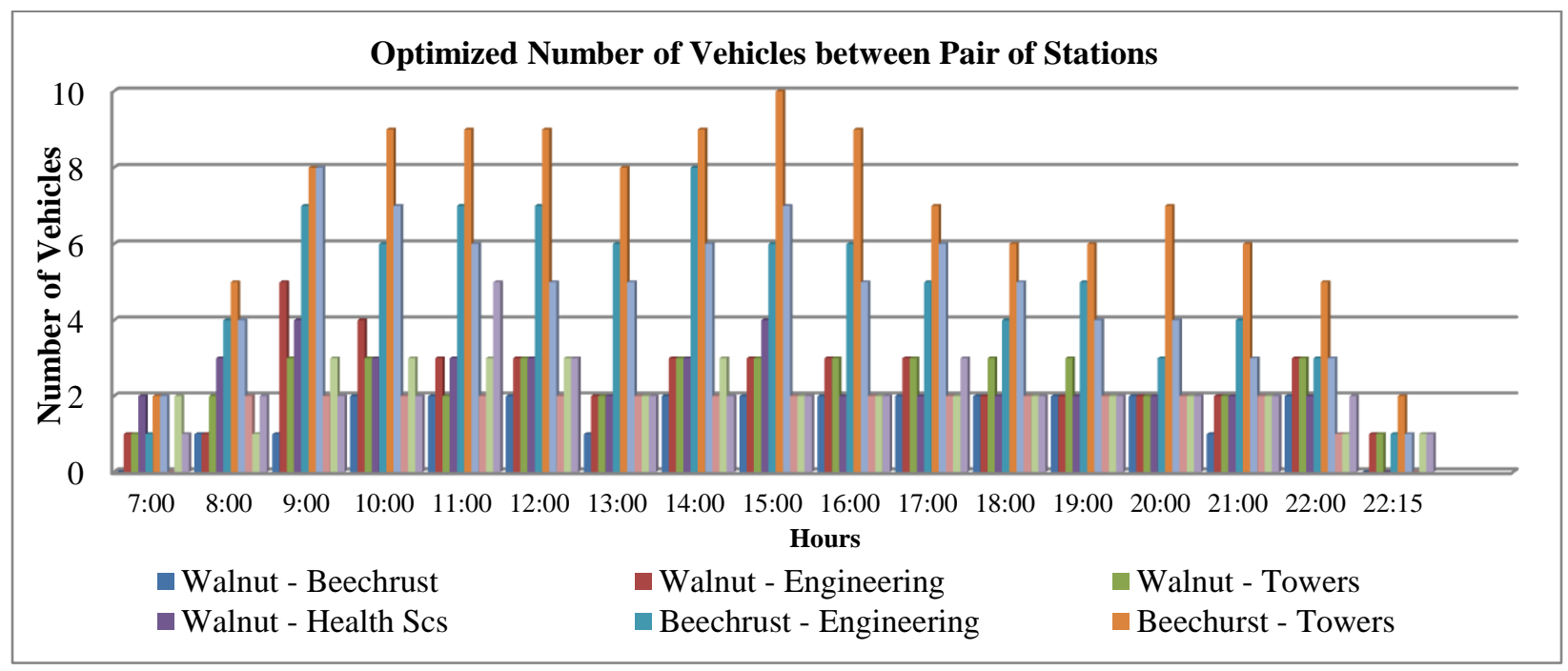

Figure 5-15 Number of vehicles at each station pair

The routing algorithm along with calculating the minimum number of vehicles also keeps track of the battery capacity of each departed vehicle. Hourly charging demand and charging demand at the end of day on distribution system are computed for two cases -

- Case 1 - Three station charging 
- Case 2 - All station charging

The stations are equipped with charging infrastructure and the transformer ratings (575V AC, 3phase) at the stations are suitable for providing fast charging which can charge the BEVs in one hour. The test system discussed in section VII is considered to perform the distribution system analysis with slight modifications of adding additional transformers at nodes coinciding with geographical location of physical stations as shown in Figure 5-16. In case 1, the intermediate stations - Beechurst, Engineering Sciences and Evansdale Residential Complex are chosen for charging BEVs as these stations has large student demand and require more vehicles.

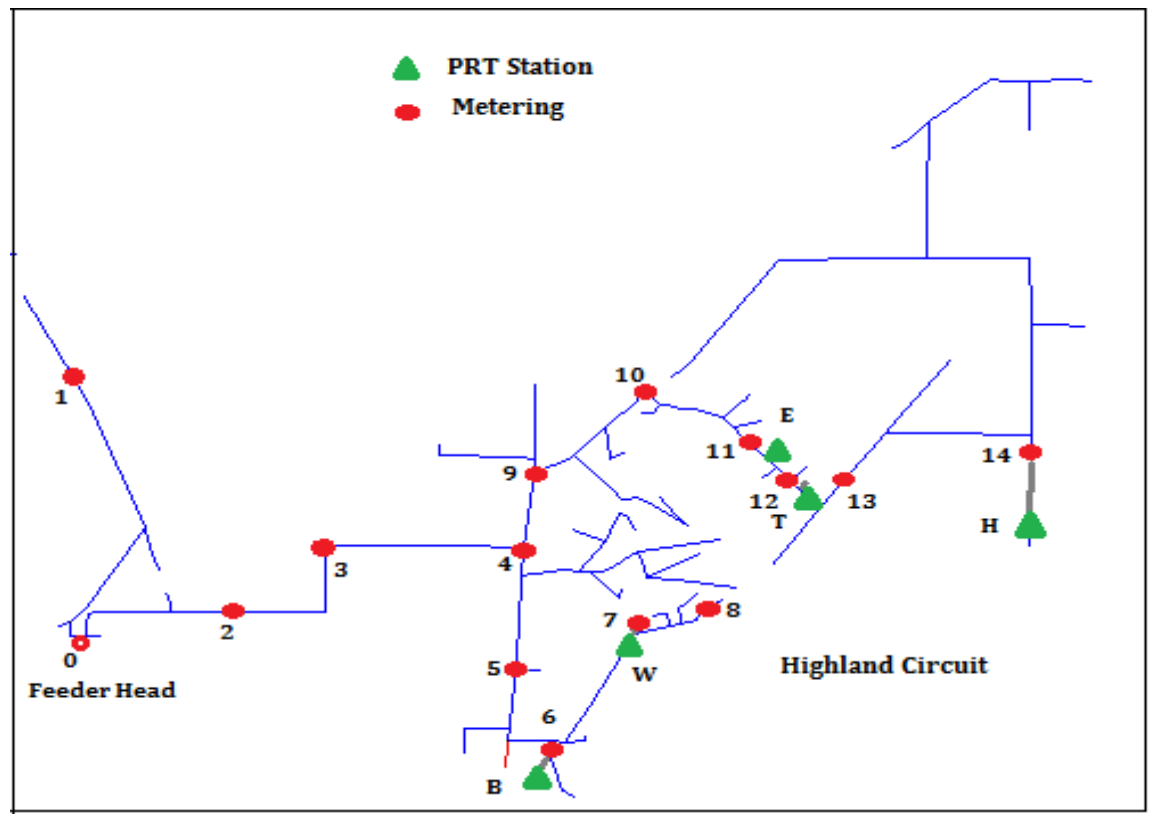

Figure 5-16 AEP Feeder-2 with PRT Stations

Number of BEVs available (i.e. total - charging) for service in next hour are fed to the algorithm as $\left(V_{a}-V_{c, t}\right)$ in constraint (18). The BEVs enter the service with full charging and for the demand shown in Figure 5-14, the first group of vehicles charge at 12:00 and as the peak charging occurs at 14:00 as shown in Figure 5-17. BEVs are assumed to charge only if the battery capacity reaches below a threshold limit and not during their ideal or non-service hours because repeated charging and discharging potentially depletes battery life-time. The threshold limit is decided based on hourly energy consumption of vehicle since once the vehicle enters the service, it must be capable of running for duration of one complete hour. The charging demand on the test feeder along with residential and industrial load is shown in Figure 5-18. The charging demand in both the cases 1 and 2 remains the same except the demand is distributed to more nodes in the latter case which has considerable effect on the voltage of the system 
when the passenger demand is too high. A more distribution of charging demand can be achieved by using batteries with fewer capacities which can avoid peaks on the distribution system.

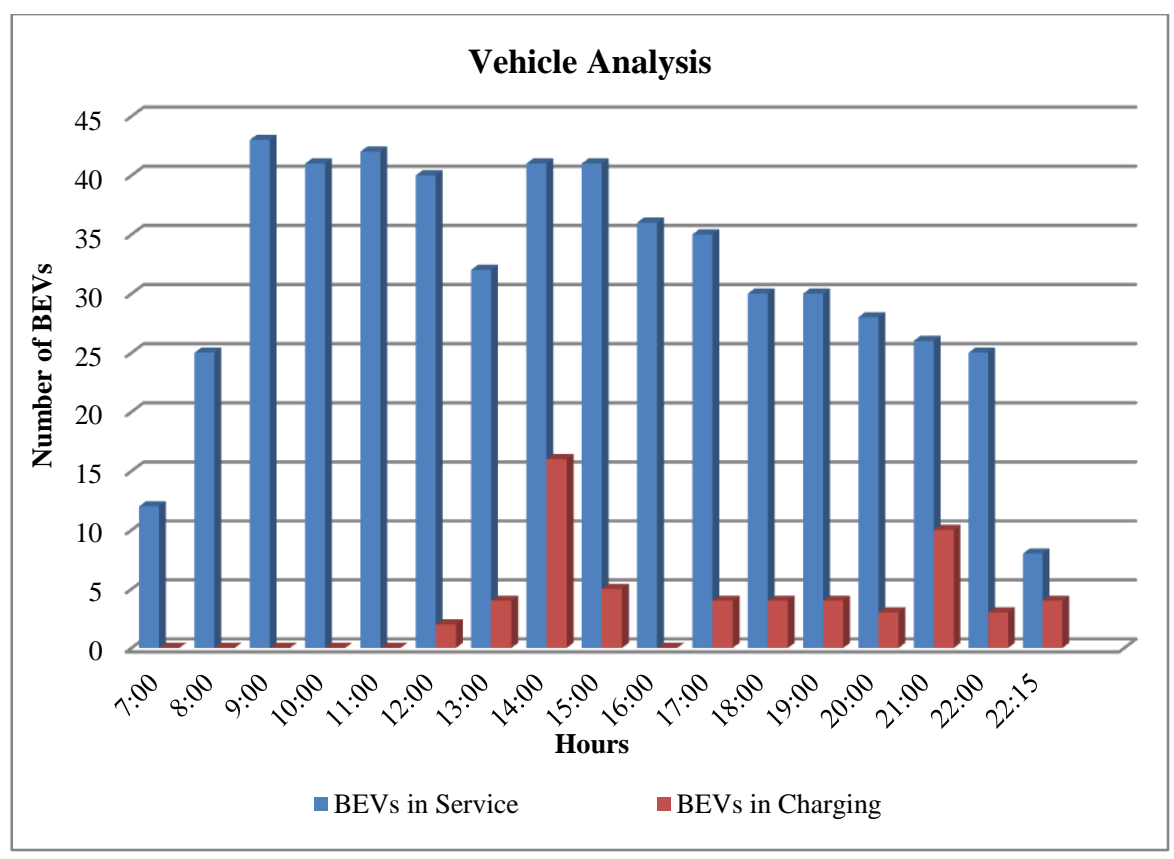

Figure 5-17 Total number of BEVs in Service and Charging modes

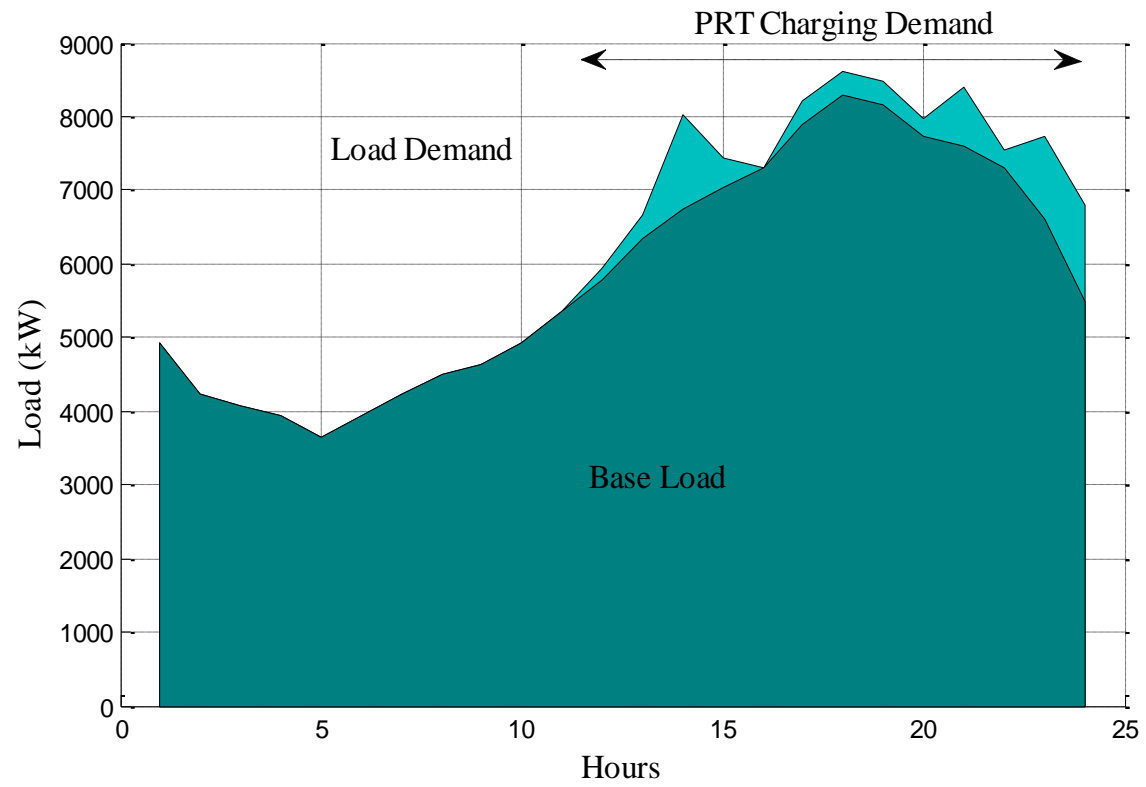

Figure 5-18 Base load and charging load of AEP distribution feeder 
By the end of service, BEVs are charged completely based on availability of slots shown in Figure 5-18 as peaks during end hours. The voltage profile of the metered nodes of the feeder is given in Figure 5-19. In order to examine the effects of case-2 on the distribution feeder, the routing algorithm is run with assumed large passenger demand which increases the charging demand and significantly affects the voltage of the feeder during peak hours. Figure 5-20 indicates the improvement in voltage profile when BEV charging is distributed among all the stations. Voltage from feeder head towards end nodes including the station nodes for normal load demand and PRT peak demand hours is plotted in Figure 520.

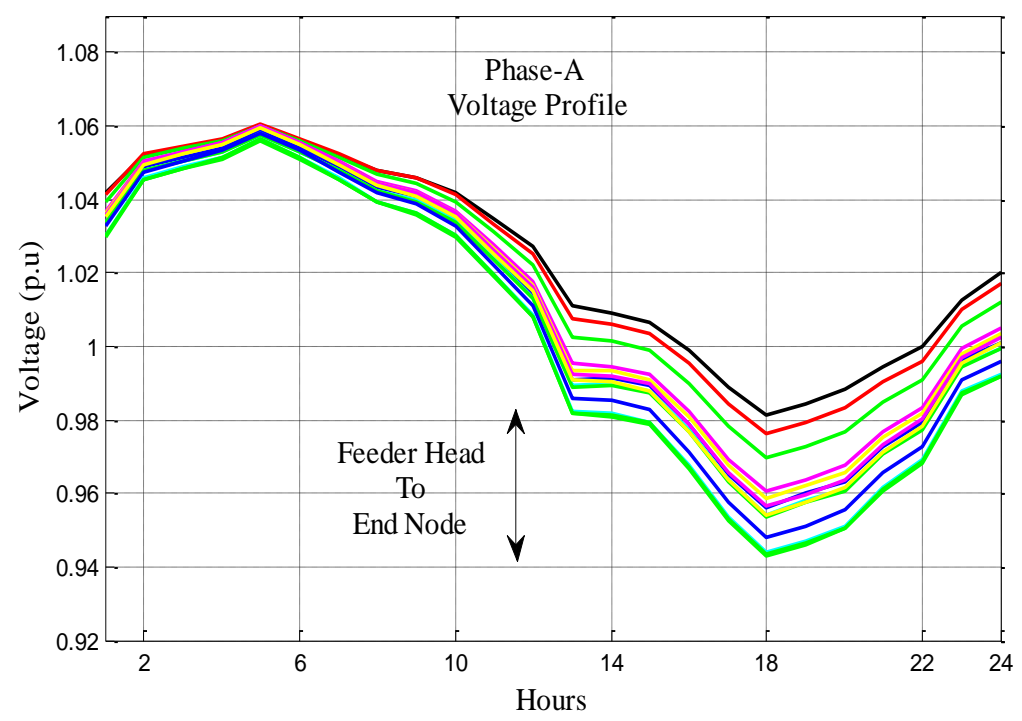

Figure 5-19 Voltage profile for 24-hours at all metered locations

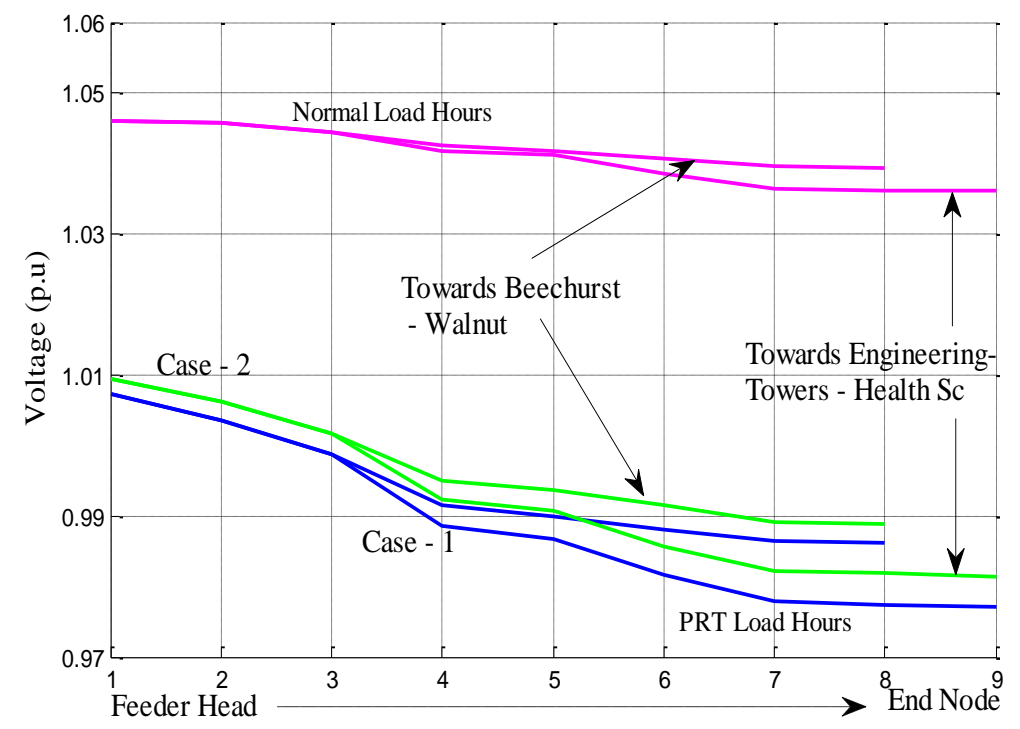

Figure 5-20 Voltage profile of Case-1 and 2 


\subsection{PHEV Impacts on LMPs}

A DCOPF on modified IEEE 13 Node test system is run in MATLAB environment for 24-hour time period and the effects of PHEV charging demand on system LMPs is discussed in this section. The dual variables of equality constraints in the optimization provide the locational marginal prices at all the 13 nodes of the system. 7 generators shown as ' $G$ ' with different price curves at different nodes as shown in Figure 5-21 are considered for the analysis which are a mixture of conventional and distributed generators. The low cost generation comes from renewables like PV and wind, and generators like gas turbine are expensive. The bid prices and capacities of generators are given in Table 5-4. Loads capable of creating congestion in the system are considered to notice the variations of prices at different nodes and are given in Table 5-5. The line flow limit is considered as 500MVA for all the lines for convenient analysis.

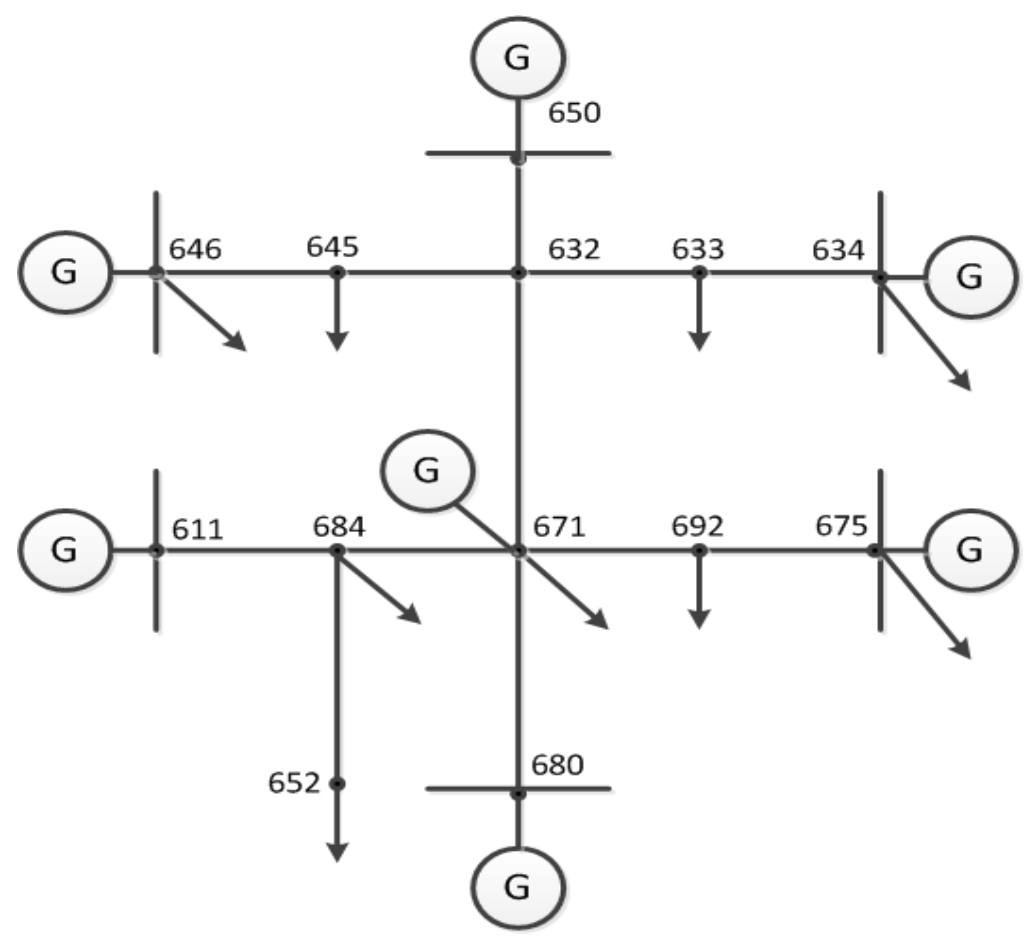

Figure 5-21 IEEE 13 Node Test Feeder

The LMPs for 24-hours at few of the nodes for base load is shown in Figure 5-22. 5 nodes are selected to notice the prices of the system. Node 645 which is near to the costly generator under goes large variation in the prices. The prices are quite low - following the least cost generator till a certain level of loading and as the system experiences high load, due to congestion the prices are influenced by the high cost generator. Figure 5-22 clearly indicates the change in prices at different nodes of the system. 
Due to uncoordinated charging of PHEVs by the owners at times of already existing peaks, the load on the system increases manifold causing congestion and increase in the prices. Under these conditions, the normal base load of the system is also charged at higher prices along with the new PHEV load. Node 675 is considered to study the effects of PHEV charging on market prices. Figure 5-23 shows the variation in prices caused by uncoordinated charging which creates congestion in the system. It is also shown that coordinated charging of PHEVs discussed in prior sections has a significant effect on the market prices by distributing the peak load to off-peak hours and thereby avoiding congestion.

\begin{tabular}{|c|c|c|}
\hline Generators & $\begin{array}{c}\text { Bidding Price } \\
(\$ / M W H)\end{array}$ & $\begin{array}{c}\text { Maximum } \\
\text { Capacity }(\mathbf{M W})\end{array}$ \\
\hline Generator-650 & 10 & 600 \\
\hline Generator-646 & 40 & 300 \\
\hline Generator-634 & 14 & 410 \\
\hline Generator-611 & 30 & 520 \\
\hline Generator-671 & 20 & 600 \\
\hline Generator-675 & 25 & 500 \\
\hline Generator-680 & 35 & 800 \\
\hline
\end{tabular}

Table 5-4: Generator Data

\begin{tabular}{|c|c|}
\hline Load & Rating (MW) \\
\hline L-675 & 100 \\
\hline L-646, L-633, L-692 & 200 \\
\hline L-645, L-634 & 300 \\
\hline L-684, L-671 & 400 \\
\hline L-652 & 500 \\
\hline
\end{tabular}

Table 5-5: Load Data 


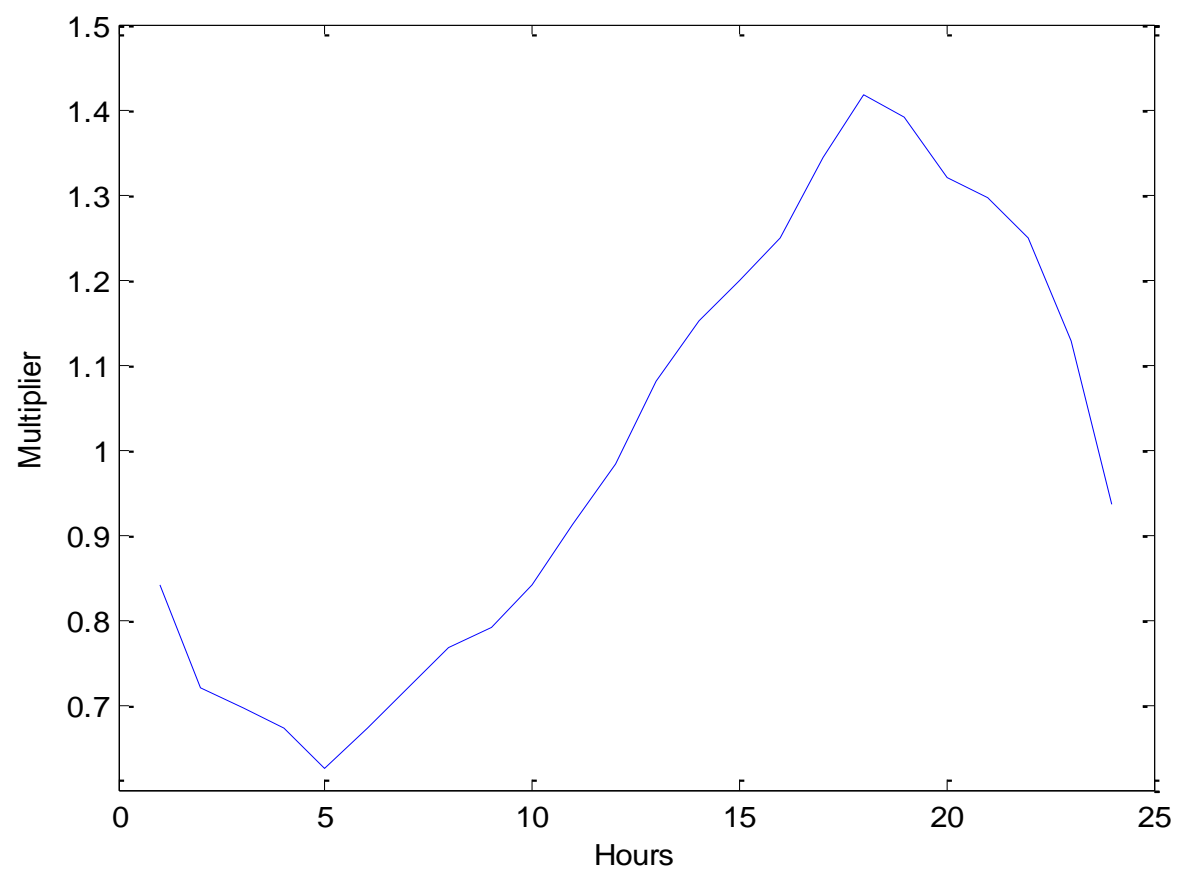

Figure 5-22: 24-hour multiplier for load nodes

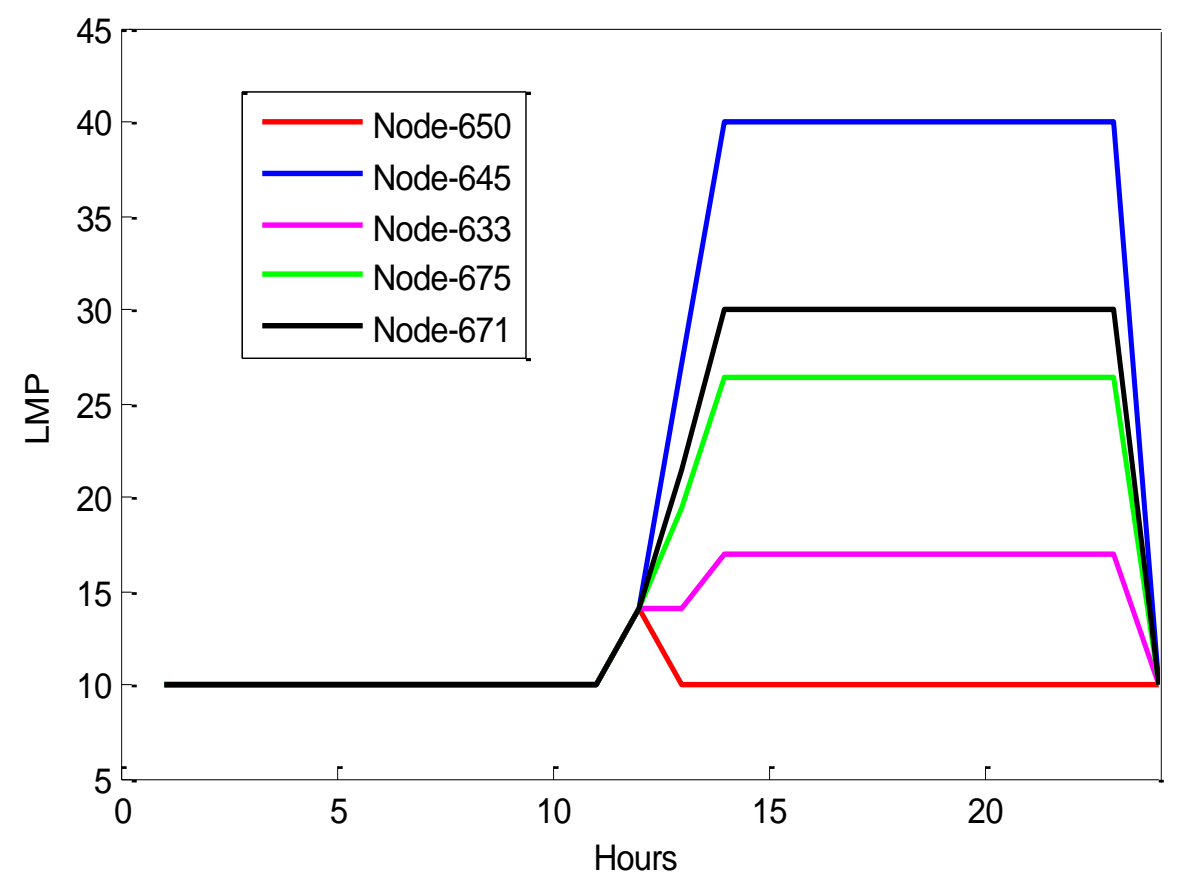

Figure 5-23: LMPs at Different Nodes 


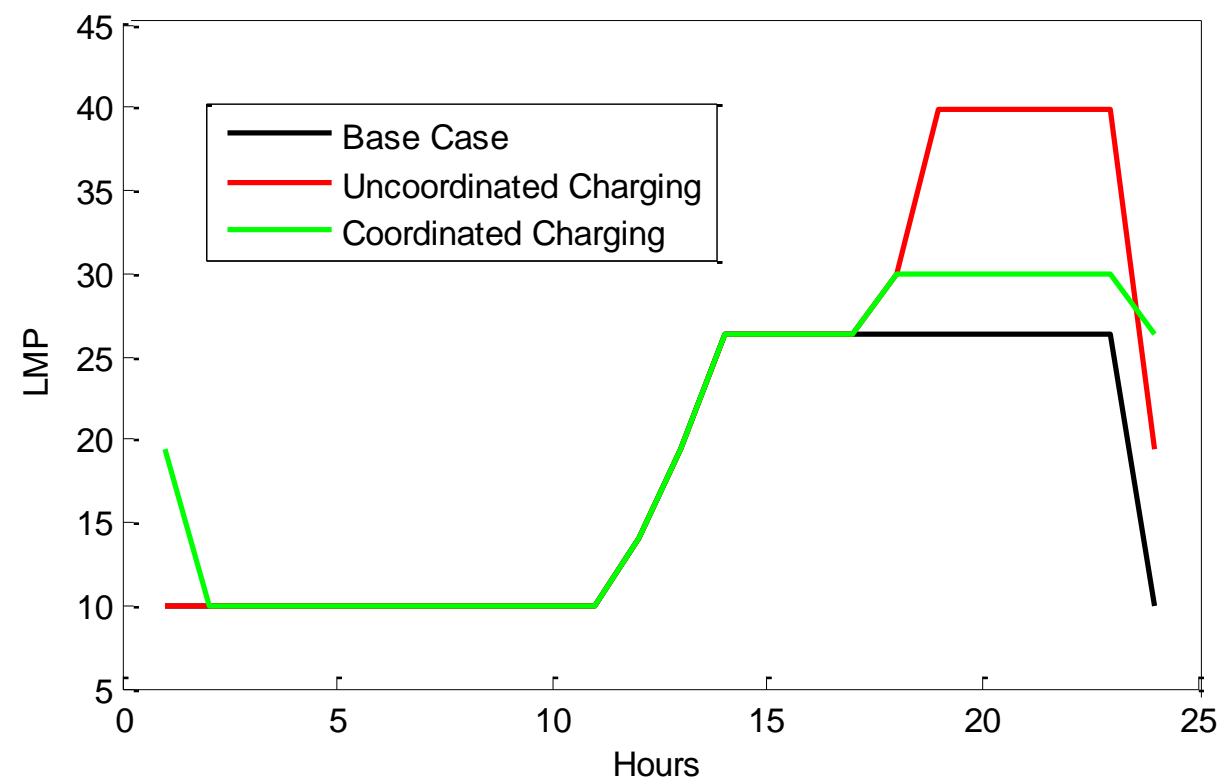

Figure 5-24: PHEV Charging Effects on LMP 


\section{Chapter 6: CONCLUSION AND FUTURE WORK}

\subsection{Conclusion}

In this thesis, a charging algorithm has been formulated for charging stations at residential complexes with the objective of charging as many vehicles as possible. A demand response application for charging of PHEVs is also implemented to enhance the longevity of the distribution system. Further, an efficient routing algorithm is designed for transit system to test the power system feasibility when converted into BEVs. The conclusions drawn from both these works have been presented in this section.

\subsubsection{Coordinated Charging Method}

In this thesis, a coordinated charging strategy for a Charging Station (CS) in the direction of maximizing the number of PHEVs charged by formulating a Mixed Integer Linear Programming (MILP) Optimization in MATLAB. The effects of coordinated charging methods on utility distribution system are analyzed using OpenDSS. PHEV customers are modeled into price responsive consumers capable of participating in Demand Response programs by developing extensive demand-price elasticity matrices (PEMs) which are utilized to calculate the level of demand response.

Results indicate that coordinated charging strategies impacts the distribution network in 3 positive ways:

1. Voltage profile improvement

2. Loss minimization

3. Valley filling

4. Customer satisfaction

\subsubsection{PRT Routing Algorithm}

The feasibility of converting the guideway power rail propelling vehicles to Battery driven vehicles (BEVs) by developing a novel routing algorithm based on scheduled mode of operation from the data provided by the West Virginia University's Department of Transportation and Parking is well accomplished by analyzing the voltage and loading of the distribution feeder due to the hourly charging demand of BEVs. This has been done by formulating an optimization in MATLAB to find optimal number of BEVs required to satisfy the student demand on a normal university working day.

The vehicles available at the stations can provide grid support during the peak demand hours and the BEVs can be charged with renewables integrated with the charging stations. 


\subsection{Future Work}

PHEVs are gaining popularity both in terms of economic and environment benefits. Tax incentives provided by the government and also reduced fuel cost per mile are the driving forces. With the advent of advanced communication and control techniques in the grid, PHEVs promises immense benefits to both electric utilities and consumers. Integration of PHEVs with grid called V2G technology is the area gaining a lot of research interest. Designing of charging stations with renewable energy sources is also feasible in the near future. Providing ancillary services to the grid in terms of frequency control is a promising application of PHEVs. Future work will focus on gathering real time data on customer participation in DR programs and imparting a customer satisfaction parameter in objective function. Designing coordinated charging and communication algorithms for complex systems such as charging at home garages needs to be focused.

BEVs offer similar advantages as PHEVs. The main application lies in treating the BEVs as mobile storage units providing V2G in larger scale than PHEVs due to their huge battery size. Many transit systems are in the process of converting guideway propelled vehicles to BEVs due to zero maintenance of the guideways offered by the BEVs. The aggregated battery storage of BEVs finds applications in microgrid applications. A comprehensive routing algorithm involving the intermediate stations irrespective of station pairs with the objective of minimizing the charging demand needs to be formulated. Minute wise scheduling of the vehicles with additional collision constraints is considered as next step in accurate analysis of energy consumption. Detailed economics related to setting up charging infrastructure at PRT stations and converting into BEVs have to be evaluated to test the feasibility of this conversion project. 


\section{References}

1. "Title XIII - Smart Grid, Sec. 1301, Statement of Policy on Modernization of Electricity Grid", Energy Independence and Security Act of 2007 (EISA), USA.

2. http://info.ornl.gov/sites/publications/files/Pub14078.pdf

3. J.A. Schellenberg, M.J. Sullivan, "Electric vehicle forecast for a large West Coast utility," in Proc. 2011 IEEE Power \& Energy Society General Meeting, pp. 1-6.

4. http://www.iea.org/topics/transport/electricvehiclesinitiative/EVI_GEO_2013_Timeline.PDF

5. Ahman, M. (2001). Primary energy efficiency of alternative powertrains in vehicles. Energy 26: 973-989.

6. http://dspace.mit.edu/bitstream/handle/1721.1/54532/565948939.pdf?...1

7. N. Shidore, J. Kwon, A. Vyas, "Trade-off between PHEV fuel efficiency and estimated battery cycle life with cost analysis", in Proc. 2009 IEEE Vehicle Power and Propulsion Conference, pp $669-677$.

8. http://www1.eere.energy.gov/vehiclesandfuels/avta/pdfs/phev/climate_leadership_conf_may09.p df

9. P. Khajavi, H. Abniki, A.B. Arani, "The role of incentive based Demand Response programs in smart grid", in Proc. 2011 International Conference on Environment and Electrical Engineering, pp. 1-4.

10. Federal Energy Regulatory Commission, United States, "Preventing Undue Discrimination and Preference in Transmission Service," [online] http://www.ferc.gov/whats-new/commmeet/091505/E-1.pdf

11. http://evworld.com/news.cfm?newsid=28119

12. M. Duoba, R. Carlson, and D. Bocci, "Calculating results and performance parameters for PHEVs,” presented at the SAE World Congr. Exhib., Detroit, MI, Apr. 2009, 2009-01-1328.

13. K. Morrow, D. Karner, and J. Francfort, "Plug-In Hybrid Electric Vehicle Charging Infrastructure Review," Idaho National Laboratory, INL/EXT-08-15058, 2008. [Online]. Available: http://avt.inel.gov/pdf/phev/phevInfrastructureReport08.pdf. [Accessed: Apr. 7, 2009].

14. M. D. Galus, G. A. Simon Art, "A hierarchical, distributed PEV charging control in low voltage distribution grids to ensure network security," in Proc. 2012 IEEE Power \& Energy Society General Meeting, pp. 1-8.

15. S. Shengnan, M. Pipattanasomporn, S. Rahman, "Challenges of PHEV penetration to the residential distribution network," in Proc. 2009 IEEE Power \& Energy Society General Meeting, pp. 1-8. 
16. Z. Darabi, M. Ferdowsi, "Extracting probability distribution functions applicable for PHEVs charging load profile," in Proc.2012 IEEE Transmission and Distribution Conference and Exhibition Conf., pp.1-6.

17. Y. Yin, D. W. Gao, "Charging load from large-scale plug-in hybrid electric vehicles: Impact and optimization,” in Proc. 2013 IEEE Innovative Smart Grid Technologies Conf.pp.1-6.

18. Tae-Kyung Lee, B. Adornato, Z.S. Filipi,Jones, "Synthesis of Real-World Driving Cycles and Their Use for Estimating PHEV Energy Consumption and Charging Opportunities: Case Study for Midwest/U.S.,"IEEE Trans. Vehicular Tech., vol. 60, no. 9, pp. 4153-416 3, Dec. 2011.

19. D. Steen, L. A. Tuan, O. Carlson, L. Bertling, "Assessment of Electric Vehicle Charging Scenarios Based on Demographical Data," IEEE Trans. Smart Grid, vol. 3, no. 3, pp. 1457-1468.

20. M. Yilmaz, P. T. Krein, "Review of charging power levels and infrastructure for plug-in electric and hybrid vehicles ," in Proc. 2012 IEEE Electric Vehicle Conf. pp. 1-8.

21. S. Acha, T. C. Green, N. Shah, "Effects of optimized plug-in hybrid vehicle charging strategies on electric distribution network losses," in Proc.2010 IEEE Transmission and Distribution Conference and Exposition Conf., pp.1-6.

22. E. Sortomme, M. M. Hindi, S. D. J. MacPherson, S. S. Venkata, "Coordinated Charging of PlugIn Hybrid Electric Vehicles to Minimize Distribution System Losses,” IEEE Trans. Smart Grid, vol. 2, no. 1, pp. 198-205, Feb 2011.

23. D. S. Deilami, A. S. Masoum, P. S. Moses, M. A. S. Masoum, "Real-Time Coordination of PlugIn Electric Vehicle Charging in Smart Grids to Minimize Power Losses and Improve Voltage Profile,” IEEE Trans. Smart Grid, vol. 2, no. 3, pp. 456-467.

24. N. Fettinger, T. Chee-Wooi, C. Chunxiao, "Minimizing residential distribution system operating costs by intelligently scheduling plug-in hybrid electric vehicle charging," in Proc. 2012 IEEE Transportation Electrification Conf. and Expo., pp. 1-8.

25. M. Hajian, S. Manish, H. Zareipour, W. D. Rosehart, "Investigation of enabling wind generations employing plug-in hybrid electric vehicles," in Proc. 2012 IEEE Power \& Energy Society General Meeting, pp. 1-7.

26. Xin Li, L. A. C. Lopes, S. S. Williamson, "On the suitability of plug-in hybrid electric vehicle (PHEV) charging infrastructures based on wind and solar energy," in Proc. 2009 IEEE Power \& Energy Society General Meeting, pp. 1-8.

27. O. Hafez, K. Bhattacharya, "Optimal PHEV charging in coordination with distributed generation operation in distribution systems," in Proc. 2012 IEEE Power \& Energy Society General Meeting, pp. $1-7$. 
28. S. Shengnan, M. Pipattanasomporn, S. Rahman, "Demand Response as a Load Shaping Tool in an Intelligent Grid With Electric Vehicles,” IEEE Trans. Smart Grid, vol. 2, no. 4, pp. 624-631.

29. M. Erol-Kantarci, H. T. Mouftah, "Management of PHEV batteries in the smart grid: Towards a cyber-physical power infrastructure," Wireless Comm. And Mobile Comp. Conf., pp. 795-800.

30. S. Wencong, C. Mo-Yuen, "Performance evaluation of a PHEV parking station using Particle Swarm Optimization,” in Proc. 2011 IEEE Power \& Energy Society General Meeting, pp. 1-6.

31. http://ens-newswire.com/2013/10/09/first-u-s-charging-station-for-all-evs-opens-in-california/

32. https://suncountryhighway.ca/worlds-longest-greenest-highway-project/

33. http://www.chargepoint.com/

34. L. Turcksin, S. Van Moll, C. Macharis, N. Sergeant, and J. Van Mierlo, "How green is the car purchase decision? A review," in 10th Int. Conf. Applic. Adv. Techn. Transportation, Athens, Greece, 27-31 May 2008

35. U.S. Dept. of Transportation, Federal Highway Administration. National household travel survey (NHTS). [Online]. Available:http://nhts.ornl.gov/download.shtm

36. Caramanis, M.C., Bohn, R.E., Schweppe, F.C., "Optimal Spot Pricing: Practice and Theory", IEEE Transactions on Power Apparatus and Systems, vol. PAS-101, no. 9, Sept. 1982, pp: 32343245.

37. Schweppe F.C., Caramanis, M.C., Tabors, R.D., Bohn, R.E., "Spot Pricing of Electricity", Boston, MA: Kluwer, 1988.

38. Schweppe, F.C., Caramanis, M.C., Tabors, R.D., "Evaluation of Spot Price Based Electricity Rates", IEEE Transactions on Power Apparatus and Systems, vol. PAS-104, no. 7, July 1985, pp.1644-1655.

39. David, A.K., Li, Y.Z., "Consumer Rationality Assumptions in the Real Time Pricing of Electricity", Proceedings of the IEEE conference on Advances in Power System Control, Operation and Management, Hong Kong, Nov 1991.

40. David, A.K., Lee Y.C., "Dynamic Tariffs: Theory of Utility-Consumer Interaction", IEEE Transactions on Power Systems, vol. 4, no. 3, Aug 1989, pp: 904-911.

41. David, A.K., Li, Y.Z., "Effect of Inter-Temporal Factors on the Real Time Pricing of Electricity", IEEE Transactions on Power Systems, vol. 8, no. 1, Feb 1993, pp: 44-52.

42. M. Mallette, G. Venkataramanan, "The role of plug-in hybrid electric vehicles in demand response and beyond," in Proc.2010 IEEE Transmission and Distribution Conference and Exposition Conf., pp.1-7. 
43. S. Shengnan,Z. Tianshu, M. Pipattanasomporn, S. Rahman, "Impact of TOU rates on distribution load shapes in a smart grid with PHEV penetration," in Proc.2010 IEEE Transmission and Distribution Conference and Exposition Conf., pp.1-6.

44. V. Naveen, S. Jignesh, S.K. Sarika, "Residential Demand Response model and impact on voltage profile and losses of an electric distribution network," in 2012 Proc. Applied Energy, vol 96, pp. $84-91$

45. https://transportation.wvu.edu/prt/facts about the prt

46. S.G. Wirasingha, N. Schofield, A. Emadi, "Feasibility analysis of converting a Chicago Transit Authority (CTA) transit bus to a plug-in hybrid electric vehicle," Vehicle Power and Propulsion Conference, 2008, pp. 1-7.

47. P. Vishnu, R. Ajaykrishna, S. Thirumalini, "Cost effective energy solution with dual battery for plug-in hybrid electric vehicle (PHEV) in a public transportation system," in IEEE Conf. 2012 on Industrial Electronics and Applications (ICIEA), pp. 1555-1560.

48. http://transportation.wvu.edu/r/download/18440

49. OpenDSS Manual, Electric Power Research Institute, Jul 2010. Available: http://sourceforge.net/projects/electricdss/

50. http://www.smartgrid.epri.com/doc/OpenDSS Level 1 Training.pdf

51. The MathWorks ${ }^{\text {TM }}$, http://www.mathworks.com/products/matlab/description1.html

52. http://www-01.ibm.com/software/integration/optimization/cplex-optimizer/ 